\title{
GIS-BASED, PYTHON MODELING OF THE SPATIAL AND TEMPORAL DISTRIBUTION OF WATER ON THE LANDSCAPE FOR WETLANDS DECISION MAKING
}

A Dissertation
presented to
the Faculty of the Graduate School
at the University of Missouri-Columbia
In partial fulfillment
of the Requirements for the Degree
Doctor of Philosophy
ZHENTAO WANG
by

Dr. Kathleen M. Trauth, Dissertation Supervisor

MAY 2020 
(C) Copyright by Zhentao Wang 2020

All Rights Reserved 
The undersigned, appointed by the dean of the Graduate School, have examined the dissertation entitled

GIS-BASED, PYTHON MODELING OF THE SPATIAL AND TEMPORAL DISTRIBUTION OF WATER ON THE LANDSCAPE FOR WETLANDS DECISION MAKING

presented by Zhentao Wang,

a candidate for the degree of Doctor of Philosophy,

and hereby certify that, in their opinion, it is worthy of acceptance.

Professor Kathleen M. Trauth

Professor Stephen H. Anderson

Professor Timothy C. Matisziw

Professor Noel Aloysius 


\section{ACKNOWLEDGEMENTS}

This work would not have been possible without the financial support of Environmental Protection Agency, Region 7 Wetland Program Development Grant CD97748001. I am especially indebted to my academic advisor, Dr. Kathleen M. Trauth, who have been supportive of my academic goals and who worked actively to provide suggestions for my research.

I am also grateful to all of those with whom I have had the pleasure to working during these projects. Each of the members of my Dissertation Committee, Dr. Stephen H. Anderson, Dr. Timothy C. Matisziw, and Dr. Noel Aloysius, has provide me extensive personal and professional guidance and taught me a great deal about both scientific research and life in general.

Furthermore, I would like to thank the team numbers in Hydrology Lab, Mr. Bryan Mayhan, Mr. Adel Hossain, Mr. Luke Kehoe, Mr. Mohammad Mohammad, Dr. Ali Shallal. I really cherish the moment we spent in our office. I hope we can reunion again.

Nobody has been more important to me in the pursuit of this project than the member of my family. I would like to take this special opportunity to thank my wife, Ting Zhao and my daughter, Claire Wang. During past several years, thanks for your support and your love. It is a long journal for us all and there are happiness and frustration. Thank you for encouraging me in all my pursuits and inspiring me to follow my dreams. 


\section{TABLE OF CONTENTS}

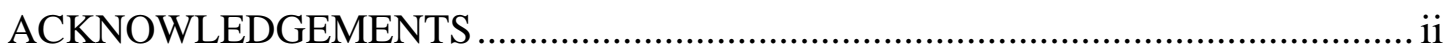

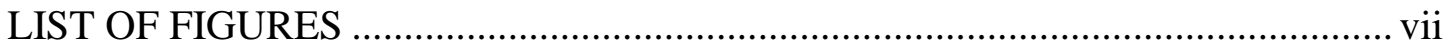

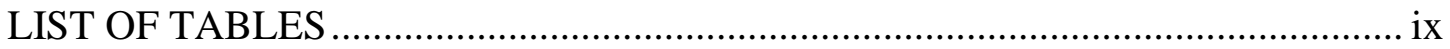

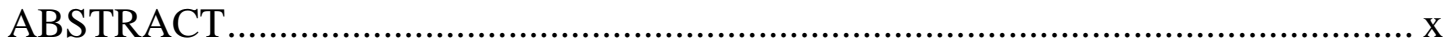

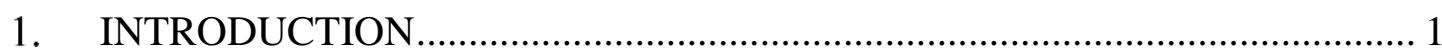

1.1 Hydrological Processes in Wetlands ........................................................ 3

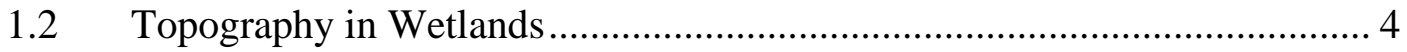

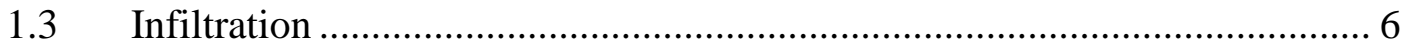

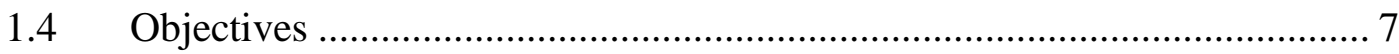

1.4.1 Water Surface Profiles on the Landscape ............................................ 7

1.4.2 Overland Flow Simulation through Wetlands .................................... 7

1.4.3 Infiltration Calculation Based on Modified Green Ampt Model .......... 8

2. WATER SURFACE PROFILES ON THE LANDSCAPE …......................... 9

2.1 Previous Studies..................................................................... 11

2.1.1 Hydraulics Background ........................................................... 11

2.1.2 Calculating Water Surface Profiles ................................................ 14

2.1.3 Hydraulic Input Parameters ........................................................ 18

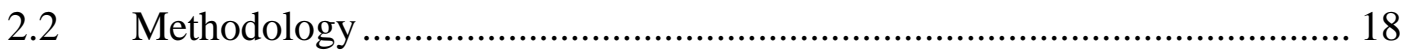




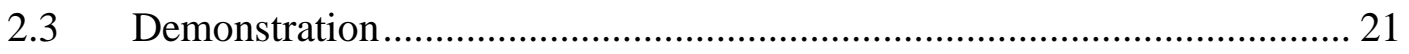

2.3.1 Backwater Curve Example ................................................................... 21

2.3.2 Pershing State Park...................................................................... 24

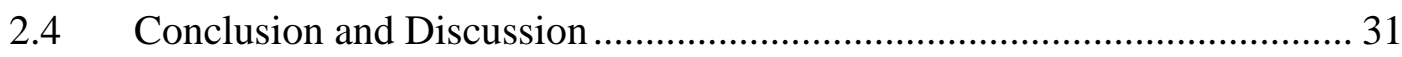

3. OVERLAND FLOW SIMULATION THROUGH WETLANDS ..................... 33

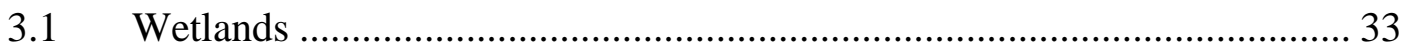

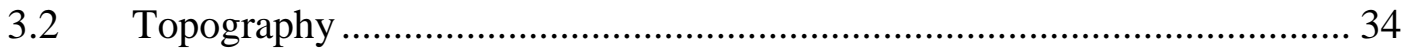

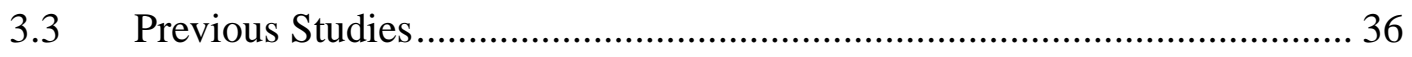

3.3.1 Sinks and Flats ............................................................................... 36

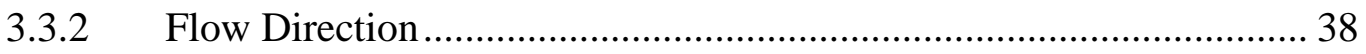

3.3.3 Hydrologic and Hydraulic Models ...................................................... 40

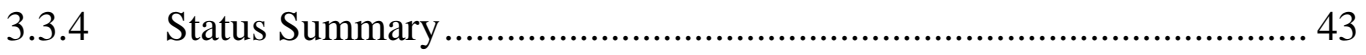

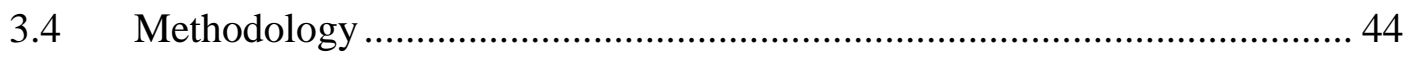

3.4.1 Dynamic Flow Direction ..................................................................... 44

3.4.2 Hydraulic Model (Manning's Equation) …………………….............. 45

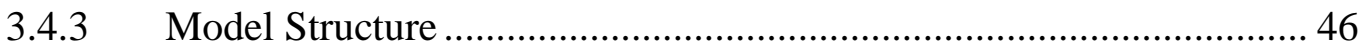

3.4.4 Compound Flow Calculation.............................................................. 47

3.5 Methodology Exercises and Demonstrations.............................................. 48

3.5.1 Exercises on an Artificial DEM........................................................ 49

3.5.2 Landscape Demonstrations ................................................................. 51 
3.6 Results and Discussion

3.6.1 Results of Water Budget Exercise with Limited Precipitation 57

3.6.2 Results of Water Budget Exercise with Sufficient Precipitation to

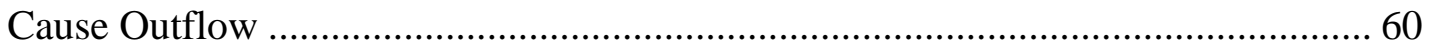

3.6.3 Results of Landscape Demonstrations.......................................... 65

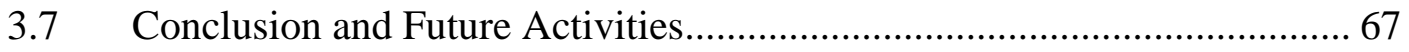

4. MODIFIED GREEN AMPT MODEL FOR UNSTEADY RAINFALL........... 71

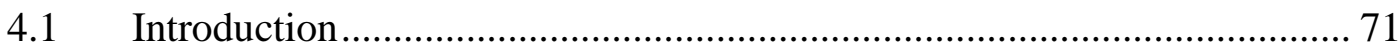

4.1.1 Green Ampt Model ............................................................... 72

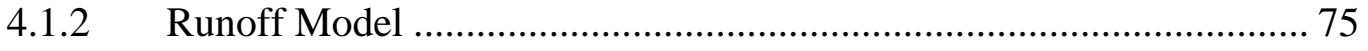

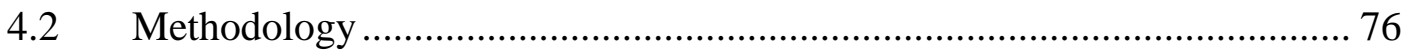

4.2.1 Modified Green Ampt Model .................................................... 76

4.2.2 Coupling the MGA model with DFD Model.................................. 80

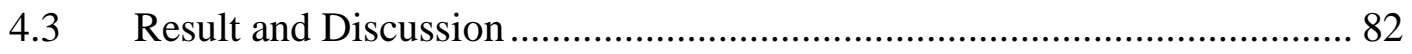

4.3.1 Comparison Between TGA and MGA Model ............................... 82

4.3.2 Calculation of Spatial and Temporal Water Budget on the Landscape84

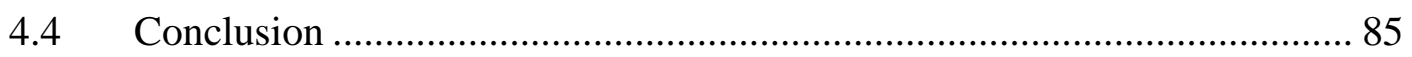

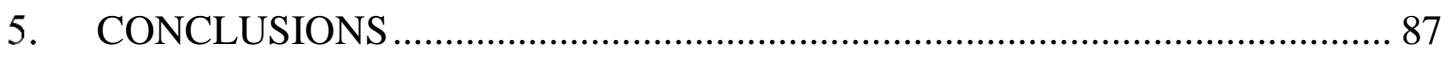

5.1 Backwater Effect on Surface Water Profile .......................................... 87

5.2 Overland Flow Simulation through Wetlands ..................................... 88 
5.3 Infiltration Calculation based on Modified Green Ampt Model

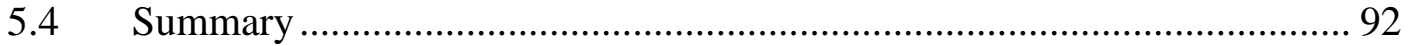

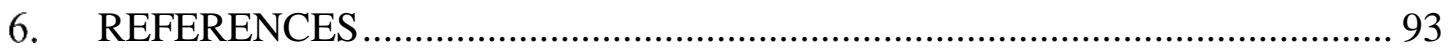

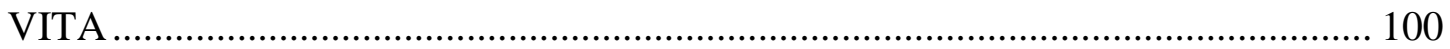




\section{LIST OF FIGURES}

Figure 2.1 Demonstration of a trapezoidal channel's cross-section. ........................ 12

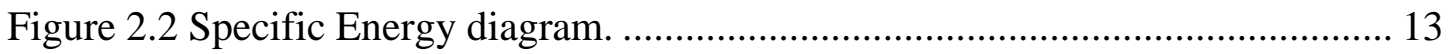

Figure 2.3 Classification of water profiles on a mild slope .................................. 14

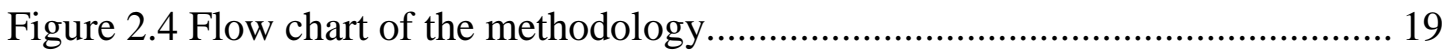

Figure 2.5 Recreation of a trapezoidal channel in ArcGIS................................... 22

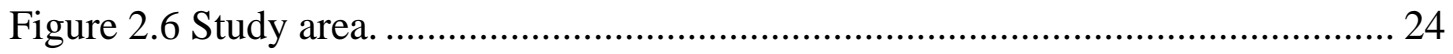

Figure 2.7 Identification of upper and lower wetlands........................................ 25

Figure 2.8 Cost map from the starting point to the ending point and flow path........ 26

Figure 2.9 Generating reaches for the channel. ................................................ 27

Figure 2.10 Cross section geometry of each reach. ............................................ 28

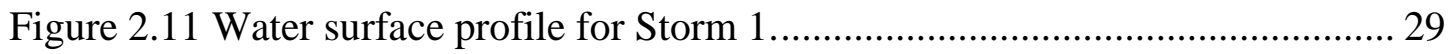

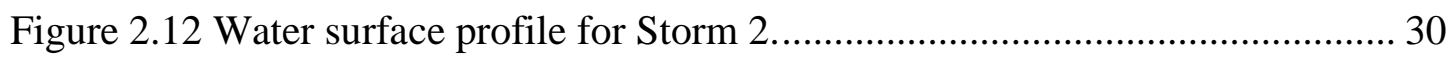

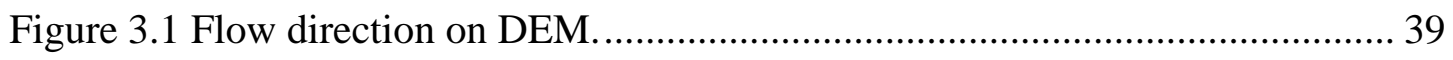

Figure 3.2 Flow direction determination comparison with and without water layer.. 45

Figure 3.3 Dynamic flow direction model flowchart....................................... 47

Figure 3.4 Different domains of flow with assigned roughness coefficients. ............ 48

Figure 3.5 Artificial DEM for exercises. ...................................................... 50

Figure 3.6 Two landscape demonstration sites............................................. 51

Figure 3.7 Procedure to approximate depression topography. ................................ 54

Figure 3.8 Digitization of water surface boundary from aerial imagery. .................. 55

Figure 3.9 Inundation area and water surface elevation as identified by the water

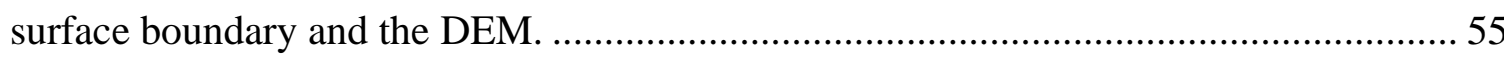


Figure 3.10 Creation of initial water depth layer. 56

Figure 3.11 Water volume changes during the limited precipitation exercise. 59

Figure 3.12 3D screenshots of the watershed and surrounding area during the limited precipitation exercise. 60

Figure 3.13 Water volume changes during the outflow exercise. 63

Figure 3.14 Water surface elevation changes for both the depression and the pour point for the first 5000s of the outflow exercise.

Figure 3.15 Water surface elevation changes for both the depression and the pour point for the entire duration of the outflow exercise. 65

Figure 3.16 Precipitation and total water volume over time in the North depression. 66 Figure 3.17 Precipitation and total water volume over time in the South depression. 67 Figure 4.1. Infiltration rate based on Green Ampt model...................................... 78

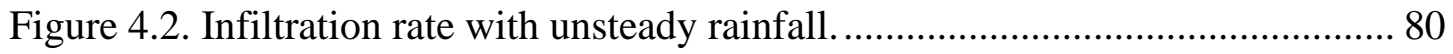

Figure 4.3. Flow chart of the coupling of the MGA model with the DFD model..... 81

Figure 4.4. Flow chart for determining the infiltration rate .................................. 82

Figure 4.5. Infiltration rate comparison between TGA and MGA models................ 83

Figure 4.6. Inundation maps created with the TGA and the MGA models............... 85 


\section{LIST OF TABLES}

Table 2.1 Hydraulic parameters calculated at given water surface elevations. 22

Table 2.2 The comparison between Excel calculation and Python calculation.......... 23

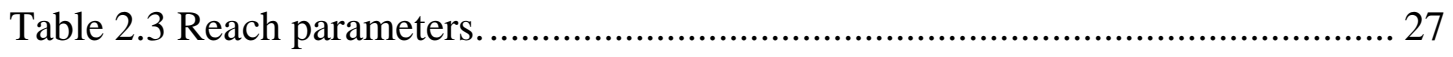

Table 3.1 Water volume changes in the limited precipitation exercise. .................... 58

Table 3.2. Water surface depths and elevations in the depression area and the pour

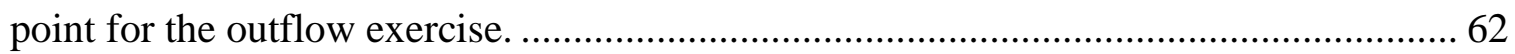

Table 4.1. Comparison of results from the TGA and the MGA models.................... 84 


\begin{abstract}
Wetlands provide many benefits for humans and the natural environment, but land use changes have reduced their number and areal extent. Interest has grown in examining surface water distribution both spatially and temporally, which help to determine those locations for which there is the greatest priority for wetland preservation or mitigation.

This research first proposes a methodology to support that examination through the application of open channel hydraulics principles to flow over a landscape. The methodology, implemented through a Python script, automatically extracts landscape characteristics from a DEM and calculates hydraulic parameters. The parameters are used to determine water surface profiles using the Modified Euler's method. Multiple tests show that the script accurately produces profiles of flow between wetlands over a landscape. Such determinations are the first step in understanding where water will exist on the surface and where there may be infiltration to support wetland functions.
\end{abstract}

Furthermore, a water balance methodology (where water will exist, how much will be there and for what period of time) is developed and demonstrated that focuses on small depressions, as locations where conservation efforts to create or regenerate wetlands may be achievable. Integral to this analysis is a detailed treatment of depressions in the landscape. Utilizing a digital elevation model, the methodology incorporates a cell-by-cell analysis to appropriately capture small-scale processes. Instead of treating these vital depressions as errors or being insignificant to the water balance calculations, they are retained. Flow direction is dynamically determined by the land surface and water characteristics. With potentially shallow flow in depressions, the use of Manning's equation incorporates stratified flow where differing values of Manning's n 
describe flow through and above vegetation. This real-time overland runoff model based on a short time step is implemented through a Python code using ArcGIS. Exercises on an artificial DEM with simulated precipitation demonstrate the ability of the model to accurately represent hydraulics principles. Simulations of two field sites over a period of a year, and incorporating precipitation, infiltration and evapotranspiration, demonstrate the ability to track water surface locations and extents with an accuracy necessary for decision making.

Additionally, this research optimizes the Green Ampt infiltration model which allows for the calculation of infiltration rates with unsteady rainfall and then couples this Modified Green Ampt (MGA) model with a previously developed Dynamic Flow Direction (DFD) model to simulate overland flow. To test the accuracy of the improvements, results show shorter times to ponding, smaller total infiltration at the time of ponding and larger total infiltration with this Modified Green Ampt (MGA) model as compared with the results with a Traditional Green Ampt (TGA) model. Additionally, coupled with the DFD model, the MGA model takes surface water movement into consideration. The total water volume on the landscape with MGA is less than predicted by the TGA. Additionally, the inundation area is deeper than $0.05 \mathrm{~m}$ with MGA and is also smaller than the result with the TGA. 


\section{INTRODUCTION}

Wetlands are unique and essential ecosystems which detain quite a large amount of water in the environment. They are commonly considered as the most biologically diverse of all ecosystems by supporting different aquatic plants and animals. In addition, the dynamic relationship among these creatures is also very complex, which makes wetlands one of the most productive ecosystems on Earth.

Multiple beneficial services have been recognized as being produced by wetlands, both for the environment and human society. First, wetlands act like natural storage reservoirs and help provide flood management. Due to their landscape characteristics, wetlands on the land surface can store a considerable amount of overland flow during floods, which decreases the peak discharge, retains overland runoff, mitigates flooding and increases the recharge to groundwater. Wetlands work efficiently in controlling floods (Mitsch and Gossilink, 2000; Pezeshki, 2001). Like sponges, they can soak up a considerable amount of stormwater runoff, holding it and releasing it slowly so that it can be conveyed in existing channels. Second, wetlands provide habitat for different species of plants and animals. A vast range of plant and animals live in wetlands, including birds, fish, reptiles and amphibians (Snodgrass et al., 2000; Willson et al., 2006). Third, wetlands also have ability to maintain and improve water quality by removing the sediment and nutrients in surface runoff. Studies show that wetlands can significantly decrease nitrates (Fennessy and Cronk, 1997; Lin et al., 2002; Anderson and Mitsch, 2005), phosphorus (Braskerud, 2002) and heavy metals (Kalbitz and Wennrich, 1998; Cheng et al., 2002) in water. 
However, human activities, such as construction, pollutant discharges, deforestation and farming, have significant effects on the quality of water resources and land cover, which furthermore impacts wetlands. For example, wetlands have been drained to provide additional acreage for agriculture and to provide land for the development and growth of communities. Land use changes have reduced the number and areal extent of wetlands. Interest has grown in examining the landscape to determine those locations for which there is the greatest priority for wetland preservation or mitigation. The importance of wetlands and their preservation has been embodied in the concept of "no net loss of wetlands". Once avoidance and minimization strategies have been taken, mitigation activities may be implemented in an effort to replace the habit impacted or lost by human actions - either adjacent to the original wetland or in a wetland bank. An alternative to the concentration of compensatory sites in mitigation banks may be the creation of small, isolated wetlands that would normally exist throughout the landscape and that are so vital to the functioning of these locations as habitats.

Integral to the existence of wetlands is the existence of sufficient water for sufficient periods of time throughout the year. Sufficient water is necessary to provide the surface saturation and exclusion of free oxygen necessary for the formation and maintenance of hydric soils. Animals, such as amphibians, need surface water for egg laying and gestation, and for specific periods of the life cycle. Understanding the water balance in specific locations in the landscape is essential in identifying those locations where there may be sufficient water to establish the conditions necessary for functioning wetlands.

In addition to precipitation, a water balance is also based on infiltration and evapotranspiration, that are both heavily impacted by the characteristics of flow over the 
landscape. Therefore, understanding the landscape in terms of how water may flow into and out of a depression (and ultimately, where water will exist, how much will be there and for what period of time) is essential for evaluating a candidate compensatory wetland site. Such knowledge, and the ability to compare the analysis over multiple locations would support informed decision making.

\subsection{Hydrological Processes in Wetlands}

Hydrological process in wetlands are associated with the spatial and temporal distribution of water. The main inflows/inputs of water for/to wetlands are precipitation, surface water runoff from contributing area and inflow from shallow groundwater. The outputs from wetlands consist of outflow to downstream locations, evapotranspiration, infiltration (and potentially recharge to groundwater). These inflow and outflow components control the water balance in wetlands.

Some wetlands are connected to other water bodies, for example lakes, seas, and channels. Some wetlands are isolated, either permanently or seasonally. However, both types of wetlands share similar unique hydric soil characteristics which are associated with wetness. This wetness causes a transformation of the soil because of the absence of free oxygen, which in turn supports plants that thrive in this specific anaerobic environment. However, this wetness does not need to occur continuously, and may only be required for a short period of time, as during the growing season for the vegetation of interest.

For some time, researchers have been interested in the connectivity between wetlands and how wetlands connect to downstream locations (Amezaga, Santamaría and Green, 
2002; Roe, Brinton and Georges, 2009; Kumar et al., 2012; Lang et al., 2012). First, these questions can help to understand the water movement among wetlands. Second, they can also provide guidance for potential mitigation and enhancement activities. Meanwhile, there are many geographically isolated wetlands which can connect with other water bodies during wet seasons. Those wetlands in floodplains or other flat areas may be separated from each other, especially during dry seasons. However, during storms, wetlands receive water from their own contributing areas. After wetlands fill up, surface water may start to flow to neighboring wetlands at lower elevations or to downstream streams and rivers. Quantification of the processes governing hydrologic connectivity between wetlands is thus important for the scientific and decision-making communities (Golden et al., 2014). Additionally, it is necessary to trace the gradual variation of the flow depth when implementing engineering practices or creating inundation maps. Normally, the slope between two wetlands is considered as mild and the flow depth can easily be impacted by backwater or drawdown effects based on the downstream condition. In this circumstance, an accurate water surface profile can provide helpful guidance for wetland decision-making.

\subsection{Topography in Wetlands}

Topography plays a fundamental role in the process of simulating overland flow and can have a significant impact on the results. Understanding the characteristics of the land surface can help hydrologic model builders better simulate how runoff flows over the land surface. Normally, wetlands in a digital elevation model (DEM) are represented as sinks or depressions, which refer to a single cell or a group of cells which have no outlet because the elevations of surrounding cells are all higher than those of the depression 
cell. Such depressions could potentially hold a considerable amount of water and have a significant impact for watershed hydrology. Flats are cells which have zero slope because the elevation of they and their neighbors are the same. For cells in sinks and flats, flow direction can be assigned to these cells but the flow path is discontinuous when using a common flow direction method, such as the four-neighbor rule or the eight-neighbor rule (Holmgren, 1994). Traditionally, when creating a DEM, during the measuring process or the interpolation process, problematic features are created in the form of sinks and flats, which have been considered as artificial and spurious (O'Callaghan and Mark, 1984; Oimoen, 2000). In most cases, these artificial sinks and flats exist in low relief and coarse resolution areas.

The most common and simplest method to solve this problem is to fill these sinks (Jenson and Domingue, 1988). Martz and Garbercht (1999) created a flow path by lowering the elevation of cells that obstruct the flow and create sinks. Stream burning is also an efficient method to generate a flow path though these sinks (Saunders, 1999). However, these strategies end up ignoring real surface depressions that may be important in wetland considerations. Jenkins and McCauley (2006) pointed out that the algorithmic filling of sinks could make these wetlands "disappear" in geographic information system (GIS) output, which may affect land use decisions. As fine resolution DEMs with greater accuracy and precision have become available, more evidence shows that some depressions are real features. By simply removing the depressions, models will neglect water which may exist in these depressions. When assigning flow direction for a DEM with depressions, both the single flow and the multiple flow methods are inadequate. Sinks on the DEM act like "black holes" which could absorb all water from their 
surrounding cells because the flow direction of these surrounding cells all point to the sinks. Additionally, because of the sinks, these cells without accurate flow direction will prevent the generation of flow paths from some cells to the outlet.

\subsection{Infiltration}

Infiltration is one of the most significant components in hydrology and has been researched for decades (Liu, Zhang and Feng, 2008; Chen, Hill and Urbano, 2009; Ali et $a l .$, 2016). Modeling accurate infiltration rates with different rainfall events is a fundamental step for simulating overland flow, predicting floods, assessing containment transport and even studying plant growth. Different kinds of models including empirical models (Tan and O'Connor, 1996; Mishra, Tyagi and Singh, 2003) and physical models (Chu, 1978; Warrick et al., 2005; Chen, Hill and Urbano, 2009) are available to describe this complex process. The Green Ampt infiltration model (Green and Ampt, 1911) has become the most widely used infiltration model because of its simplicity, its physical

grounding in the law of conservation of mass and use of Darcy's law (Mishra, Tyagi and Singh, 2003; Wang, Chen and Yu, 2018). Multiple studies using the Green Ampt model have been conducted at different spatial scales and in different locations (Kalman, 1960; Chen and Young, 2006; Kacimov, Al-Ismaily and Al-Maktoumi, 2010; Chen et al., 2015).

Because of its simplicity, several assumptions are made before applying the Green Ampt method. For example, it assumes a homogenous soil profile and a uniform distribution of initial water conditions (Chu and Mariño, 2005; Kale and Sahoo, 2011). 
Additionally, it does not consider unsteady rainfall or surface water movement in the horizontal direction (Chu, 1978; Mao et al., 2016).

\subsection{Objectives}

\subsubsection{Water Surface Profiles on the Landscape}

The first objective of this research is to investigate and characterize the flow connection between two wetlands. A workflow is proposed to simulate water surface profile development over a landscape using GIS technology and a Python script. The Modified Euler's method is employed to calculate the water profile caused by backwater or drawdown effects between wetlands on a mild slope. In this workflow, GIS technology can precisely extract the detailed landscape information directly from a digital elevation model (DEM), which is very helpful, especially for the vast majority wetland locations where there are no field measurements. With the help of a Python script, this resultsoriented model can provide flow characteristics to inform decision-making.

\subsubsection{Overland Flow Simulation through Wetlands}

A water balance methodology (where water will exist, how much will be there and for what period of time) is developed and demonstrated that focuses on small depressions, as locations where conservation efforts to create or regenerate wetlands may be achievable. Integral to this analysis is a detailed treatment of depressions in the landscape. Utilizing a digital elevation model, the methodology incorporates a cell-bycell analysis to appropriately capture small-scale processes. Instead of treating these vital depressions as errors or being insignificant to the water balance calculations, they are retained. Flow direction is dynamically determined by the land surface and water 
characteristics. With potentially shallow flow in depressions, the use of Manning's equation incorporates stratified flow where differing values of Manning's $n$ describe flow through and above vegetation. This real-time overland runoff model based on a short time step is implemented through a Python code using ArcGIS. Exercises on an artificial DEM with simulated precipitation demonstrate the ability of the model to accurately represent hydraulics principles. Simulations of two field sites over a period of a year, and incorporating precipitation, infiltration and evapotranspiration, demonstrate the ability to track water surface locations and extents with an accuracy necessary for decision making.

\subsubsection{Infiltration Calculation Based on Modified Green Ampt Model}

In its original development, the Green Ampt methodology considered only steady precipitation. The third objective of this research is to build upon enhancements to the original Green Ampt methodology (i.e., considering unsteady rainfall as a sequence of very short periods of steady rainfall) in order to calculate infiltration rates with unsteady precipitation over the landscape. This landscape-based assessment of infiltration is carried out using a GIS-based Python script. As water moves over the landscape, some cells experience run on and some cells experience runoff, resulting in different water depths on each cell over time. Because Green Ampt infiltration is based on the existence of excess water on the surface, this variable water depth is incorporated into the scrip to capture this important hydrologic process. 


\section{WATER SURFACE PROFILES ON THE LANDSCAPE}

As the names suggests, wetlands are locations that are associated with wetness. This wetness causes a transformation of the soil because of the absence of free oxygen, which in turn supports plants that thrive in this specific anaerobic environment. However, this wetness does not need to occur continuously, and may only be required for a short period of time, as during the growing season for the vegetation of interest.

Wetlands provide multiple beneficial services for the environment and human society. Different kinds of plants and animals are supported by wetlands and the dynamic relationship among these creatures is very complex, which makes wetlands one of the most productive ecosystems on Earth. For human society, wetlands can provide multiple unique advantages that no other ecosystem can. On the other hand, human activities, such as construction, pollutant discharges, deforestation and farming, can significantly impact on the quality of water resources. With these potential tensions, wetlands act like buffer zones to mitigate the negative impacts. One notable function of wetlands can be to remove pollutants introduced by human activities(Brix, 1994; Robb, Novotny and Olem, 1996; Kadlec et al., 2000). Studies show that wetlands can significantly decrease nitrates (Fennessy and Cronk, 1997; Mitsch and Gossilink, 2000; Lin et al., 2002), phosphorus(Carpenter et al., 1998; Braskerud, 2002) and heavy metals in water (Kalbitz and Wennrich, 1998; Cheng et al., 2002). Wetlands also work efficiently in controlling floods (Mitsch and Gossilink, 2000; Pezeshki, 2001). Like sponges, they can soak up a considerable amount of water of storm runoff, holding it and releasing it slowly so that it can be conveyed in existing channels. Besides these benefits, wetlands also provide crucial habitats for many plants and animals, such as birds, amphibians and reptiles. 
For some time, researchers have been interested in the connectivity between wetlands and how wetlands connect to downstream locations. First, these questions can help to understand the water movement among wetlands. Second, they can also provide guidance for potential mitigation and enhancement activities. Meanwhile, there are many geographically isolated wetlands which can connect with other water bodies during wet seasons. Those wetlands in floodplains or other flat areas may be separated from each other, especially during dry seasons. However, during storms, wetlands receive water from their own contributing areas. After wetlands fill up, surface water may start to flow to neighboring wetlands at lower elevations or to downstream streams and rivers. Quantification of the processes governing hydrologic connectivity between wetlands is thus important for the scientific and decision-making communities (Golden et al., 2014). Additionally, it is necessary to trace the gradual variation of the flow depth when implementing engineering practice or creating inundation maps. Normally, the slope between two wetlands is considered as mild and the flow depth can easily be impacted by backwater or drawdown effects based on the downstream condition. In this circumstance, an accurate water surface profile can provide helpful guidance for wetland decisionmaking.

The objective of this study is to investigate and characterize the flow connection between two wetlands. A workflow is proposed to simulate water surface profile development over a landscape using GIS technology and a Python script. The Modified Euler's method is employed to calculate the water profile caused by backwater or drawdown effects between wetlands on a mild slope. In this workflow, GIS technology can precisely extract the detailed landscape information directly from a digital elevation 
model (DEM), which is very helpful, especially for the vast majority wetland locations where there are no field measurements. With the help of a Python script, this resultsoriented model can provide flow characteristics to inform decision-making.

\subsection{Previous Studies}

\subsubsection{Hydraulics Background}

The flow in a channel with a regular cross section (rectangular or trapezoidal) has been studied for many years (Manning, 1891; Straub, 1932). Modeling the flow over a landscape is a different undertaking and introduces additional complexity. As water drains into a depression from the surrounding contributing area, it will exist at a certain depth, that will vary based on the size of the contributing area and the type of storm generating the runoff. As water flows between depressions, there exists a water surface profile that connects the depth of water in one depression with the depth of water in the connecting upstream or downstream depression. A water surface profile depicts the changing flow depth in the longitudinal direction of flow. The profiles can be classified into different categories based on the relationship between the actual depth of flow, the uniform depth (depth of equilibrium), and the critical depth (the depth of minimum energy).

The flow in a channel or between depressions is characterized as open channel flow because the water surface is open to the atmosphere. With no external sources of energy, such as seen in a water distribution system, this open channel flow is driven solely by gravity. While gravity (expressed as the land surface slope) imparts energy to the system, energy is lost through friction, as water flows over a surface. This balance (i.e., 
equilibrium) between energy in and energy out is expressed through Manning's equation (Eq 2.1):

$$
\begin{gathered}
\mathrm{Q}=1 / n A R^{\frac{2}{3}} \sqrt{S} \\
\mathrm{R}=A / P
\end{gathered}
$$

where $\mathrm{Q}$ is the flow (discharge) $\left(\mathrm{m}^{3} / \mathrm{s}\right), n$ is Manning's roughness coefficient, $\mathrm{A}$ is the cross-sectional area of flow $\left(\mathrm{m}^{2}\right), \mathrm{R}$ is the hydraulic radius $(\mathrm{m})$ and $S$ is the channel slope $(\mathrm{m} / \mathrm{m})$. The hydraulic radius is calculated as the area divided by the wetted perimeter, $\mathrm{P}$ (m) in Eq 2.2. In any given channel, the cross-sectional area, the wetted perimeter and the hydraulic radius vary as the depth of flow varies, as shown in Fig. 2.1. For a given set of flow conditions $(\mathrm{Q}, \mathrm{n}$, and slope $)$ in a channel, there exists a depth of flow, $\mathrm{y}_{\mathrm{o}}$, at which the equality of Manning's equation is maintained. This depth of flow is called uniform depth, and the equilibrium of this type of flow is called uniform flow (where the depth does not change with distance) along a channel.

The energy of a flowing system can be characterized in terms of a specific energy, E, that has a depth component and a velocity head component as shown in Eq 2.3:

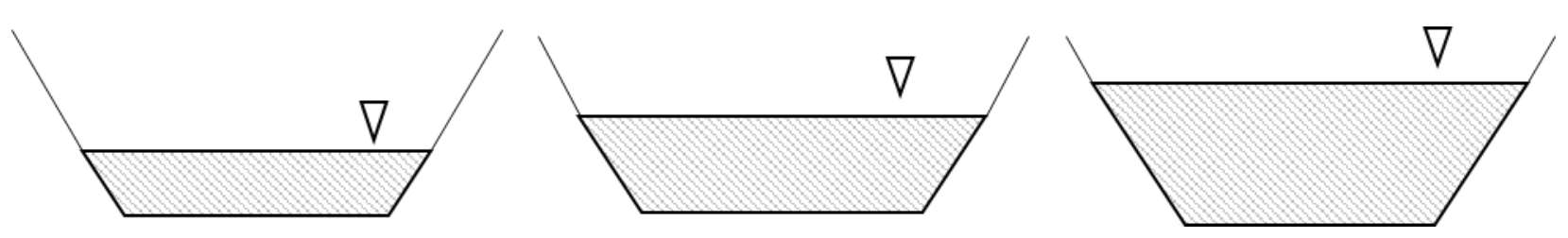

Figure 2.1 Demonstration of a trapezoidal channel's cross-section.

$$
\mathrm{E}=V^{2} / 2 g+y
$$

where $y$ is the water depth (m), $V$ is the velocity of the flow $(\mathrm{m} / \mathrm{sec})$ and $g$ is the gravitational constant $\left(\mathrm{m} / \mathrm{s}^{2}\right)$. For any value of $\mathrm{E}$, there exist two different depths of flow, one deeper and one shallower. The exception to this statement is the fact that at a critical 
specific energy, $E_{c}$, there exists only one depth, a critical depth, $y_{c}$. This critical condition of flow is the most efficient (lowest energy state) for impelling flow through a channel. These conditions are depicted within a specific energy diagram in Fig. 2.2. Depths greater than $\mathrm{y}_{\mathrm{c}}$ are characterized as subcritical flow and exist on hydraulically mild slopes (where $y_{0}>y_{c}$ ). Hydraulically mild slopes are those most commonly seen on the natural landscape and thus are the locations of interest for wetlands considerations. Depths below $y_{c}$ are characterized as supercritical flow and exist on hydraulically steep slopes (where $y_{o}$ $\left.<y_{c}\right)$. Hydraulically steep channels may be seen with mountain streams or reservoir spillways and are therefore not considered in this analysis.

When a system is disturbed and shifted out of the equilibrium represented by Manning's equation, the system returns to equilibrium through gradual changes in the

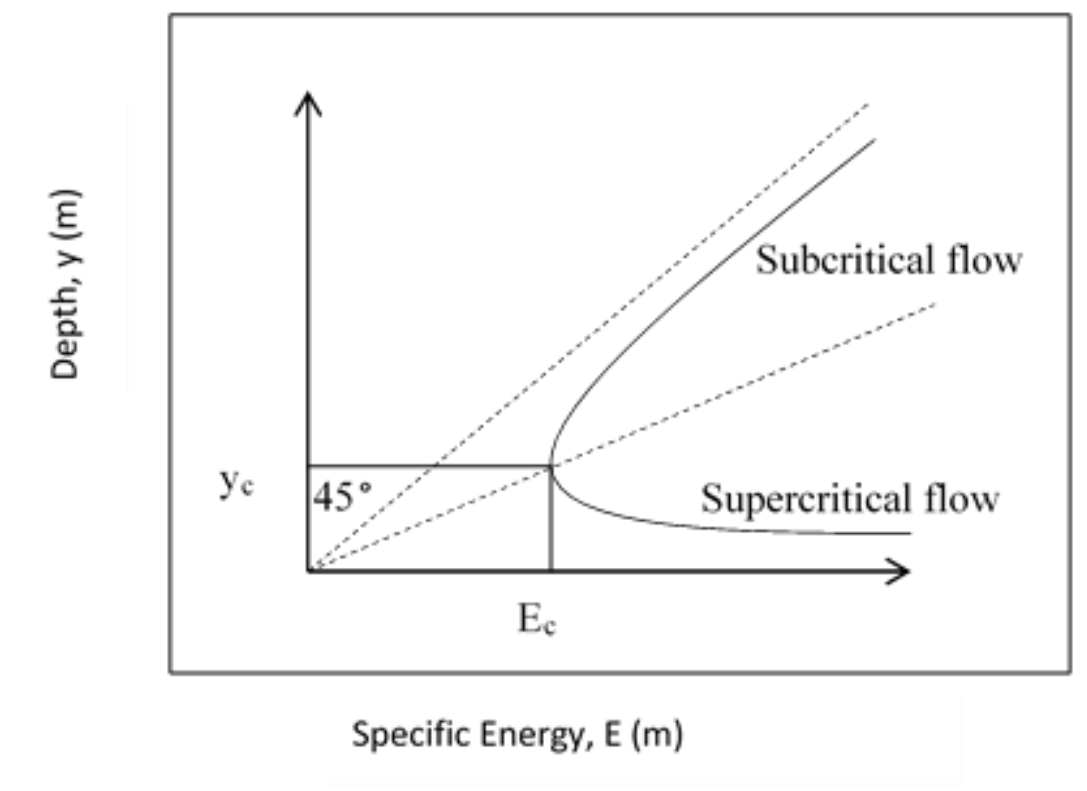

Figure 2.2 Specific Energy diagram.

depth of flow along a channel, known as gradually varied flow. Equilibrium flow can be disrupted if, for example, there is a downstream depression with a water surface elevation that is not equal to the depth of the incoming flow. On the mild slopes of interest, if the depression depth of flow is greater than $y_{0}$, the return to equilibrium is achieved via a 
backwater curve (designated as M1), progressing from the downstream location to the upstream location. A water surface elevation between $\mathrm{y}_{\mathrm{n}}$ and $\mathrm{y}_{\mathrm{c}}$ will require an $\mathrm{M} 2$ (drawdown) curve to return to equilibrium, while an M3 curve will result if water surface elevation is below $\mathrm{y}_{\mathrm{c}}$. No further consideration is given to M3 curves because they only exist where constructed infrastructure forces the existence of extremely shallow flow (e.g., from under a sluice gate) and this condition does not occur with wetlands. All three of these curves are shown in Fig. 2.3. The interest in the curves arises because on a landscape, a depth of flow is associated with areas that are covered by water. These areas that are covered by water are subject to infiltration and may be part of a wetland.

\subsubsection{Calculating Water Surface Profiles}

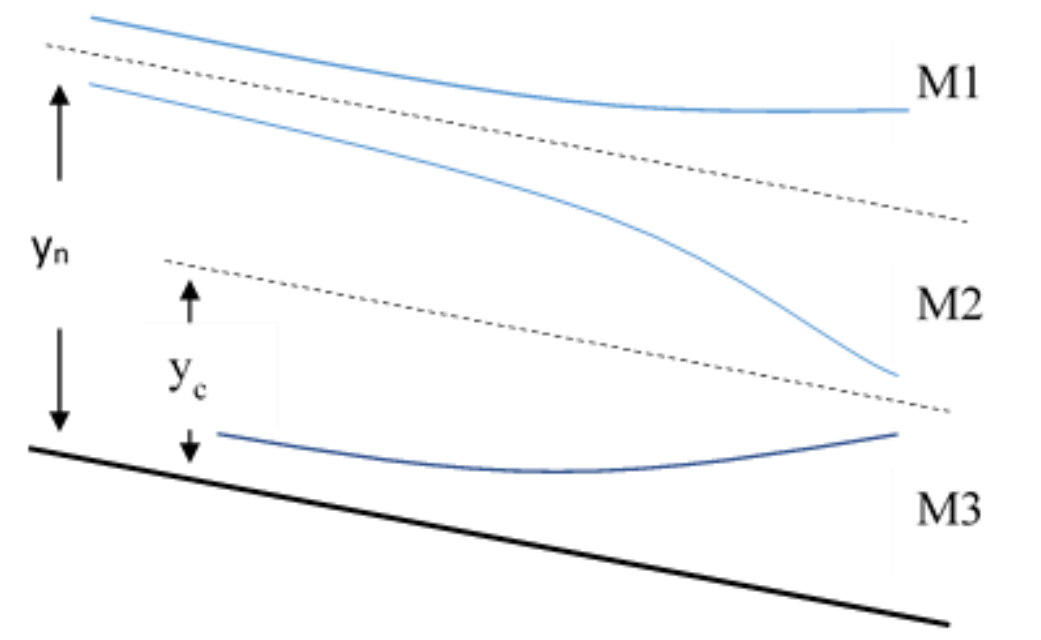

Figure 2.3 Classification of water profiles on a mild slope.

Water surface profiles play an important role in engineering practice. Infrastructure, such as channels, sewers or culverts should be designed with the consideration of gradually varied flow. Different methods to calculate the water surface profiles have been developed, including the standard step method, the direct step method, and the Modified 
Euler's method (Chow, 1959; Karim et al., 2012). These methods are based on the energy, momentum and continuity equations.

\subsubsection{Standard Step Method}

Currently, the most commonly used method is the Standard Step method which is utilized to compute a one-dimensional water surface profile for gradually varied flow. It is also imbedded in HEC-RAS, developed by the US Army Corps of Engineers (US Army Corps of Engineers, 2010). The flow characteristics at certain cross sections are calculated from the given channel information at another cross section and the reach length between them. The basic equations used in the Standard Step method to compute the water surface profile are the energy equation (Eq 2.4) and the momentum equation $(\operatorname{Eq} 2.5)$ :

$$
\begin{gathered}
z_{1}+y_{1}+\alpha_{1} V_{1}^{2} / 2 g=z_{2}+y_{2}+\alpha_{2} \mathrm{~V}_{2}^{2} / 2 g+h \\
A_{1} h_{c 1}+Q^{2} / g A_{1}=A_{2} h_{c 2}+Q^{2} / g A_{2}
\end{gathered}
$$

where subscripts 1 and 2 represent cross sections 1 and 2, $z$ is the bed elevation, $y$ is the water depth, $V$ is the velocity, $\alpha$ is the velocity correction coefficient, $h$ is the energy loss between sections 1 and 2, $g$ is gravitational acceleration, $A$ is the cross-sectional area of flow and $h_{c}$ is the distance below the free surface of the centroid of the area. The bed elevation, depth and velocity terms are collectively known as energy head, or simply, head. While energy is lost between sections (Eq 2.4), momentum is conserved (Eq 2.5).

The Standard Step computational procedure is a trial and error process. Based on the given discharge, and the boundary and channel conditions, the method assumes an initial water surface elevation for a target cross-section. It then recomputes a new water surface 
by calculating the headloss as a result of friction between the two cross-sections. Iterative calculations with different assumed initial water surface elevations continue until the difference in the total heads is within an acceptable range.

Chow (1959) indicated that profile calculations should be carried out from downstream to upstream if the flow is subcritical and from upstream to downstream if the flow is supercritical. Performing calculations in the wrong direction could cause the water profile to diverge from the correct one. The Standard Step method can be used to perform calculations in either direction depending upon the flow conditions.

\subsubsection{Direct Step Method}

The Direct Step method is used to calculate the distance associated with a specific depth change along the channel. At any cross section of a channel, the total energy head, $\mathrm{H}$, is calculated by

$$
H=z+y+\alpha^{\mathrm{V}^{2} / 2 g}
$$

as $H$ is differentiated with respect to $x$, which is the coordinate in the flow direction, Eq 2.6 can be converted to

$$
d H / d x=-S_{e}=-S_{0}+d E / d x
$$

and

$$
d E / d x=S_{0}-S_{e}
$$

in which $S_{e}$ is the slope of the energy grade line and $S_{0}$ is bed slope. Using the finite difference form to approximate the derivative $\frac{d E}{d x}$, Eq 2.8 results in

$$
x_{i+1}-x_{i}=\left(E_{i+1}-E_{i}\right) /\left(S_{0}-\bar{S}_{e}\right)
$$


where $\bar{S}_{e}$ is the arithmetic mean slope of the energy grade line between cross sections $i$ and $i+1$. This method will calculate $\Delta x$ values step by step by assuming a depth $y$ and a specific energy $E$. Normally, the Direct Step method is recognized as the easiest approach to calculate a water surface, but it requires interpolation if the depth of flow is required at specified locations of interest.

\subsubsection{Modified Euler's Method}

The Modified Euler's method is designed to compute the flow depth changes for specified changes in distance along a channel. Strum (2001) reported that this method is more appropriate for natural channels because the channel geometry can be collected from field surveys. It simply treats the water surface curve between two cross sections as a straight line to compute an approximate water depth for the next station. As a result, this method requires a small longitudinal increment to achieve accurate results. The Modified Euler's method moves forward and uses the arithmetic mean of the water surface slope values from two cross sections to obtain a more precise number. Because the slope value is unknown at the beginning, the method uses a predicted water depth and corrects it using the mean slope value from the predicted slope and ending slope value in each interval. This two-step method utilizes prediction (Eq 2.10) and correction (Eq 2.11) equations:

$$
\begin{gathered}
y_{\text {pre }(i+1)}=y_{i}+\operatorname{slope}\left(y_{i}\right) \Delta x \\
y_{i+1}=y_{i}+\left(\operatorname{slope}\left(y_{i}\right)+\operatorname{slope}\left(y_{\text {pre }(i+1)}\right)\right) / 2_{2} * \Delta x
\end{gathered}
$$

where $\Delta x$ is the distance between the two calculation locations, and $\mathrm{i}$ indicates the current calculated depth and $i+1$ indicates the depth at the next location. The method is straight 
forward enough so that once the channel parameters have been established, the water surface profile for a channel can be calculated using a spreadsheet (Sturm, 2010).

\subsubsection{Hydraulic Input Parameters}

Correct assessment of input parameters is essential for the correct calculation of water surface profiles. Unlike regularly shaped channels (e.g., rectangular, trapezoidal or parabolic) where cross-sectional area, wetted perimeter and hydraulic radius can be calculated from equations, simulating the water surface profile on a natural channel presents several challenges. The first is the fact that irregular cross sections are difficult to quantify, typically requiring a field survey at each and every cross section of interesteverywhere the cross-section changes. The second is that the hydraulic parameters such as channel roughness and slope can vary continuously both in the direction of flow and along the cross-section. GIS offers an efficient means to extract channel geometry information directly from DEMs, especially from LiDAR data, with great accuracy and precision. Current technologies also offer different abilities to utilize and analyze the landscape data, such as delineating the watershed boundary (Jenson and Domingue, 1988) and generating the flow direction and the flow path (Quinn et al., 1991).

\subsection{Methodology}

A methodology has been developed to generate the water surface profile on a landscape rather than in a defined channel. It utilizes the Modified Euler's method for computational efficiency over potentially large areas (instead of the Standard Step method), and is implemented via a Python script. The method was specifically developed for hydraulically mild landscapes of particular interest for wetlands evaluations. 
The computational methodology consists of two main parts: extracting the necessary hydraulic parameters from the DEM for a water surface profile calculation and generating the water surface profile, as shown in Fig. 2.4. Once a high-resolution DEM for the area of interest has been identified, the flow chart shows the specific steps involved in the process.

\section{DEM}

- Identify wetlands

- Identify basins boundaries

- Identify weir cross-section locations

- Create the centerline of the flow

- Divide the flow into reaches

- Create cross-section for each reach

- Extract hydraulic parameters for each reach

- Apply Modified Euler's method

- Generate water surface profile

Figure 2.4 Flow chart of the methodology.

The first set of steps to derive the necessary landscape information from a DEM include identifying the upstream and downstream wetlands, outlining the contributing basin boundaries and creating a weir cross-section at the pour point, which controls the outflow from the upstream wetland. The next step is to locate the central flow line with a starting point and an ending point. The starting point is normally recognized as the pour point of the upper wetland which is the lowest point of the weir. Correspondingly, the lowest point of the downstream wetland is considered as the ending point. The least-cost 
line (the steepest route) between these two points generated from the DEM is treated as the central line of the flow pathway.

A natural stream channel is not a straight line and has variable characteristics at different locations, so the overall flow pathway is divided into several reaches which approximate straight lines and share similar characteristics. The slope of each reach can be calculated from the reach length and the starting and ending points of each reach. With the establishment of the reaches, a perpendicular line is created at the midpoint of each reach and is perpendicular to the invisible straight line of the starting and ending point of a reach. Then a series of points can be extracted from the original DEM using a perpendicular line, and the elevation data of these points are used to develop the crosssection of each reach. Multiple reaches can be identified to capture the variability in landscape parameters. In order to characterize the hydraulic characteristics of the landscape for the range of flow conditions, the hydraulics parameters of area, wetted perimeter and hydraulic radius are calculated for varying depths of flow (i.e., for different water surface elevations). The cross-sectional area of flow at a given depth is calculated as:

$$
\mathrm{A}=\sum_{1}^{m} A_{i}=\sum_{1}^{m}\left(W S-h_{i}\right) * l
$$

where $W S$ is the given water surface elevation, $h$ is the elevation of pixel $\mathrm{i}, l$ is the length of each pixel and $m$ represents the number of pixels which are lower than the water surface elevation. The wetted perimeter is calculated as:

$$
\mathrm{P}=\sum_{1}^{n} \sqrt[2]{\left(h_{i+1}-h_{i}\right)^{2}+l^{2}}
$$

and the hydraulic radius is calculated using Eq 2.2. 
The last step is to implement the Modified Euler's method and compute the water surface profile for each reach. Based on an initial downstream water depth, the water surface profile is calculated from downstream to upstream. For each reach, the upstream water depth is used as the downstream water depth for the subsequent calculation in the next upper reach. Calculations continue until the upstream pour point is reached, and the set of calculated $y$ value constitutes the water surface profile.

\subsection{Demonstration}

This methodology is demonstrated in two different ways. The first demonstration is conducted by using the script to extract the hydraulic input parameters for a rectangular channel from an artificial landscape and then calculating the backwater curve for an example provided by Sturm (2010). In this fashion, it is easy to ascertain that the Python script is carrying out the calculations properly. The second demonstration is performed on two connected depressions in the vicinity of Pershing State Park in Linn County, Missouri. This location is selected because of the historic presence of wetlands and current interest in wetland rehabilitation.

\subsubsection{Backwater Curve Example}

To verify the accuracy of the Python script, an artificial trapezoidal channel is created in ArcGIS using elevation data (Fig. 2.5). It has the same channel geometry as an example provided by Sturm (2010). This trapezoidal channel has a channel slope of 0.001 $\mathrm{m} / \mathrm{m}$, a side slope ratio of $2: 1$ and a bottom width of 8 meters. The Manning's $n$ of the channel is 0.025 . The Python script detects the DEM of the trapezoidal channel and extracts all geometric information directly from it. The script then calculates the 
hydraulic parameters (i.e., cross-sectional area, wetted perimeter and hydraulic radius), as they vary by water depth (Table 2.1).

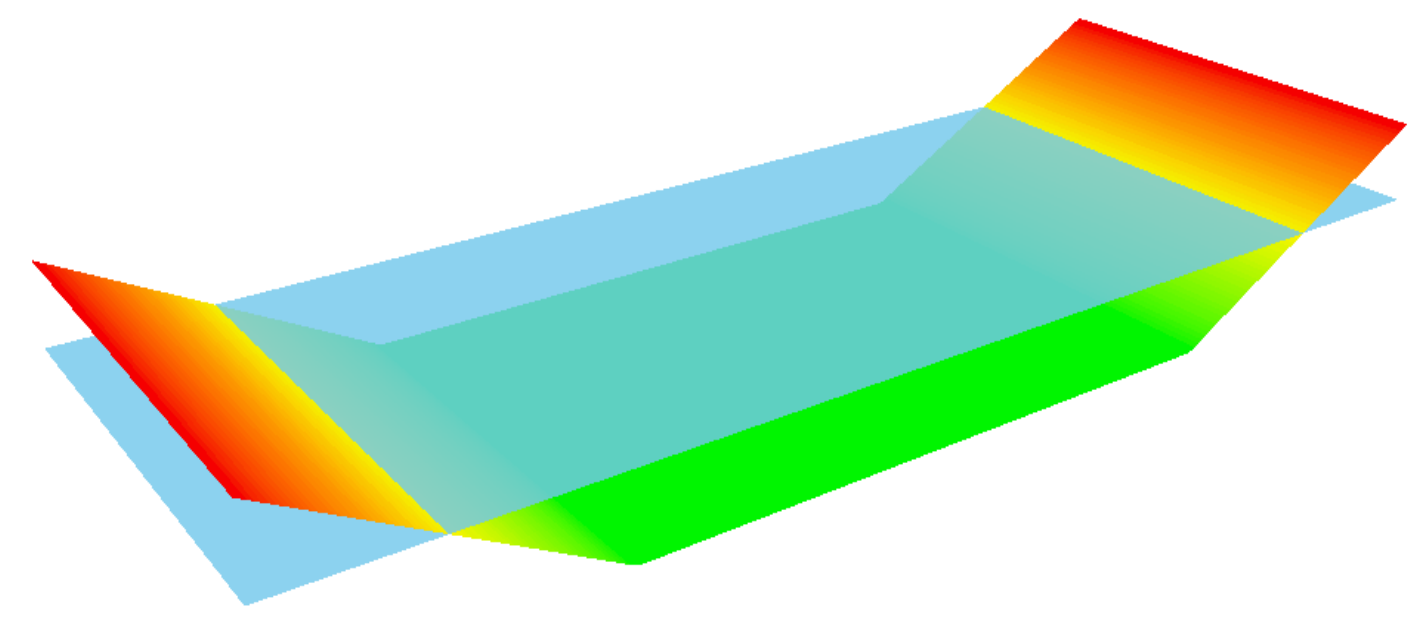

Figure 2.5 Recreation of a trapezoidal channel in ArcGIS.

Table 2.1 Hydraulic parameters calculated at given water surface elevations.

\begin{tabular}{ccccc}
\hline $\begin{array}{c}\text { Water } \\
\text { surface } \\
\text { elevation }(\mathrm{m})\end{array}$ & $\begin{array}{c}\text { Water } \\
\text { depth }(\mathrm{m})\end{array}$ & $\begin{array}{c}\text { Area } \\
\left(\mathrm{m}^{2}\right)\end{array}$ & $\begin{array}{c}\text { Wetted } \\
\text { perimeter }(\mathrm{m})\end{array}$ & $\begin{array}{c}\text { Hydraulic } \\
\text { radius }\left(\mathrm{m}^{-1}\right)\end{array}$ \\
\hline 100.49 & 0 & 0 & 0 & 0 \\
100.5 & 0.01 & 0.05 & 10.85 & 0.005 \\
100.51 & 0.02 & 0.19 & 16.74 & 0.011 \\
100.52 & 0.03 & 0.38 & 20.46 & 0.019 \\
100.53 & 0.04 & 0.6 & 24.49 & 0.025 \\
100.54 & 0.05 & 0.87 & 27.9 & 0.031 \\
100.55 & 0.06 & 1.16 & 30.38 & 0.038 \\
100.56 & 0.07 & 1.47 & 32.55 & 0.045 \\
$\ldots$ & $\ldots$ & $\ldots$ & $\ldots$ & $\ldots$ \\
\hline
\end{tabular}

Table 2.2 shows the results of the backwater calculations from Sturm (2010) and the Python script difference between these two calculations. Column 1 shows the distance from the starting point 0 to the upstream ending location 20 meters away. At the beginning of the calculation, the $\mathrm{x}$ intervals are very small in order to obtain precise 
results where there may be significant curvature of the flow, as with an M2 water surface profile. Column 2 lists the water depths as given by Sturm (2010). Column 3 depicts the water depths calculated using a spreadsheet created for this effort, while Column 4 displays the depths calculated using the Python script. The very minor differences between these two processes indicates that the Modified Euler's method can be implemented using this Python script.

Table 2.2 The comparison between Excel calculation and Python calculation.

\begin{tabular}{|c|c|c|c|}
\hline $\mathrm{x}(\mathrm{m})$ & Sturm (2010) & y1 (m) By Excel & y1 (m) By Python \\
\hline 0 & 1.0300 & 1.0300 & 1.0300 \\
\hline 0.005 & 1.0575 & 1.0575 & 1.0576 \\
\hline 0.01 & 1.0578 & 1.0578 & 1.0580 \\
\hline 0.02 & 1.0585 & 1.0585 & 1.0586 \\
\hline 0.04 & 1.0596 & 1.0596 & 1.0598 \\
\hline 0.06 & 1.0608 & 1.0608 & 1.0610 \\
\hline 0.08 & 1.0619 & 1.0619 & 1.0621 \\
\hline 0.1 & 1.0629 & 1.0629 & 1.0630 \\
\hline 0.2 & 1.0677 & 1.0677 & 1.0676 \\
\hline 0.4 & 1.0757 & 1.0757 & 1.0751 \\
\hline 0.6 & 1.0824 & 1.0824 & 1.0815 \\
\hline 0.8 & 1.0883 & 1.0883 & 1.0869 \\
\hline 1 & 1.0936 & 1.0936 & 1.0922 \\
\hline 2 & 1.1147 & 1.1147 & 1.1142 \\
\hline 4 & 1.1446 & 1.1446 & 1.1434 \\
\hline 6 & 1.1669 & 1.1669 & 1.1650 \\
\hline 8 & 1.1852 & 1.1852 & 1.1826 \\
\hline 10 & 1.2010 & 1.2010 & 1.1978 \\
\hline 20 & 1.2596 & 1.2596 & 1.2545 \\
\hline
\end{tabular}




\subsubsection{Pershing State Park}

A 1-meter resolution DEM is created based on the LiDAR data (downloaded from www.msdis.missouri.edu). The study area includes two depressions connected by a landscape with a mild natural slope (Fig. 2.6). During a rainfall event, these two depressions start to accumulate surface runoff from their respective contributing areas. Once the runoff fills up the upper depression, excess runoff will flow out of it and contribute to the lower depression. Normally, the lower depression, with a larger contributing area may often have a deeper water depth which could cause drawdown or backwater effects. The procedure of calculating the water depth profile is demonstrated with different tools in ArcGIS and a script as described below.

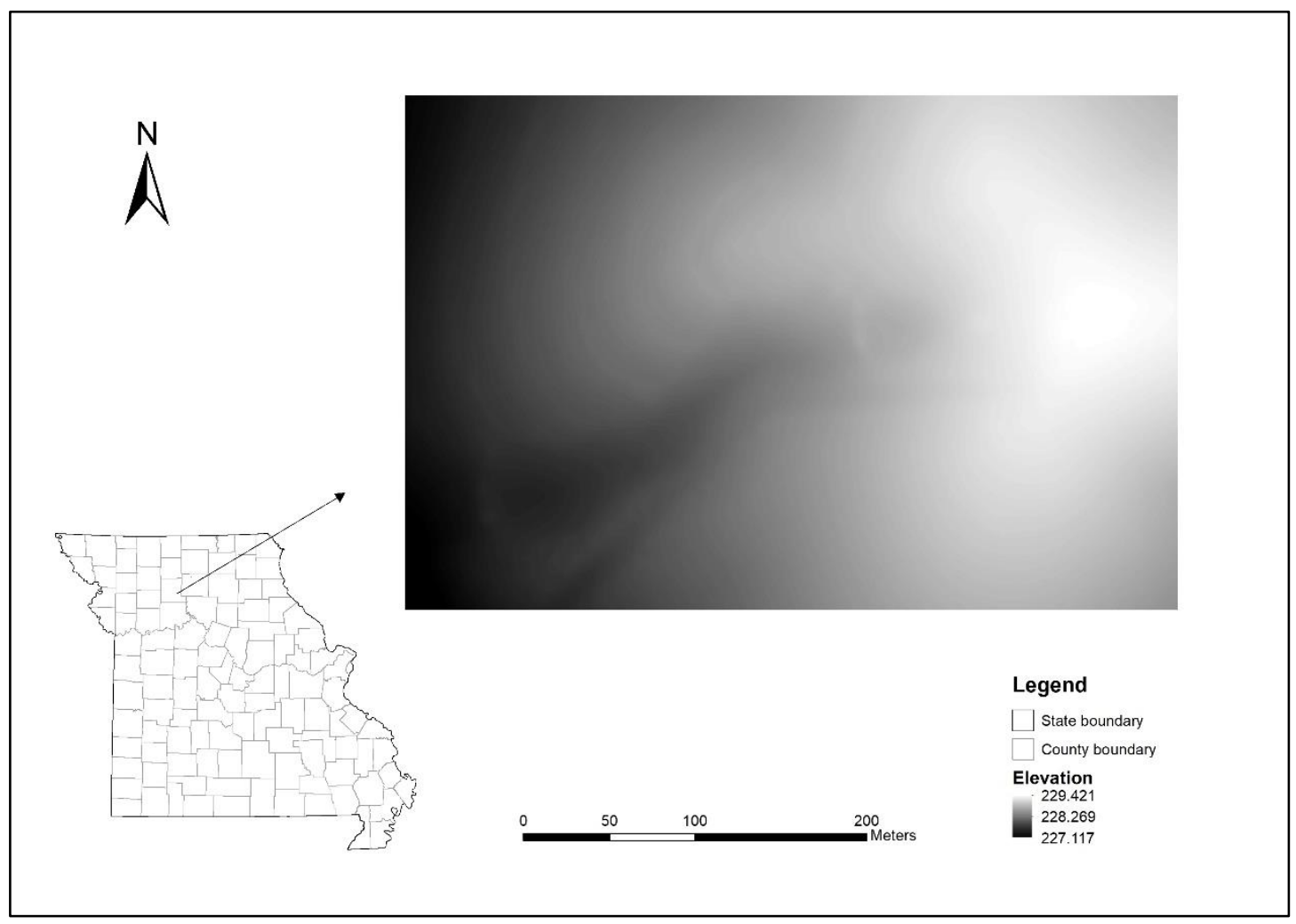

Figure 2.6 Study area. 


\subsubsection{Identify the Contributing Areas, Outline the Basin Boundaries and Create a Weir Cross Section}

The contributing area for each subbasin can help to explain the flow accumulation. The first step is using the embedded spatial analysis tools in ArcGIS to generate boundaries for each depression (Fig. 2.7). In this example, depressions are identified from the DEM. With sufficient rain, surface water will flow out of the upper depression and contribute to the lower depression. The starting point for flow (Fig. 2.7) is located at the lowest point along the boundary of the upper depression (i.e., the pour point of the upstream watershed). The ending point is the lowest point in the lower depression (i.e., the sink).

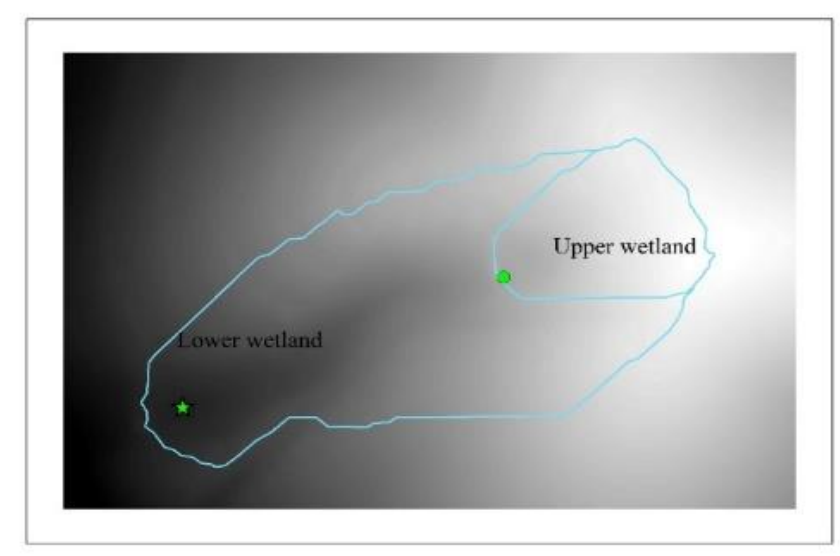

Figure 2.7 Identification of upper and lower wetlands.

\subsubsection{Create the Centerline of the Flow}

The surface runoff always flows along the steepest slope over the landscape. The distance tools in ArcGIS can create a cost map (Fig. 2.8a) based on the slope of the landscape and then generate the least cost path (Fig. 2.8b) which can be recognized as the centerline of the flow. For this study site, the elevation of the starting point is $228.65 \mathrm{~m}$ 
and the elevation of the ending point is $227.52 \mathrm{~m}$. The total length of the flow is $229 \mathrm{~m}$ and the slope of the overall flow pathway is $0.0049 \mathrm{~m} / \mathrm{m}$.
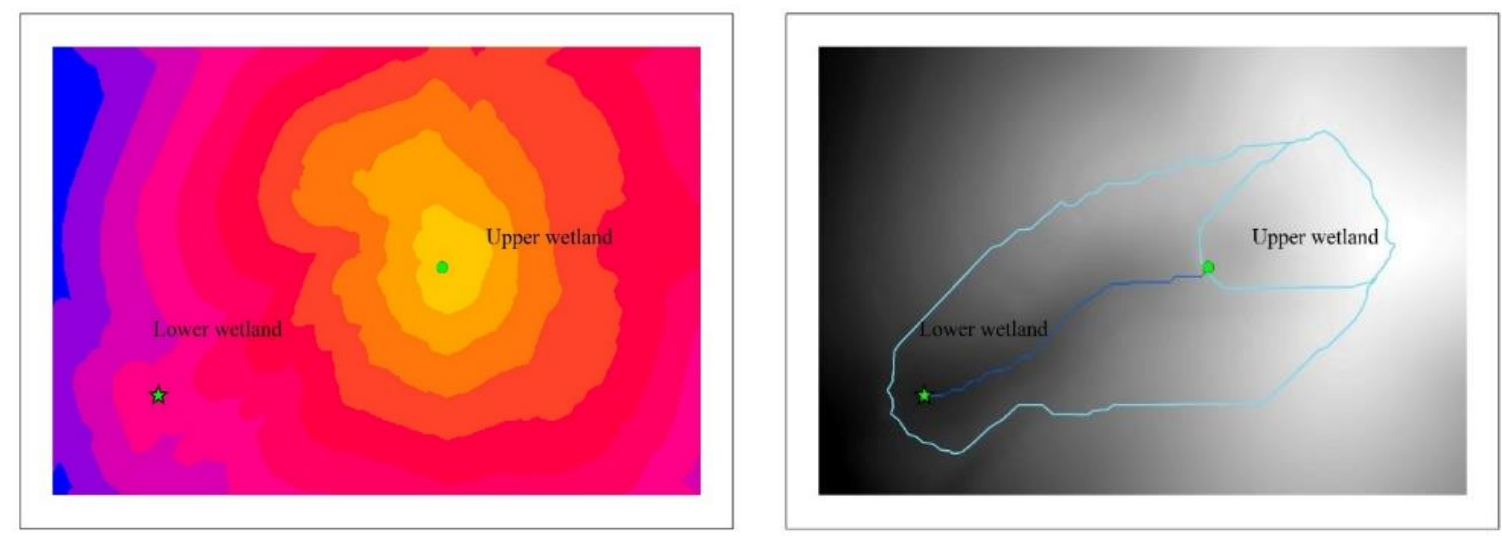

Figure 2.8 Cost map from the starting point to the ending point and flow path.

\subsubsection{Split the Channel into Reaches and Extract the Cross-section}

\section{Parameters}

From the cost map of Fig. 2.8, the centerline of the flow path is generated and is shown in Fig. 2.9. In general, separate reaches are identified where the direction of the flow path, the hydraulic characteristics of slope, land cover or geometry are consistent. For each reach, slope, land cover and other parameters are treated as uniform. For purposes of representing the different landscape characteristics in this demonstration, in this case, the flow path is divided into three reaches of equal length (Fig. 9a). Each reach has different slope and cross-section parameters which can be extracted from the DEM using the Python script. First, the script creates perpendicular lines from the middle point of each reach (Fig. 9b). The elevation data along each perpendicular line are extracted from the DEM. Second, the cross section for each reach is built from these elevation data. The width of each cross-section is set at $100 \mathrm{~m}$ and can be modified by the user as 
necessary. In standard hydraulic convention, reach lengths are numbered starting from the downstream-most location.
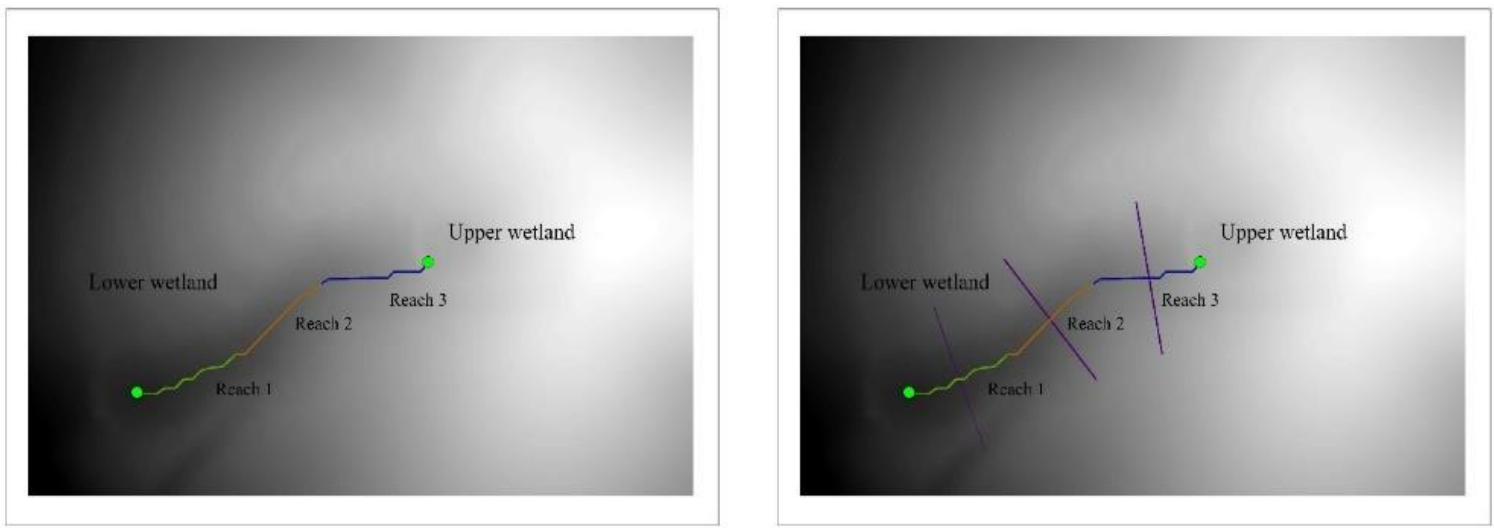

Figure 2.9 Generating reaches for the channel.

Table 2.3 Reach parameters.

\begin{tabular}{llllllll}
\hline & \multicolumn{3}{c}{ Length (meters) } & \multicolumn{3}{c}{ Ground surface (meters) } & Slope (m/m) \\
\cline { 2 - 6 } & Start & End & Difference & Start & End & Difference & \\
\hline Reach 1 & 0 & 76.35 & 76.35 & 227.52 & 227.80 & 0.28 & 0.0036 \\
Reach 2 & 76.35 & 152.7 & 76.35 & 227.80 & 228.16 & 0.36 & 0.0047 \\
Reach 3 & 152.7 & 229.05 & 76.35 & 228.16 & 228.65 & 0.50 & 0.0065 \\
\hline
\end{tabular}

Table 2.3 shows the elevation data of the starting and ending points for each reach, along with the length and slope. Fig. 2.10 shows how the geometry of different crosssections can vary significantly, having a great impact on the hydraulic calculations. Compared with Reaches 1 and 3, the geometry of Reach 2 has steeper sides (impacting the cross-sectional area of flow), resulting in an increasing depth when water flows from Reach 3 to Reach 2 and a decreasing depth when the water flows from Reach 2 to Reach 1. 

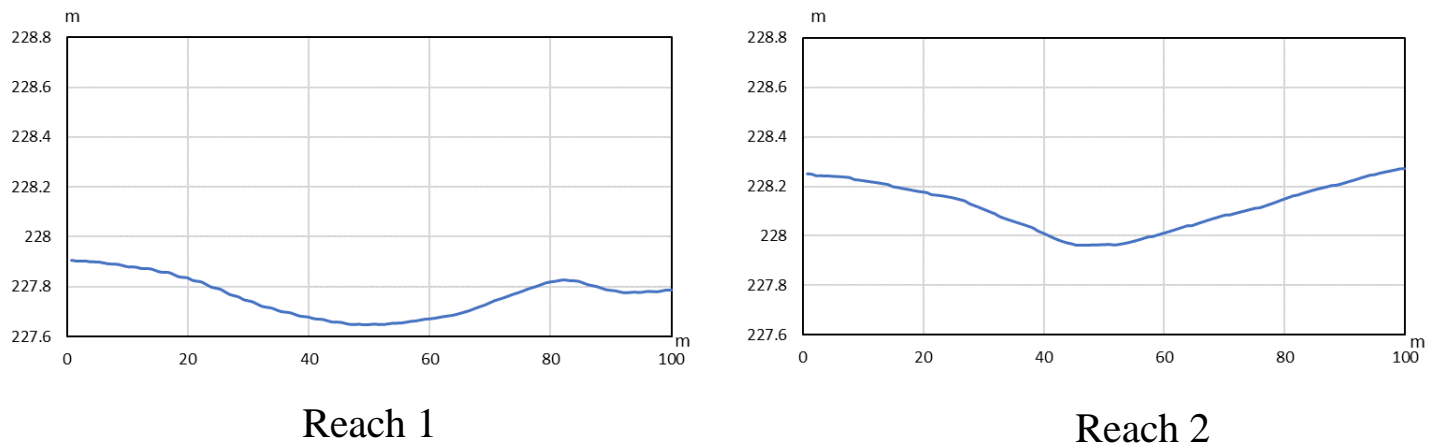

Reach 1

Reach 2

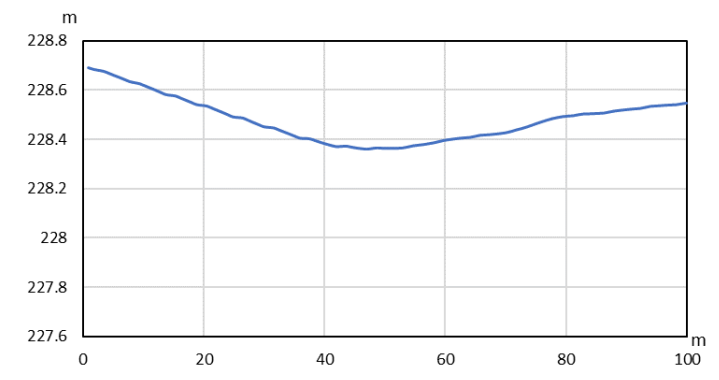

Reach 3

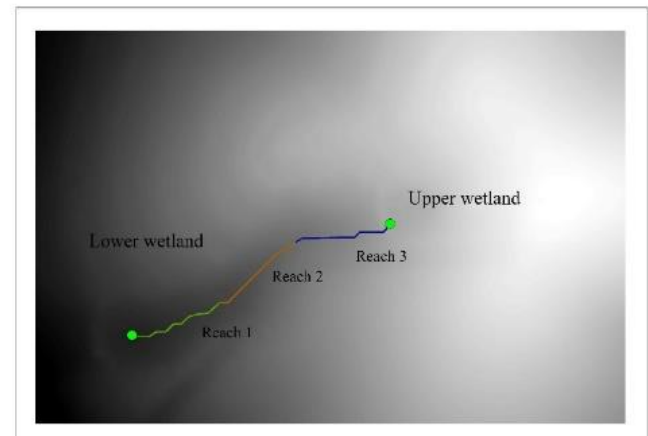

Figure 2.10 Cross section geometry of each reach.

\subsubsection{Generate the Water Depth Profile}

The water surface profile for each reach is calculated from downstream to upstream in a continuous process. Starting with a given water depth, the script calculates the water depth at the end of Reach 1 and uses that depth as the starting water depth for Reach 2 . Here, the profiles are calculated for two different flow circumstances (i.e., from a more intense Storm 1 generating greater flow and from a less intense Storm 2 generating less flow). 


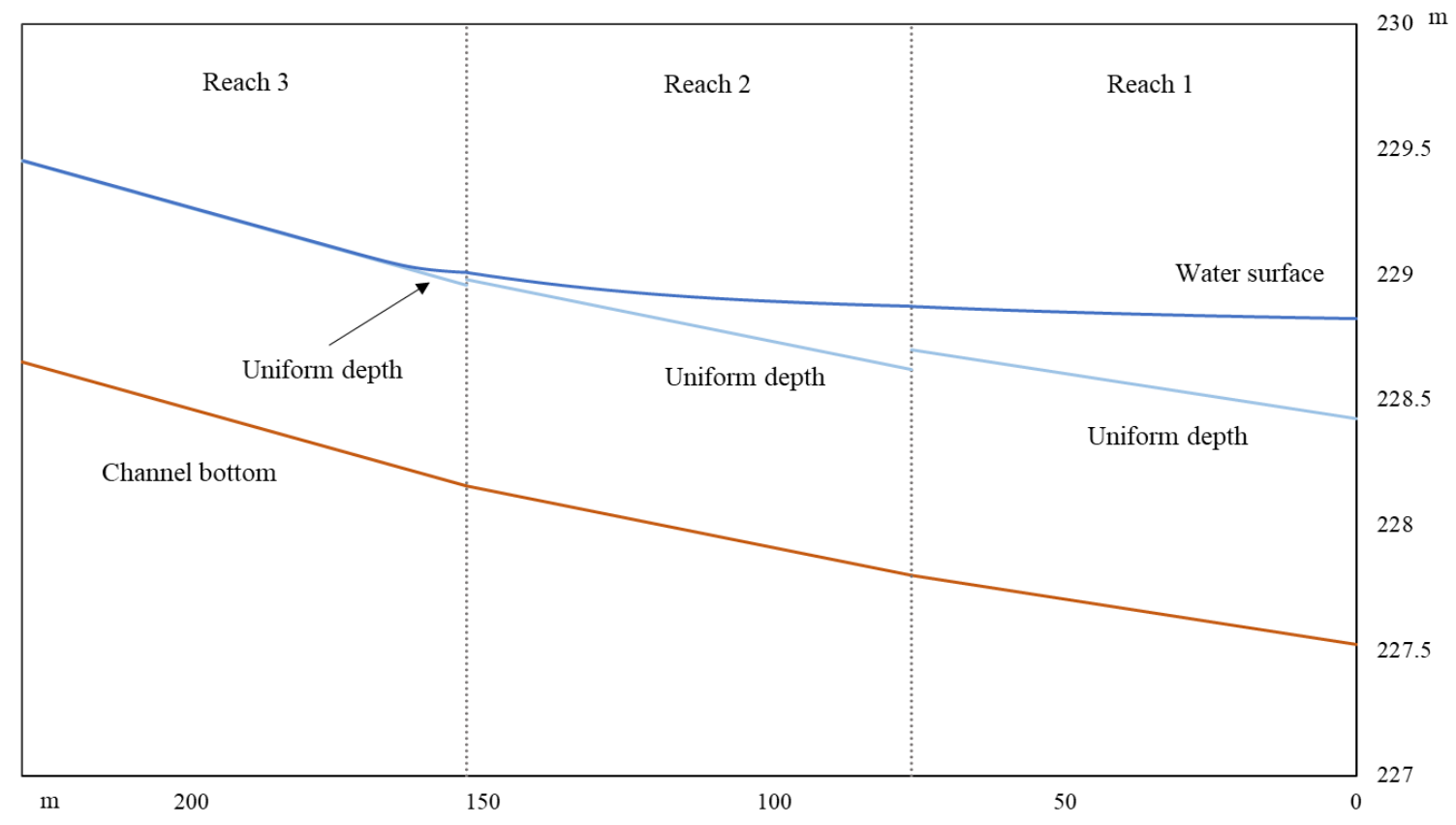

Figure 2.11 Water surface profile for Storm 1.

Fig. 2.11 shows the results Storm 1 (with a larger discharge and a deeper downstream depth) as generated by the Python script. In this test, the discharge of the flow is $200 \mathrm{~m}^{3} / \mathrm{s}$ with an initial depth of $1.3 \mathrm{~m}$ at the bottom of the lower depression. The roughness coefficient for all three reaches is set to 0.025 . The red line indicates the channel bottom and the right vertical axis is elevation. The light blue line is the calculated uniform depth. The uniform depth changes between the different reaches because the landscape characteristics are different between the reaches. The dark blue line represents the water surface profile, which always varies in terms of approaching uniform depth asymptotically. The $1.3 \mathrm{~m}$ depth in the downstream depression is greater than the calculated uniform depth of $0.90 \mathrm{~m}$. Therefore, the water surface must decrease with an M1 curve in the process of approaching the equilibrium condition of uniform depth. Even as the uniform depth changes, as from Reach 1 to Reach 2, the water surface is shown to 
be continuous, as would actually occur on the landscape. The transition from Reach 2 to Reach 3 shows the continuous water surface, with the shape adjusting from the steeper sides of Reach 2 to the flatter sides of Reach 3. For most of Reach 3, the plot shows the water surface profile coinciding with the uniform depth line, indicating that the water surface profile is very close to the uniform depth in its asymptotic approach, as would be expected.

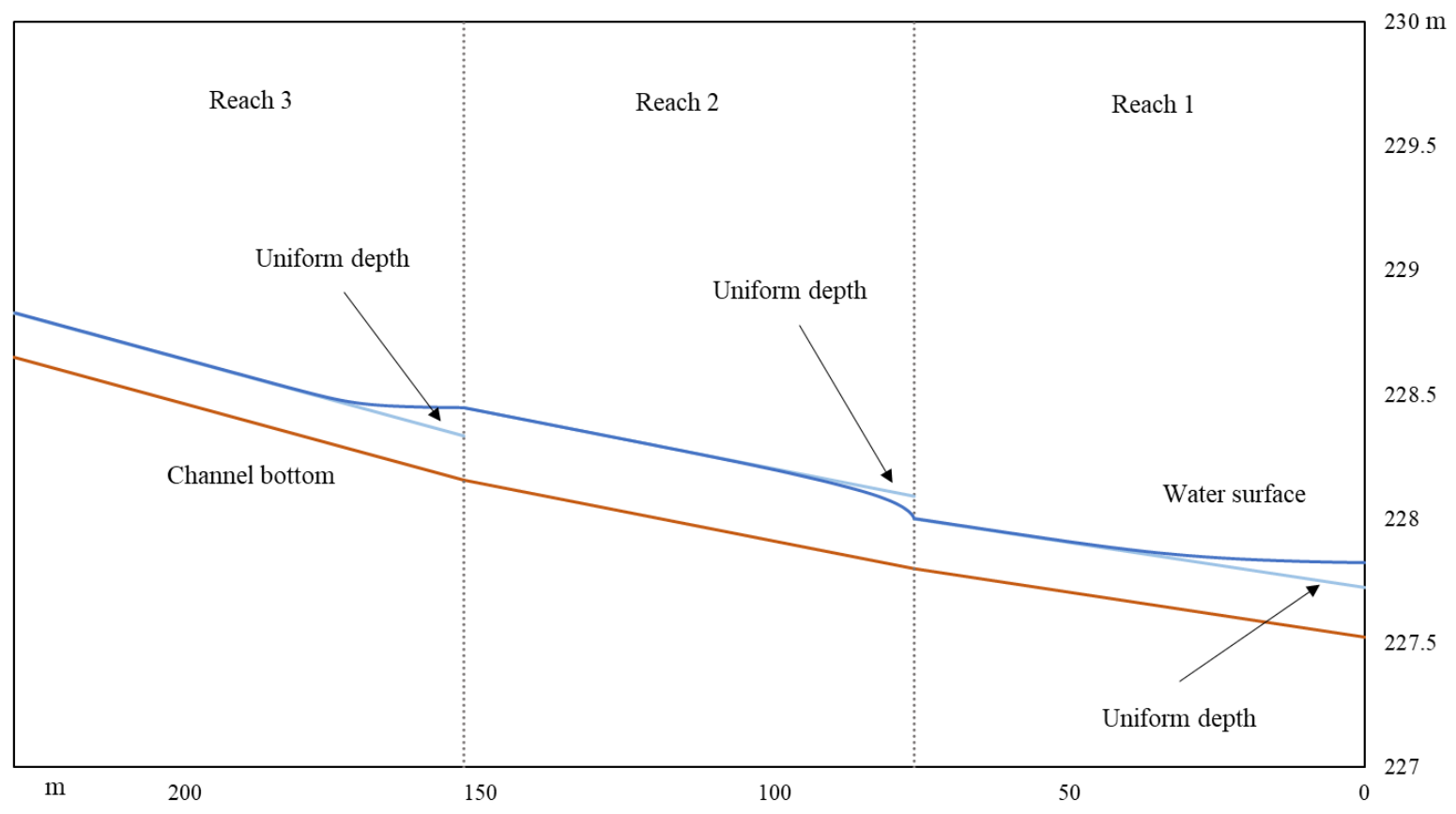

Figure 2.12 Water surface profile for Storm 2.

For Storm 2, the discharge is $5.0 \mathrm{~m}^{3} / \mathrm{s}$ with a given depth 0.3 meter at the bottom of the lower depression. The roughness coefficient for Reach 2 is set to 0.05 and Reach 1 and 3 are unchanged at 0.025 . In this scenario, the flow depth in Reach 1 decreases gradually following an M1 curve (Fig. 2.12) because the water depth in the downstream wetland is larger than the uniform depth of $0.20 \mathrm{~m}$ in the region connecting the two wetlands. Unlike the plot from Storm 1, there is an M2 curve in the transition between Reach 1 and 2 as the water surface now needs to increase to approach uniform depth. 
This condition exists because a larger roughness coefficient is assumed for Reach 2 resulting in a deeper uniform depth of flow, even without changing any of the other parameters. Once in Reach 3, water depth again follows an M1 curve to decrease the depth of flow to approach the lower uniform depth.

\subsection{Conclusion and Discussion}

This paper introduces an efficient methodology for using the Modified Euler's method to calculate water surface profiles over a natural landscape on the mild slopes connecting wetlands. A Python script has been created to perform the calculations, including the extraction of landscape data directly from a DEM, eliminating the need for a field survey at every potential depression of interest. The efficiency of the methodology allows for widespread scoping calculations to assess locations for more detailed investigations for wetland protection or mitigation. Its simplicity and automation can help users with little hydraulics background to calculate profiles for decision-making.

Multiple tests have been performed to verify the accuracy of this methodology. The Python script created for this project automatically extracts the necessary data and computes all necessary hydraulic parameters. The first test recreated a drawdown curve demonstration in a textbook. This was accomplished by generating an artificial landscape matching the trapezoidal channel of the example. The Python script extracted the necessary landscape parameters from the DEM, calculated the appropriate hydraulic parameters and developed the drawdown curve, exactly matching the published results. The second test was performed on a natural landscape with a discharge that would be associated with an intense storm. This set of conditions produced a sequence of backwater (M1) curves expected as landscape characteristics change, causing the water 
surface profile to adjust accordingly in moving from one reach to another. The third test was conducted on the same natural landscape (while changing one surface roughness value), but with a less intense storm. The lower flows associated with these more common, less intense storms, are of particular interest for continued wetland functioning. With the lower discharge, the script demonstrated the ability to calculate a water surface profile that incorporates both backwater (M1) and drawdown (M2) curves.

This effort addresses the challenge of quantifying the flow characteristics (i.e., a water surface profile) over a landscape in contrast to the current focus on flow in defined channels. It is able to accommodate the inherent variability in the landscape elevations and land covers. It is now possible to make assessments that could provide a first-step screening tool for wetland scientists to assist in the selection of locations that may warrant further investigation with respect to the preservation, restoration or mitigation of wetlands. Effort is ongoing, specifically in the depiction of the landscape implications of a given water surface profile - the extent of the land surface that would be covered by water from the given profile), leading to infiltration to support wetland function. 


\section{OVERLAND FLOW SIMULATION THROUGH WETLANDS}

\subsection{Wetlands}

Wetlands are essential components on the landscape. They act as barriers to retain overland runoff, mitigate floods and increase the recharge to groundwater. Biologically, they provide habitat to plants and animals integral to the overall ecosystem, including microorganisms capable of removing contaminants. Wetlands have often been drained to provide additional acreage for agriculture and to provide land for the development and growth of communities. The importance of wetlands and their preservation has been embodied in the concept of "no net loss of wetlands". Once avoidance and minimization strategies have been taken, mitigation activities may be implemented in an effort to replace the habit impacted or lost by human actions - either adjacent to the original wetland or in a wetland bank. An alternative to the concentration of compensatory sites in mitigation banks may be the creation of small, isolated wetlands that would normally exist throughout the landscape and that are so vital to the functioning of these locations as habitats.

Integral to the existence of wetlands is the existence of sufficient water for sufficient periods of time throughout the year. Sufficient water is necessary to provide the surface saturation and exclusion of free oxygen necessary for the formation and maintenance of hydric soils. Animals, such as amphibians, need surface water for egg laying and gestation, and for specific periods of the life cycle. Understanding the water balance in 
specific locations in the landscape is essential in identifying those locations where there may be sufficient water to establish the conditions necessary for functioning wetlands.

In addition to precipitation, a water balance is also based on infiltration and evapotranspiration, that are both heavily impacted by the characteristics of flow over the landscape. Therefore, understanding the landscape in terms of how water may flow into and out of a depression (and ultimately, where water will exist, how much will be there and for what period of time) is essential for evaluating a candidate compensatory wetland site. Such knowledge, and the ability to compare the analysis over multiple locations would support informed decision making.

\subsection{Topography}

Topography plays a fundamental role in the process of simulating overland flow and can have a significant impact on the results. Understanding the characteristics of the land surface can help hydrologic model builders better simulate how runoff flows over the land surface. Because digital elevation models (DEMs) are created to represent the real surface as a raster data model, numerous hydrologic and hydraulic analyses have been performed based on DEMs (Holmgren, 1994). In prior decades, DEMs were usually generated using topographic maps or geological surveys using aerial photography or remote sensing (Kenny, Matthews and Todd, 2008). Accuracy and precision are always major concerns and have been greatly improved by developments in technology. Recently, high spatial resolution elevation data derived from light detection and ranging (LiDAR) technology allows for the rapid generation of DEMs. High accuracy and low 
cost make these products widely used in hydrological analyses (Barber and Shortridge, 2005; Gritzner, 2006; Zandbergen, 2010).

Because of the simplicity of DEMs and their well-organized structure, powerful hydrologic models and analysis tools are built on them. In hydrologic modeling, the most common usage of a DEM is to determine flow direction in each cell by comparing a cell's elevation with that of adjacent neighbors (Holmgren, 1994; Kollet and Maxwell, 2006; Daniels, Maxwell and Chow, 2011; Arguelles et al., 2013; Heeren et al., 2014; Rampi, Knight and Lenhart, 2014). This simple method is quite efficient for determining a flow path. For many model users or analysts, the DEM they are using may have already been processed or smoothed. Thus, it is essential for researchers to completely understand the generation and modification history of the DEMs with which they are working. The existence of depressions is inevitable and attention needs to be paid to their origin. Some sinks in DEMs can be identified as natural depressions, such as wetlands, while some are simply imperfections. Some wetlands may remain wet throughout the year, meanwhile some wetlands may have periodic dry seasons. It is necessary to study the volume and aerial extent of changes in water on the surface throughout the year. As a result, the treatment of these depressions is important because it can impact the assessment of the accumulation and movement of water on the landscape surface.

The objective of this study is to develop and demonstrate a Dynamic Flow Direction (DFD) model for simulating overland runoff on landscapes containing depressions. The model utilizes a DEM which retains the depressions that may otherwise be removed from consideration. In this model, an additional layer which represents the water depth is created to determine the dynamic flow direction within the DEM layer. Further 
enhancing the modeling of water movement in small depressions is the incorporation of variable roughness coefficients for water that flows through and over vegetation. Due to the complexity of infiltration and evapotranspiration processes, appropriate simplification is applied in this current model, and these modules will be fully considered in future studies, along with groundwater movement. To verify that the proposed model can simulate the water movement through depressions, two different types of exercises are demonstrated, and the results show the capability of the model to track the location and the quantity of water.

\subsection{Previous Studies}

There has been a high demand for numerical hydrological modeling in recent years, which can improve the understanding and simulation of the key processes in overland runoff flow. In fact, by taking advantage of computer technology and spatial data availability, models of this kind have become more sophisticated and can simulate more detailed physical characteristics (Lane, 1998). Normally to achieve these purposes, more and more input data are required to establish the database and more complex equations are imbedded. However, the treatment of some basic and essential elements may need to be re-examined, such as with DEMs and identification of flow direction.

\subsubsection{Sinks and Flats}

Sinks, representing depressions in a DEM, refer to a single cell or a group of cells which have no outlet because the elevations of surrounding cells are all higher than those of the depression cell(s). Such depressions could potentially hold a considerable amount of water and have a significant impact for watershed hydrology. Flats are cells which 
have zero slope because the elevation of them and their neighbors are the same. For cells in sinks and flats, flow direction can be assigned to these cells, but the flow path is discontinuous when using a common flow direction method, such as the four-neighbor rule or the eight-neighbor rule (Holmgren, 1994). Traditionally, when creating a DEM, during the measuring process or the interpolation process, problematic features are created in the form of sinks and flats, which have been considered as artificial and not really existing (O’Callaghan and Mark, 1984; Oimoen, 2000). In most cases, these artificial sinks and flats exist in low relief and coarse resolution areas.

Because these cells cannot be assigned a rational flow direction, dealing with sinks becomes a complicated topic when simulating overland runoff. The most common and simplest method to solve this problem is to fill these sinks (Jenson and Domingue, 1988). Martz (1999) created a flow path by lowering the elevation of cells that obstruct the flow and create sinks. Stream burning is also an efficient method to generate a flow path though these sinks. However, these strategies end up ignoring real surface depressions that may be important in wetland considerations.

Normally, when preprocessing a DEM, topographic depressions, sinks and flats are "Filled" by a specific algorithm in ArcGIS. These kinds of sinks may be small and could represent isolated wetlands which perform essential functions in the hydrological and biological cycles (Semlitsch and Bodie, 1998). Jenkins and McCauley (2006) pointed out that the algorithmic filling of sinks could make these wetlands "disappear" in GIS output, which may affect land use decisions.

As fine resolution DEMs with greater accuracy and precision have become available, more evidence shows that some depressions are real features. By simply removing the 
depressions, models will neglect water which may exist in these depressions. Although there is not yet an established method to distinguish which depressions are real and which are not, to remove all depressions is not a wise choice to simulate overland runoff (Arnold, 2010). Lindsay and Creed (2005) have pointed out that "the goal of depression removal methods should be to enforce continuous flow paths descending from catchment divides to outlets in a way that requires the least modification of the DEM." Arnold (2010) developed a new flow routing method to deal with depressions without modification. The method treats depressions as a temporary storage for water and fills the depression with water until the water surface elevation is higher than the outlet elevation. However, use of this method presents challenges in calculating the dynamic change of water volume in depressions.

\subsubsection{Flow Direction}

It can be efficient to remove the sinks in a DEM for further analysis and assign flow directions to the flat cells by modifying the initial elevation and simply assuming that all sinks and flats are artifacts. The small increment (filling the sink) in elevation change is relatively negligible in comparison with the overall vertical elevation, but that difference is sufficient for determining flow direction between adjacent cells. Two flow directionsfrom a higher elevation and towards a lower elevation—are generated by these elevationchanged cells, which helps to produce a drainage network in subsequent analysis (Garbrecht and Martz, 1997).

To determine the flow direction for a cell, there are two major methods: the single flow direction method which assumes that the flow can only go to one neighboring cell, and the multiple flow direction method which assumes that runoff can flow to more than 
one neighboring cell (Rampi, Knight and Lenhart, 2014). The single flow direction method is also known as the D8 algorithm which was first introduced by O'Callaghan and Mark (1984) and has been widely used because of its simplicity. Fig. 3.1 shows the flow direction in a DEM with a depression by using the single flow method. In some circumstances, a grid-based DEM cannot be used to produce correct flow direction, because runoff is only allowed in one direction per cell (Holmgren, 1994). To solve this problem, multiple flow direction algorithms have been developed to simulate reality (Holmgren, 1994; Rampi, Knight and Lenhart, 2014) and produce more accurate results (Costa-Cabral and Burges, 1994; Tarboton, 1997; Seibert and McGlynn, 2007; Peckham, 2009). Basically, outflow from the central cell is divided into two or more portions to those cells with lower elevations. Each portion of the flow is determined by the elevation difference between the original cell and the destination cell.

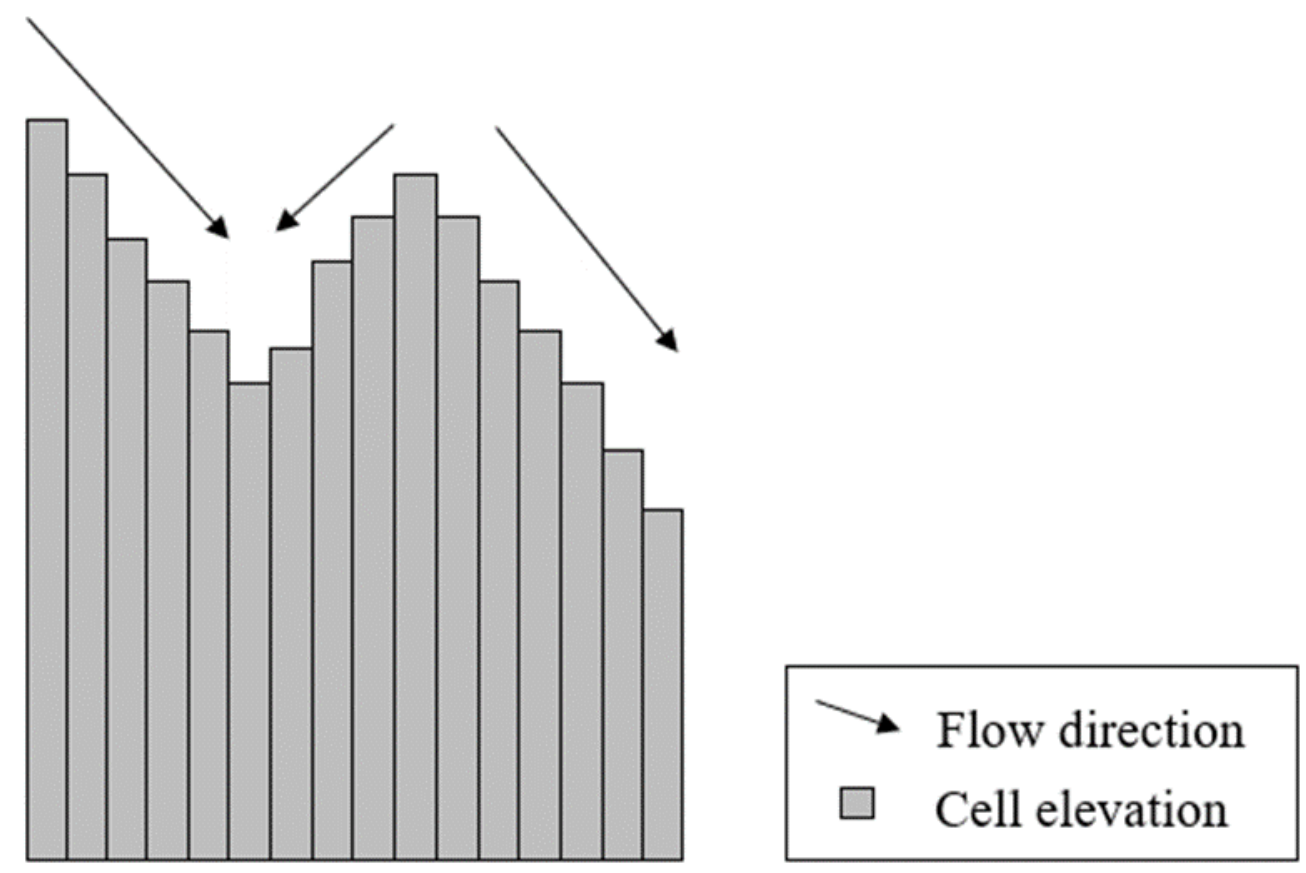

Figure 3.1 Flow direction on DEM. 
When assigning flow direction for a DEM with depressions, both the single flow and the multiple flow methods are inadequate. Sinks on the DEM act like "black holes" which could absorb all water from their surrounding cells because the flow direction of these surrounding cells all points to the sinks. Additionally, because of the sinks, these cells without accurate flow direction will prevent the generation of flow paths from some cells to the outlet. Barnes et al. (2014) present a new method to generate flow direction on a flat area or within a depression which cannot be assigned flow direction by traditional means. An elevation mask created by the improved algorithm is used to determine flow direction for the flat area without modifying the original DEM.

\subsubsection{Hydrologic and Hydraulic Models}

Taking advantage of high-performance computers and high-resolution geospatial data, multiple hydrologic and hydraulic models have been designed for simulating overland flow (Maheshwari and McMahon, 1992; Liu et al., 2004; Giustolisi and Berardi, 2011; Costabile, Costanzo and MacChione, 2012; Arguelles et al., 2013). Various methods and equations are employed in these models, including Manning's equation, the kinematic wave equation, and the dynamic wave equation. All efforts were aimed at better understanding the complex processes, but many of the efforts ignored the existence and impact of depressions.

Hydraulic parameters of overland flow, such as flow depth and velocity, are crucial and variable over the period of a simulation. These are also important aspects for the consideration of depressions. In recent decades, to deal with these complex processes, hydraulic concepts have been introduced into the simulation system to simplify the process and represent detailed information. 
Distributed hydrologic models calculate the volume of water on each grid cell of the DEM, which can easily be imagined as a finite amount of water stored on the land surface. Due to gravity, water will flow from cell to cell. For a cell-to-cell calculation, the time step is subject to a stability condition. Water movement cannot move further than the grid size during one time step. This constraint requires defining a suitable time step based on the flow velocity. Governed by discharge or storage equations and the continuity water-balance equation, Mateo Lázaro et al. (2015) used a linear reservoir to represent the cell-to-cell situation to calculate the discharge.

Infiltration characteristics, flow velocity, roughness and land surface condition are variables when simulating overland flow, which make this process so complex. Roughness is one of the critical components in the model which is also the most difficult to estimate. It varies based on different conditions of soil moisture, vegetation and flow depth. Maheshwari and McMahon (1992) found that Manning's equation is not adequate for this process and a discharge-depth equation is more appropriate for surface flow. To develop a shallow runoff model, researchers usually need to deal with a very small water depth. In this situation, elevation accuracy, mass balance and flow resistance (roughness) are extremely crucial factors (Defina, 2000).

Overland runoff in grid cells of relatively small area is commonly shallow and slow. During a rainfall event, in the horizontal direction, water on a certain cell may flow out to its neighbors and at the same time receive flow in. In the vertical direction, sheet flow will receive a contribution from precipitation and lose water by infiltration. This process could be modelled by a one-dimensional or a two-dimensional approach. A onedimensional governing equation has been employed in hydrology and hydraulics for 
decades in channel flow calculations and still shows some advantages in certain situations (Howes, Abrahams and Pitman, 2006; Gąsiorowski, 2014). Two-dimensional models are more complex than one-dimensional models, but to simulate overland runoff, twodimensional models produce more accuracy and realism than one-dimensional models (Howes, Abrahams and Pitman, 2006).

Two-dimensional models are based on numerical integration of the Saint-Venant's equation, which can be applied in small watersheds with shallow flow. Esteves et al. (2000a) adopted Saint Venant's equation using an explicit finite difference scheme for overland flow simulation. To solve the Saint Venant's equation, several numerical methods have been developed in fluid dynamics (such as by Lax and Wendroff (1964), Lapidus (1967) and Audusse et al. (2004)) to examine the applicability of Saint-Venant's equation for shallow water flow based on a non-flat bottom study area. Numerical solution of the equation is accomplished using the finite volume method.

Studies have already proven that two-dimensional shallow water equations can accurately predict the hydrograph at the outlet of a basin. However, more information is still needed for other purposes, such as determining flow velocity, flow depth, crosssectional area of flow and other spatially varying parameters in different time steps, which are more difficult to calculate. This information could provide benefits in flood forecasting, and in the assessment of soil erosion and nutrient transport. Cea et al. (2014) verified the two-dimensional overland flow model by using a variable roughness parameterization. Their experimental results show that by considering surface roughness at both "micro" and "macro" levels, a two-dimensional shallow water model is capable of satisfactorily predicting velocity and discharge. 


\subsubsection{Status Summary}

Water movement on a real landscape acts quite differently from an ideal surface without depressions. For landscapes with depressions, overland runoff will first concentrate in these depressions and fill them up due to gravity flow. When the depth of water reaches the lowest point of the depression's boundary (the pour point), water will flow across the boundary and contribute to downstream flow. If the outflow is less than that coming from the upstream contributing area, water will continue concentrating in the depression and the water surface in the depression will rise, which would result in a wider and deeper outlet for outflow.

In previous studies, first, filling or removing the sink can simplify hydrological modeling but neglects the existence and function of very small wetlands. Calculating the total volume of the sink is an alternative method to measure the wetlands' ability to store water but it doesn't consider the varying depth of water within a wetland or the aerial extent of the water surface that may exist over time. Second, the dynamic accumulation process in wetlands causes the flow direction to change and thus a constant flow direction consideration is inadequate to represent the process. And overland runoff on a land surface with depressions may be considered as unsteady (depth changing with time) and non-uniform (depth changing with distance) flow, which are difficult to interpret. Third, it is also necessary to take spatial characteristics of landscape into account, such as different types of soils and landcovers. 


\subsection{Methodology}

In the DFD model, depressions in the DEM are treated as real features on the landscape. A variable water depth layer which has the same spatial extent as the ground surface DEM is used to track the water volume on each cell at different points in time. Flow direction is determined by combining the original DEM and the water depth layer. Inflow to and outflow from each cell are calculated in a short time interval using Manning's equation. A water budget for each cell is performed at the end of each time step and is used to prepare a new water depth layer for the next time step calculation.

\subsubsection{Dynamic Flow Direction}

To model this dynamic process, first and foremost, sinks and flats must be treated as real features on the land surface. These sinks act exactly as depressions which can hold surface runoff on the landscape. In this situation, the traditional flow direction determination is not capable of handling depressions within a DEM.

Fig. 3.2a shows the flow direction determination by traditional methods using only a DEM. To make a flow direction determination in this methodology, a same-size variable raster layer representing the water depth on each cell is first added to the original DEM (Fig. 3.2b). This layer records the depth of water on each cell as it changes throughout the simulation. Second, flow direction and slope are determined by the water surface elevation which is calculated based on the water depth layer on the top of the original DEM instead of simply using the original DEM only. After a period of precipitation, when individual cells will be experiencing water run-on and water runoff, water accumulates in the sink area and causes the water surface elevation in a depression to be 
higher than the edge (Fig. 3.2c). Flow direction is recalculated and guides the overland runoff to downstream locations. Compared with the traditional constant flow direction method, this dynamic flow direction method is more suitable to simulate flow into and through a shallow depression of interest.

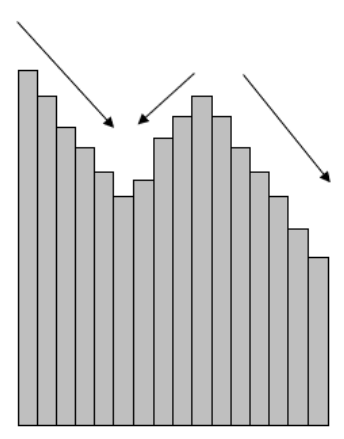

a

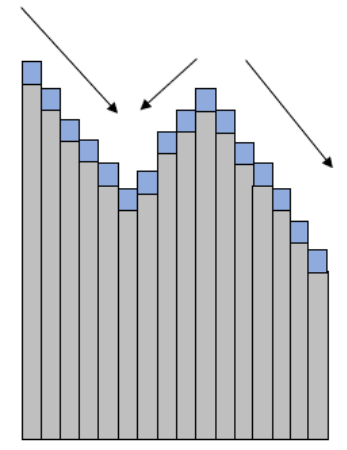

b

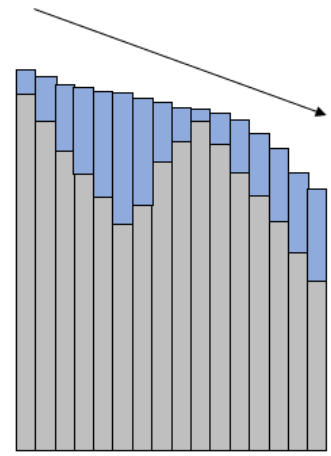

C $\rightarrow$ Flow direction

$\square$ Cell elevation

$\square \quad$ Water depth

Figure 3.2 Flow direction determination comparison with and without water layer.

\subsubsection{Hydraulic Model (Manning's Equation)}

Observation data in a very wide-open channel show that the velocity in the center of the cross-section is similar to the velocity in an infinitely wide channel where there is minimal impact from wall friction. Because the effect from the channel sides is relatively less, overland runoff shares some characteristics with open channel flow. Therefore, for analytical purposes, it is assumed that overland runoff can be treated as occurring in an infinitely wide rectangular channel (Singh, 2010). This assumption is also used in HECRAS for flow routing (US Army Corps of Engineers, 2010).

Manning's equation is the most widely used method to describe hydraulics in an open channel. Overland runoff can also be treated as flow in a wide channel using Manning's equation: 


$$
\mathrm{Q}=\mathrm{VA}=\frac{k A R^{\frac{2}{3}} \sqrt{S}}{n}
$$

where $\mathrm{Q}$ is the flow rate $\left(\mathrm{m}^{3} / \mathrm{s}\right), \mathrm{k}$ is a unit conversion factor: $\mathrm{k}=1.49$ for English units and $\mathrm{k}=1$ for SI units, $\mathrm{V}$ is the velocity $(\mathrm{m} / \mathrm{s}), \mathrm{A}$ is the cross-sectional area of flow $\left(\mathrm{m}^{2}\right), \mathrm{n}$ is the Manning's roughness coefficient, $\mathrm{R}$ is the hydraulic radius ( $\mathrm{m}$ ) and $\mathrm{S}$ is the slope $(\mathrm{m} / \mathrm{m})$.

In this new methodology, a cell-by-cell calculation is performed and repeats in every time step. In a short time interval and over a short distance, overland flow is treated as steady and uniform flow. From a longitudinal view, a continuous non-uniform flow is separated into a sequence of uniform sections. From a timeline view, the unsteady flow between two cells is considered as a series of steady flow calculations in each time step.

\subsubsection{Model Structure}

The core of this model is based on time step calculations. The flowchart in Fig. 3.3 shows the basic structure of the model. At the beginning of each time step, a water depth layer is calculated using the precipitation, infiltration and evapotranspiration. Then, the DEM and water depth layer together create a water surface layer which generates flow direction and the slope of the water surface for each cell. Meanwhile, each cell also has its own surface roughness coefficient and vegetation type. By utilizing these parameters, Manning's equation is used to calculate the outflow from each cell. Based on the flow direction and outflow of each cell, the model identifies the destination cell and the flow to that cell. Thus, by recording all information above, the volume of water remaining on the cell at the end of each time step is calculated by using the inflow and outflow according to the continuity equation. This remaining water volume generates a new water depth 
layer for the next time step calculation. This iterative process continues throughout a period of precipitation and until runoff stops flowing.
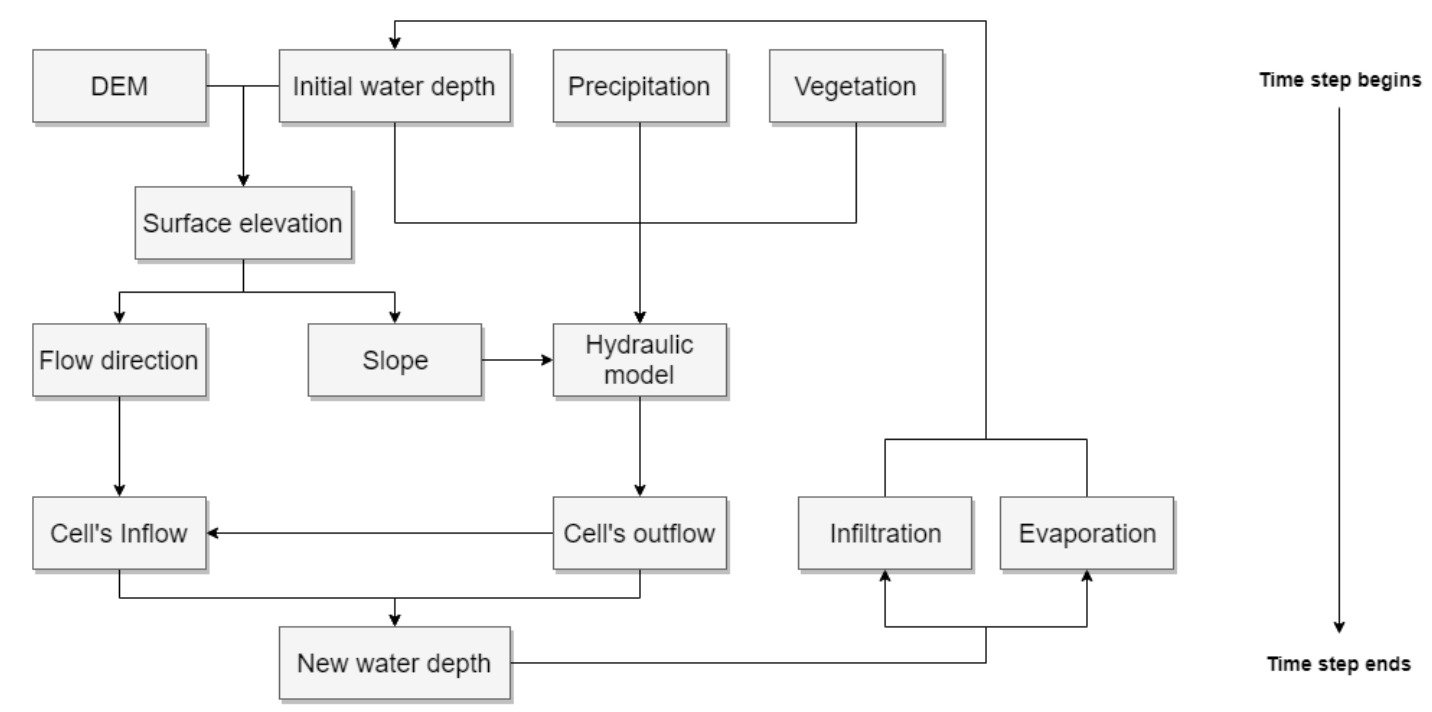

Figure 3.3 Dynamic flow direction model flowchart.

\subsubsection{Compound Flow Calculation}

Flow resistance, or Manning's roughness, is a critical parameter when applying Manning's equation in hydraulics. It can be impacted by vegetation and the flow environment in the stream. In the past, various studies have been undertaken to understand the resistance force generated from surface roughness (Dawson and Robinson, 1984; Löpez and Garcia, 2001; Carollo, Ferro and Termini, 2002; Shi et al., 2013). Recognizing that overland runoff is usually shallow flow, different Manning's n values from normal channel applications are appropriate.

Shi et al. (2013) performed experiments to examine the vertical distribution of flow velocity as water flowed through and above vegetation. They divided the flow into three zones: Zone I is from the ground surface to the canopy, Zone II is the transitional zone, and Zone III is above the transition zone (Fig. 3.4). In Zone I, the flow velocity, which is 
also called vegetated flow is relatively small and constant. In Zone II, the velocity gradient increases to the maximum velocity. Velocity is at its maximum where there is the least impact from the channel bottom roughness in Zone III. To represent this situation in practice, flow is divided into three domains: D1, D2 and D3. D1 is mainly controlled by surface tension associated with water on the land surface. Water stays on the land surface if water depth is less than D1. Above D1, two different roughness coefficients are assigned to the flow on each cell: one for flow through the vegetation (D2) and one for flow above the vegetation (D3). When the water depth is lower than the vegetation height, the discharge calculation uses a high roughness coefficient (n value). When the water depth is higher than the vegetation, the vegetated flow still uses a high roughness coefficient, while the upper portion is assigned a relatively small roughness coefficient to represent the reduced impact of surface roughness.
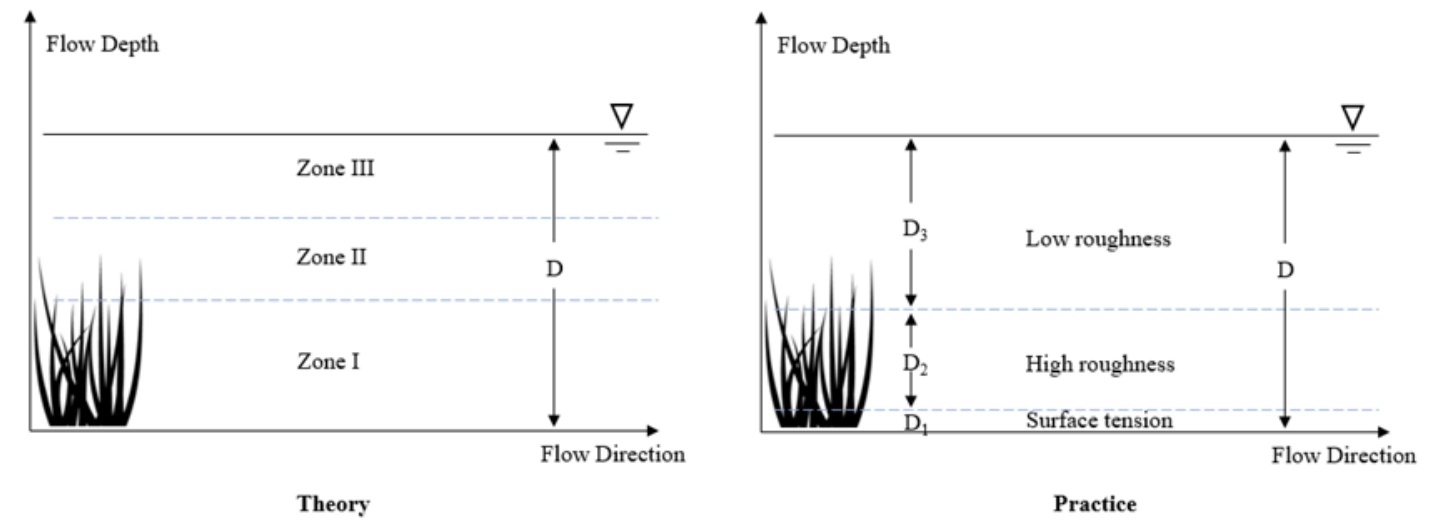

Figure 3.4 Different domains of flow with assigned roughness coefficients.

\subsection{Methodology Exercises and Demonstrations}

In order to verify that the model can accurately simulate overland flow and accumulation, tracking the spatial location and the quantity of overland flow, two 
exercises and two landscape demonstrations are undertaken. The exercises are performed on an artificial unfilled DEM over a relatively short period of time. The landscape demonstrations are performed for actual landscape locations over a period of a year.

\subsubsection{Exercises on an Artificial DEM}

The purpose of the tracking exercises is to simulate the movement of water on a landscape during and after a rainfall event to demonstrate that the script is able to accurately track the occurrence of rainfall as it becomes runoff. An artificial $200 \mathrm{~m}$ by $200 \mathrm{~m}$ DEM is produced (Fig. 3.5) containing a watershed in the northwest corner indicated by the solid blue line. The watershed consists of 13,869 cells, and with a $1 \mathrm{~m}$ resolution for the DEM, the total area of the watershed is $13,869 \mathrm{~m}^{2}$. The solid blue dot indicates the pour point — the location from which water would first exit the watershed if the water surface were high enough (i.e., the lowest point of the watershed boundary)and the total volume of the depression up to the pour point is $1779.73 \mathrm{~m}^{3}$. A uniform roughness coefficient of 0.03 (similar in roughness to grass with some weeds) is used for the calculations, which takes place with a time step of 1 second. For these exercises developed to test the ability of the script to track water, both evapotranspiration and infiltration are assumed to be zero. 


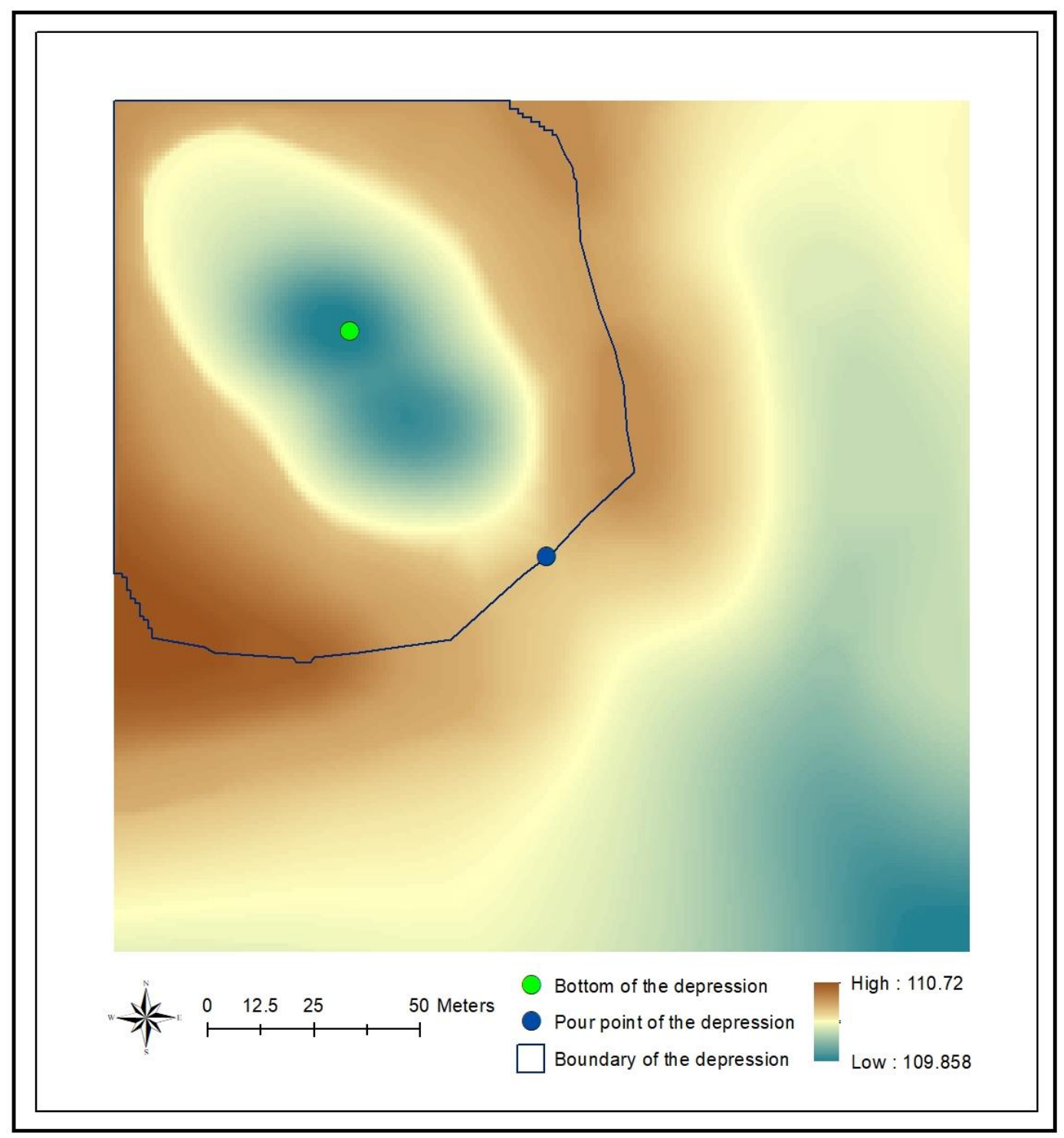

Figure 3.5 Artificial DEM for exercises.

\subsubsection{Water Budget Exercise with Limited Precipitation}

During the first exercise, the precipitation has a low intensity of $0.1 \mathrm{~mm} / \mathrm{s}$ for 1000 seconds, producing a total depth of precipitation of $0.1 \mathrm{~m}$, or a total volume of water falling within the contributing area of $1386.9 \mathrm{~m}^{3}$. This volume is less than the depression volume at the pour point, so no water would be expected to flow out of the watershed depression. 


\subsubsection{Water Budget Exercise with Sufficient Precipitation to Cause Outflow}

The second exercise is conducted with a precipitation intensity of $0.2 \mathrm{~mm} / \mathrm{s}$ for 1000 seconds. The total volume of precipitation falling on the watershed is $2773.8 \mathrm{~m}^{3}$, greater than the volume below the pour point of the depression $\left(1779.73 \mathrm{~m}^{3}\right)$. Therefore, excess water would be expected to flow out of the depression. This exercise tests the ability of the model to track the flow out of the depression until the water level returns to the pour point elevation.

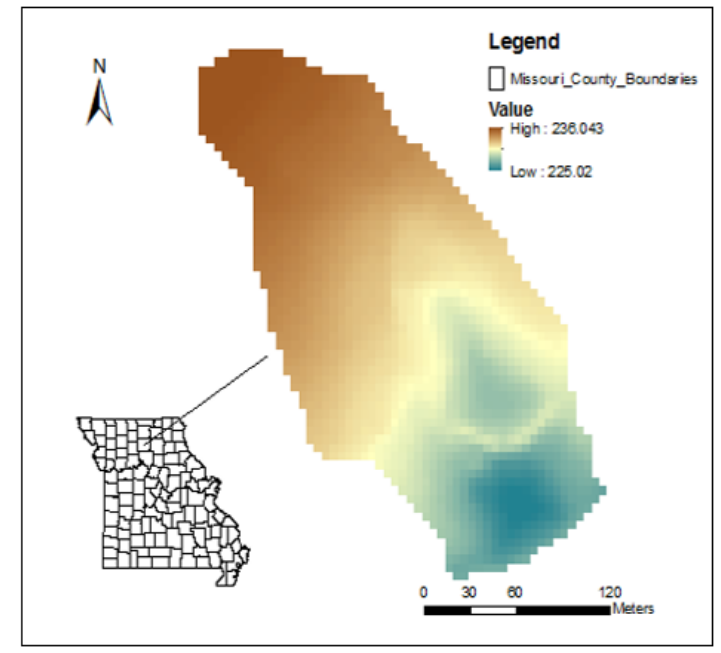

a. South site

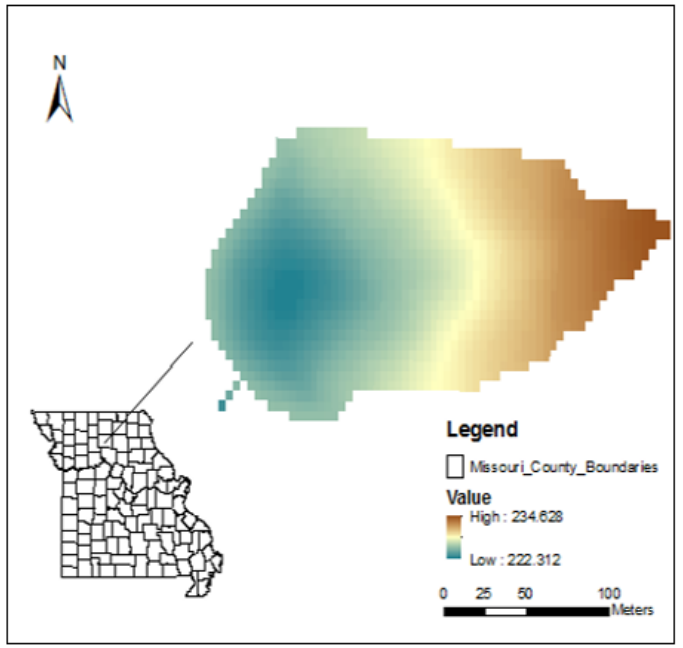

b. North site

Figure 3.6 Two landscape demonstration sites.

\subsubsection{Landscape Demonstrations}

Based on the previous exercises, two sites are selected to test the methodology of tracking overland flow and accumulation in a depression over the period of a year. These 
two sites are located near Pershing State Park in central Missouri (Fig. 3.6), an historic location for wetlands and where wetland restoration efforts might be undertaken.

\subsubsection{Input Preparation}

DEM data from the Missouri Spatial Data Information Service (MSDIS) that was collected in 2008 provides land surface elevations (MSDIS 2019) and is used to extrapolate contour lines to estimate the storage volumes of the sites, while National Agriculture Imagery Program (NAIP) aerial imagery from 2009 and 2010 (MSDIS 2019) is utilized to determine the areal extent of water surface elevations. The NAIP imagery is taken during the summer growing season, but no specific date is provided. National Oceanic and Atmospheric Administration (NOAA) hourly precipitation data from August 1, 2009 to August 1, 2010 (NOAA 2019) are used via a text file that is read throughout the simulation. Two different Manning's roughness values are set for upper flow and lower flow. In these calculations, an $n$ value of 0.5 is used for the flow region under the vegetation height, while an $\mathrm{n}$ of 0.03 is used for the flow region above the vegetation height (Sturm, 2010). The vegetation height is set to $0.05 \mathrm{~m}$.

\subsubsection{Evapotranspiration and Infiltration}

While the first two exercises did not consider the potential impacts of evapotranspiration (ET) and infiltration in order to ensure the correct tracking of water as it moved on the surface, these field demonstrations incorporate these processes. An assessment of ET is based on a number of factors. The soil and vegetative cover characteristics are combined with the potential evapotranspiration (PET) of a given location and month of the year and used to develop an hourly ET rate for each month. For 
the methodology development effort described here, a text file was developed that provides an hourly ET rate for each individual month throughout the test period. The ET development process is described by Mohammed and Trauth (2019).

A similar text file was developed in an effort to approximate infiltration, utilizing a transformation of the cumulative infiltration-based Green-Ampt model to a time-based model. The infiltration text file was prepared in parallel with the precipitation text file. Whenever precipitation occurs, a sequence of infiltration rates is calculated, For this effort, an average initial moisture content of 0.27 (deminenless in engineering calculation) for the silty clay loam is utilized as the starting condition for the Green-Ampt calculation. Both the ET and infiltration rates are subtracted from the precipitation rate to derive net precipitation that is available for overland flow to the depression. Details of the development of the infiltration text file are described by Mohammed and Trauth (2020). 


\subsubsection{Calculation of Water Volumes from Aerial Imagery}

There are no field data to record the water volume at these two sites. Because the laser used in the LiDAR sensors cannot penetrate water and the available DEM shows the water surface in an area of inundation as if it were the ground surface, it is necessary to approximate the underwater contours of the depression in order to calculate water volumes. Fig. 3.7 shows the procedure to create the depression for the North site, where the generated contour lines follow the same pattern as the visible contour lines.

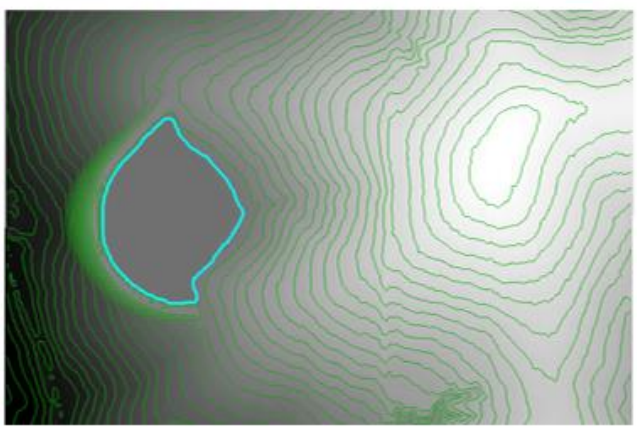

a

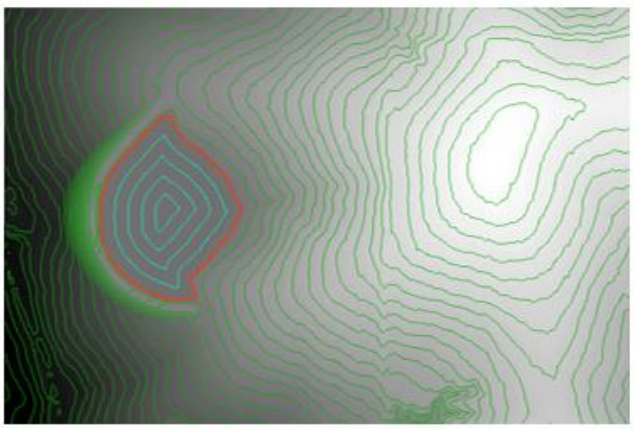

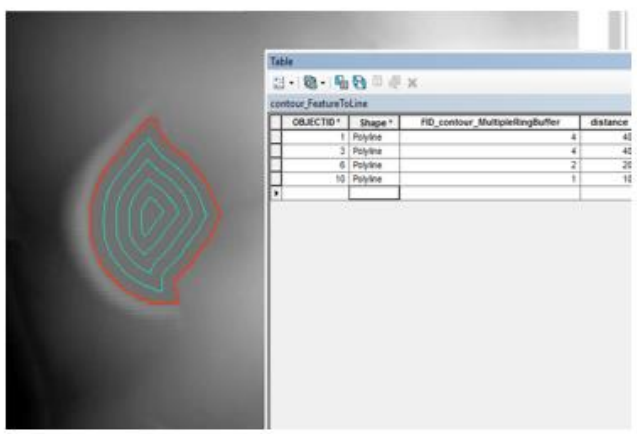

b

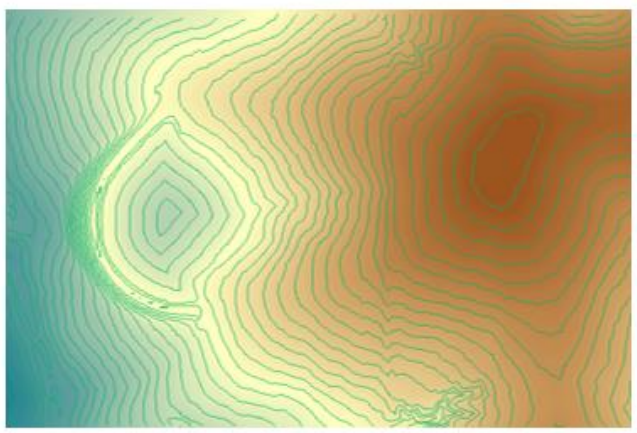

Figure 3.7 Procedure to approximate depression topography.

First, the water boundary is extracted by digitalizing the aerial imagery (Fig. 3.8). Second, the inundation area and water surface elevation are identified by the boundary 
and DEM (Fig. 3.9). Third, the total water volume is calculated based on the elevation of all inundated cells and the water surface elevation.

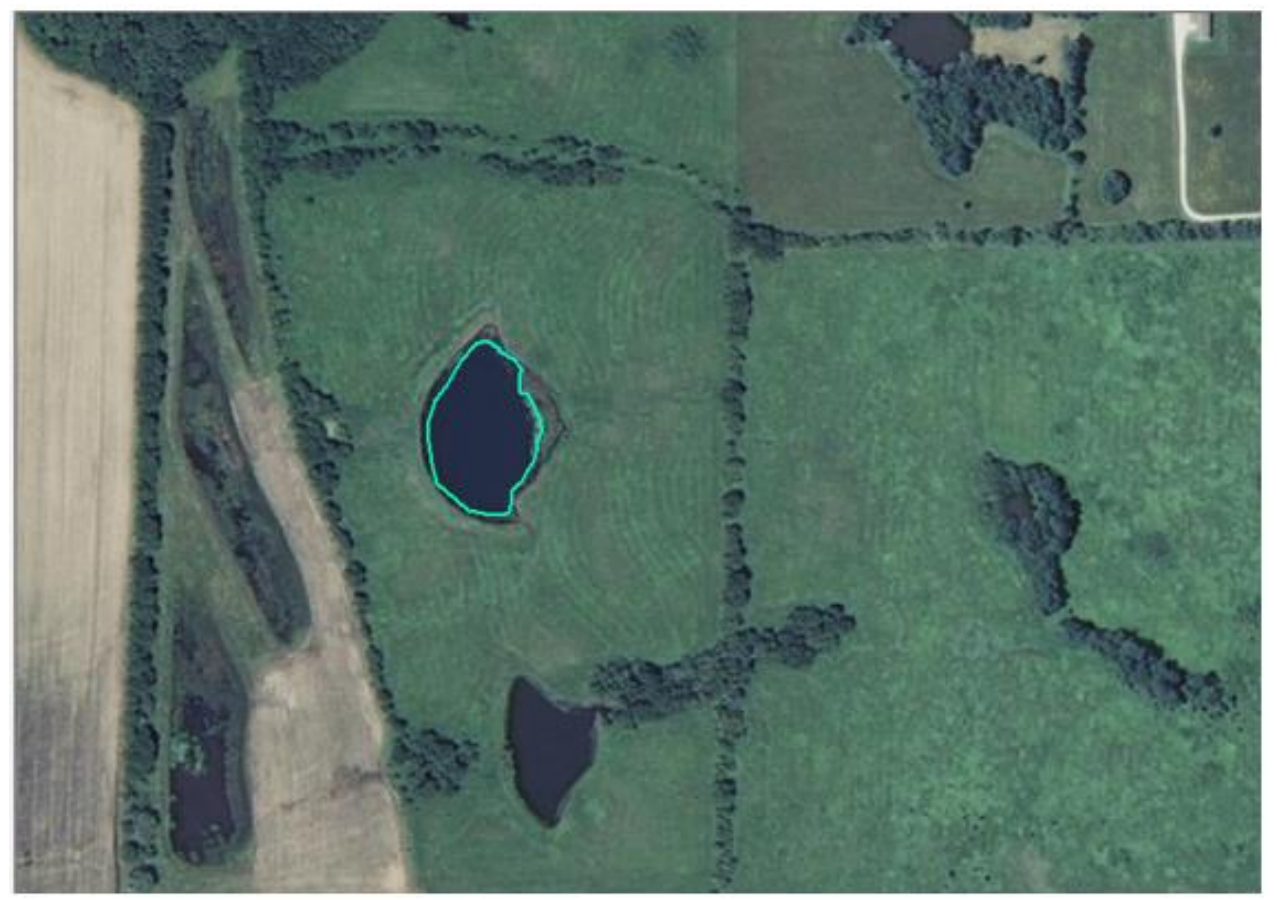

Figure 3.8 Digitization of water surface boundary from aerial imagery.

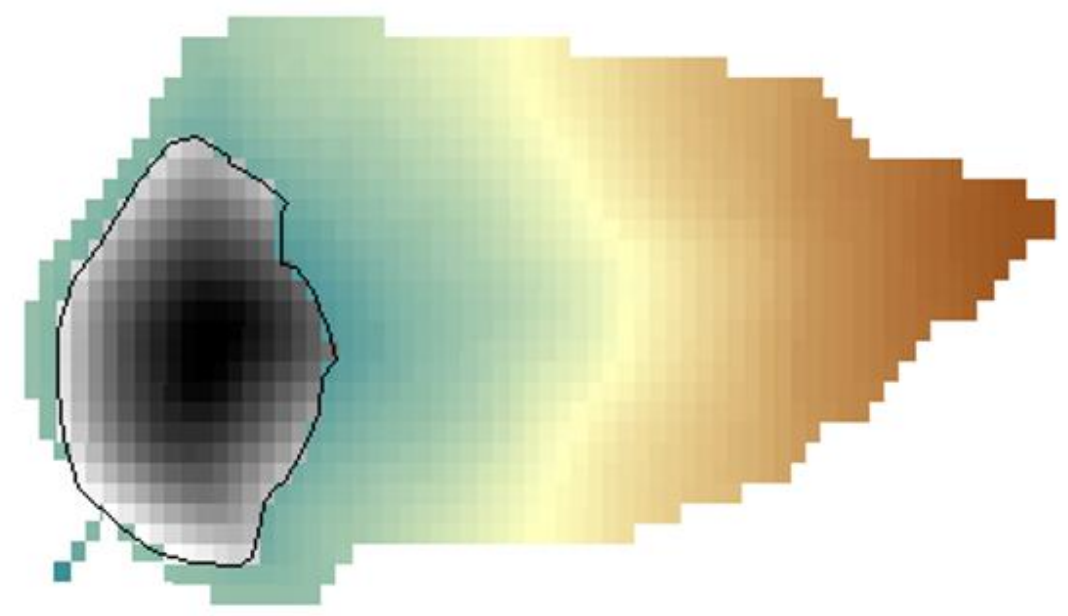

Figure 3.9 Inundation area and water surface elevation as identified by the water surface boundary and the DEM. 


\subsubsection{Preparation of Initial Water Depth}

From the previous step, the water surface elevation is $225.153 \mathrm{~m}$. The process to create the initial water depth layer is to use Con (IsNull(Extract), DEM, 225.153) to recreate the water surface on an unfilled DEM first, and then to continue to use Con $(($ FILL - DEM) $>=0$, FILL- DEM,0) to generate the initial water depth layer (Fig. 3.10). When using the Con function in ArcGIS, it is necessary to ensure that extent is set to "same with DEM" in the Environment processing option.

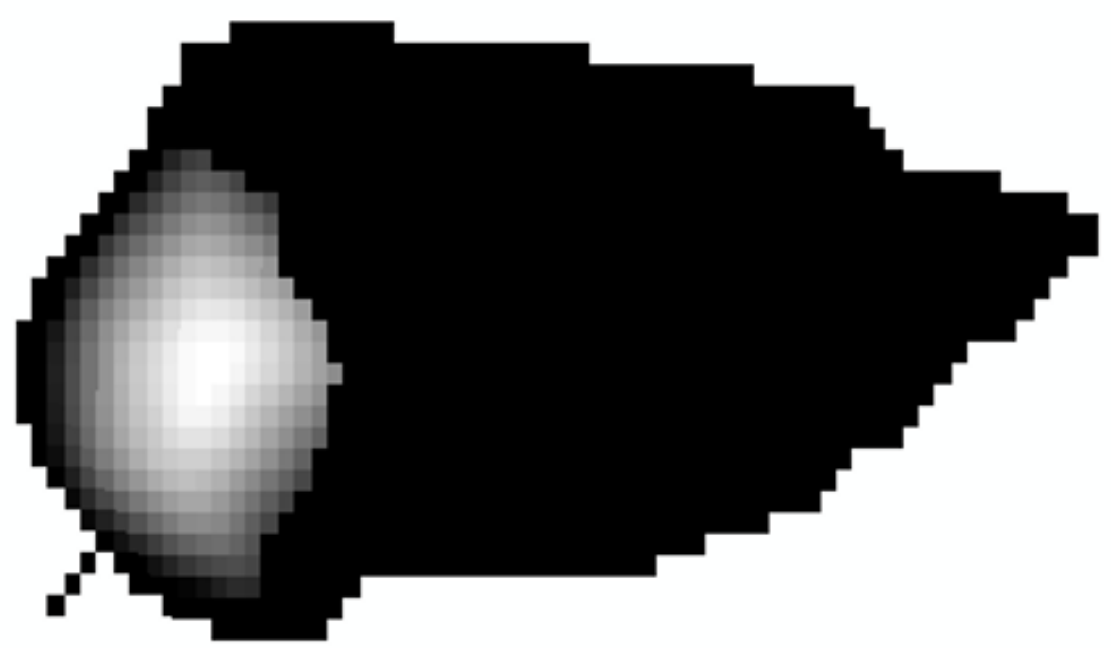

Figure 3.10 Creation of initial water depth layer.

\subsubsection{Calibration and Verification}

Without a specific date for the NAIP imagery, the calculations are performed based on an assumption that the images were from August 1 of the applicable year. The topography of the depressions is assessed based upon a combination of the NAIP aerial image and the LiDAR DEM of the land surface surrounding the depression. The assessed topography of the depression is used with the aerial extent of the open water surface at 
the beginning and at the end of the period of tracking to calculate initial and final values for the volume of water in storage. The calculations accounted for actual precipitation, and employed location-based text files for ET and infiltration in order to model overland flow and water storage. The process was run with a computational time step of 1 minute for the entire one-year duration (i.e., August 1, 2009 to August 1, 2010). All parameters are confirmed based on the test of the South site first for calibration purposes. The calibration process consisted of defining a D1 value above where there would be overland flow. The North site is run using the same settings and parameters for verification.

\subsection{Results and Discussion}

\subsubsection{Results of Water Budget Exercise with Limited Precipitation}

Table 3.1 displays the accumulation of water in the bottom depression of the watershed during and after the precipitation. For the 1000 seconds (16.67 min) of the storm, the volume tracked increases steadily up to a volume of $1372.75 \mathrm{~m}^{3}$. Even after the precipitation ends, the volume of water in the depression continues to increase, representing the time it takes for water falling on the furthest portions of the watershed to flow overland to the depression. Over time, the rate of increase in the volume slows to a rate of $0.12 \mathrm{~m}^{3} / 1,000 \mathrm{~s}$ at a total time of $9,000 \mathrm{~s}$ when the total volume is recorded as $1,389.11 \mathrm{~m}^{3}$. This volume is $2.21 \mathrm{~m}^{3}$ greater than the volume of precipitation that fell, a difference of $0.16 \%$. A possible reason for the difference is that the boundary of the watershed consists of cells with an area of $1 \mathrm{~m}^{3}$ at a given elevation rather than a sharp line that is the basis for traditional watershed delineations. The direction of flow for rain 
falling on a boundary cell will be impacted by the ground elevation of the adjacent cells and the water surface elevation (i.e., ground elevation plus water depth) of the adjacent cells. This mechanism may lead some portion of water from the boundary cells to flow into the watershed.

Table 3.1 Water volume changes in the limited precipitation exercise.

\begin{tabular}{|c|c|c|}
\hline & Time (s) & $\begin{array}{c}\text { Water volume in the depression } \\
\text { of the watershed }\left(\mathrm{m}^{3}\right)\end{array}$ \\
\hline \multirow{11}{*}{ 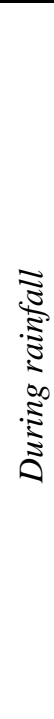 } & 0 & 0 \\
\hline & 100 & 138.37 \\
\hline & 200 & 276.81 \\
\hline & 300 & 415.44 \\
\hline & 400 & 554.14 \\
\hline & 500 & 692.85 \\
\hline & 600 & 831.61 \\
\hline & 700 & 970.40 \\
\hline & 800 & 1109.17 \\
\hline & 900 & 1247.86 \\
\hline & 1000 & 1372.75 \\
\hline \multirow{8}{*}{ 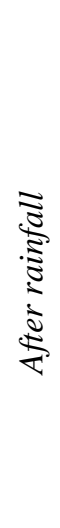 } & 2000 & 1378.84 \\
\hline & 3000 & 1384.53 \\
\hline & 4000 & 1387.06 \\
\hline & 5000 & 1388.10 \\
\hline & 6000 & 1388.56 \\
\hline & 7000 & 1388.82 \\
\hline & 8000 & 1388.99 \\
\hline & 9000 & 1389.11 \\
\hline
\end{tabular}

Fig. 3.11 shows the water volume changes during the entire simulation process. The blue line represents the total volume of water within the watershed. During the rainfall, 
the volume line has a constant slope, corresponding to a constant rainfall intensity. After the precipitation event, the blue line is flat, representing that there is no water coming into or leaving the basin. This makes sense as the total volume of precipitation is less than the storage volume available at the pour point. Fig. 3.12 consists of 3D screenshots of the watershed and the surrounding area at discrete points in time during and after the precipitation, where the darker the blue, the greater the depth of water. To better demonstrate the spatial distribution of surface water, the blue color only shows on the DEM when water depth is larger than $0.03 \mathrm{~m}$. The very light blue area indicated in the circle at $t=1000 \mathrm{~s}$ is not a representation of a depth of flow exiting the watershed, but depicts the fact that with precipitation, water will exist on the ground surface prior to its movement to a lower elevation. A comparison of the images for $3000 \mathrm{~s}$ and $4000 \mathrm{~s}$ indicates very little difference meaning that virtually all of the water has drained to the depression within the watershed.

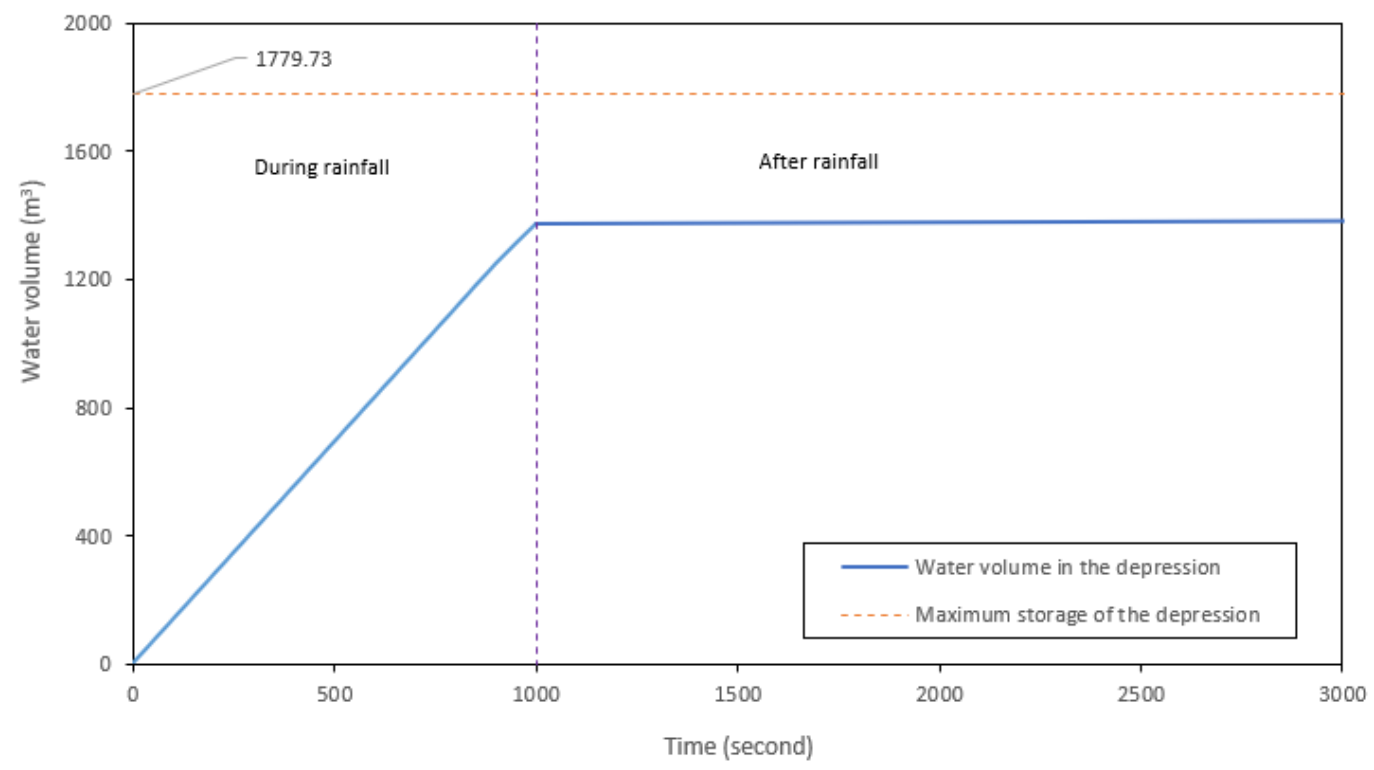

Figure 3.11 Water volume changes during the limited precipitation exercise. 


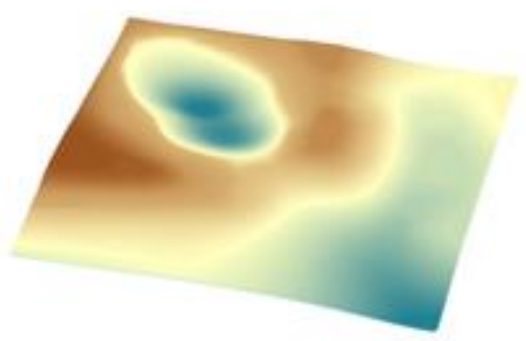

$\mathrm{t}=200 \mathrm{~s}$

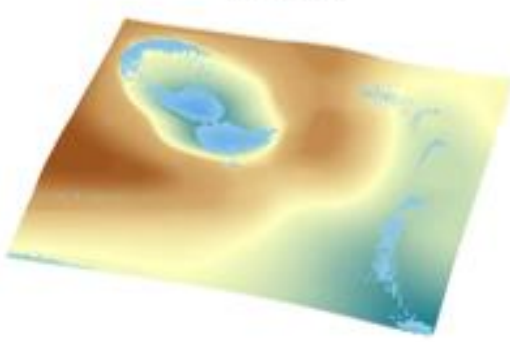

$\mathrm{t}=600 \mathrm{~s}$

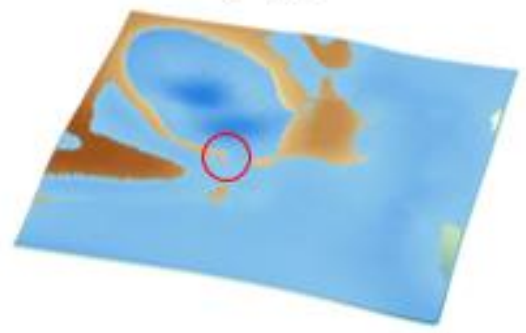

$\mathrm{t}=1000 \mathrm{~s}$

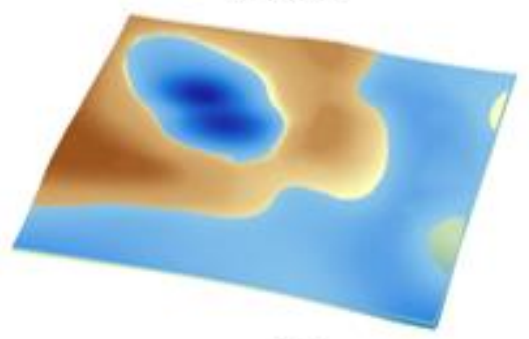

$\mathrm{t}=4000 \mathrm{~s}$

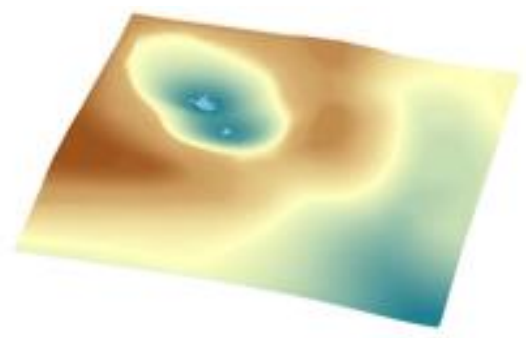

$\mathrm{t}=400 \mathrm{~s}$

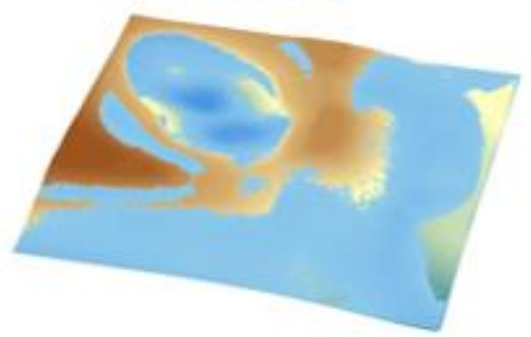

$\mathrm{t}=800 \mathrm{~s}$

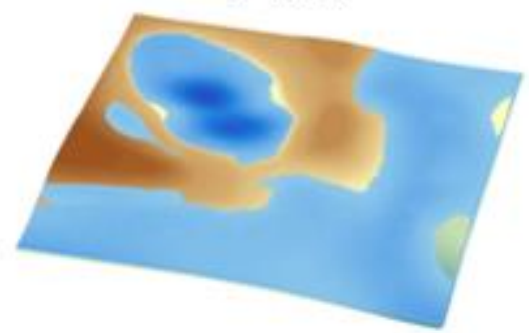

$\mathrm{t}=2000 \mathrm{~s}$

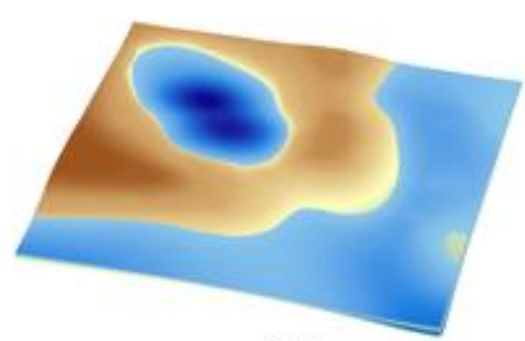

$\mathrm{t}=8000 \mathrm{~s}$

Figure 3.12 3D screenshots of the watershed and surrounding area during the limited precipitation exercise.

\subsubsection{Results of Water Budget Exercise with Sufficient Precipitation to}

\section{Cause Outflow}

Water backs up in the depression and flows out when the water surface elevation is higher than the pour point. Table 3.2 records the water volume both during the rainfall 
and after. During this exercise, the water surface elevations and water depths at both the bottom of the depression and the pour point are also recorded for reference. The ground elevation of the bottom of the depression is $109.90 \mathrm{~m}$, while the ground elevation of the pour point is $110.46 \mathrm{~m}$. As with reservoir routing, water will begin to exit the watershed, albeit very slowly, as soon as the water surface elevation is above the pour point ground elevation. Thus, the maximum volume contained in the watershed depression (2858.35 $\mathrm{m}^{3}$ ) never reaches the value of the volume of precipitation $\left(2773.8 \mathrm{~m}^{3}\right)$. After the precipitation ceases, the volume in the watershed depression decreases (rapidly at first and then more slowly), approaching the storage volume available at the pour point $\left(1793.73 \mathrm{~m}^{3}\right)$. The water depth in the depression increases rapidly for the first $200 \mathrm{~s}$ as water drains from the watershed into the depression. The rate of increase of the depth then decreases as the depression opens up and it takes a greater volume of water to produce an increase in the water surface. The maximum depression depth is reached shortly after the rain stops as water continues to flow to the depression from the furthest points within the watershed, and then decreases with the flow out from the watershed over the pour point, approaching the $0.56 \mathrm{~m}$ depth which is equal to the pour point elevation. In examining the water depth at the pour point, it increases, but then levels off as the water falling there flows into the depression or out as discussed earlier with regards to the watershed boundary. Later in the storm, the water depth increases as the water surface elevation increases, until the time of outflow, when the depth then begins to decrease. Depths are only presented to hundredths of a meter, so values shown as 0.00 
simply mean that the depth of flow is less than $1 \mathrm{~cm}$. At this depth, and with a rough surface, the flow across the landscape is very slow.

Table 3.2. Water surface depths and elevations in the depression area and the pour point for the outflow exercise.

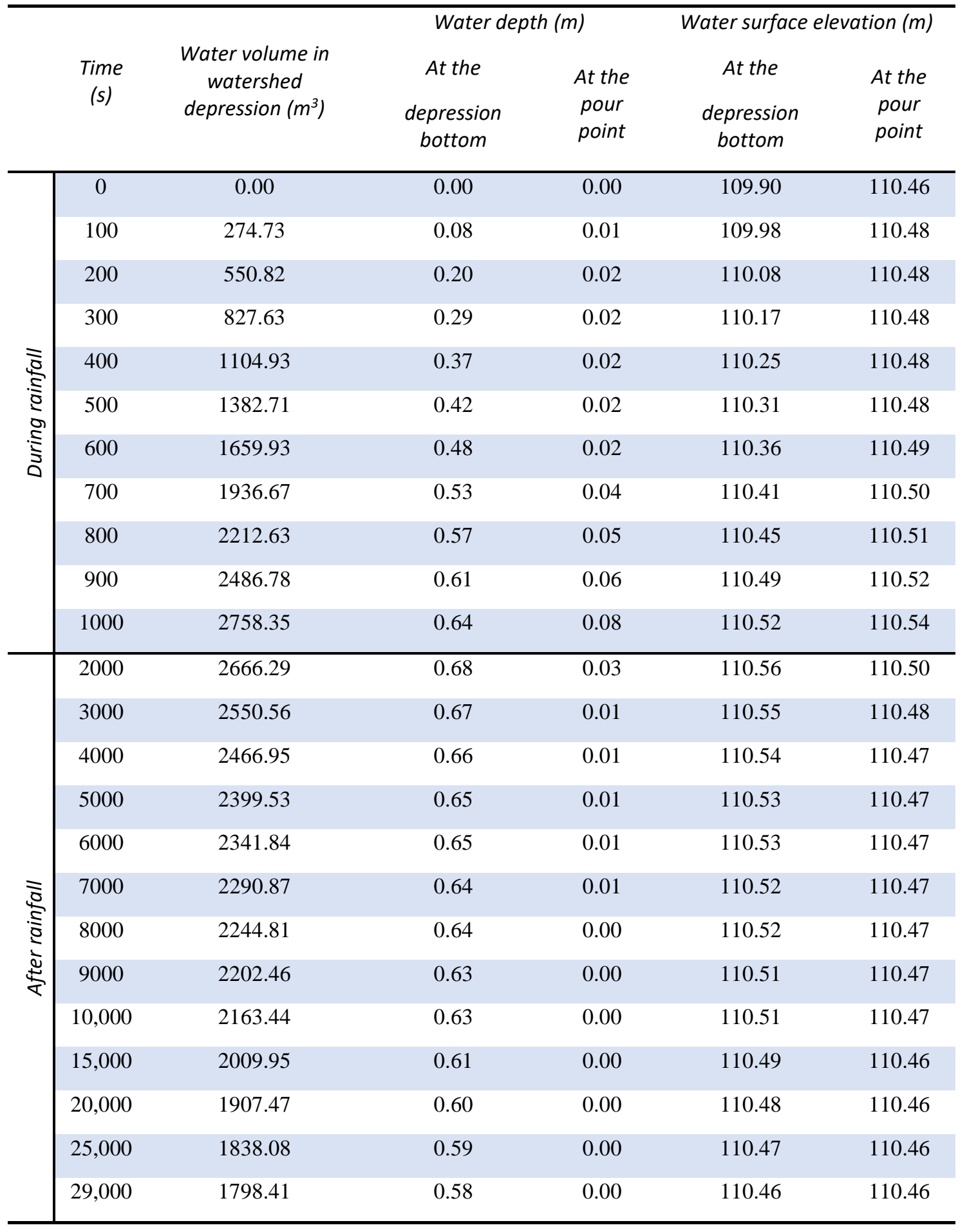




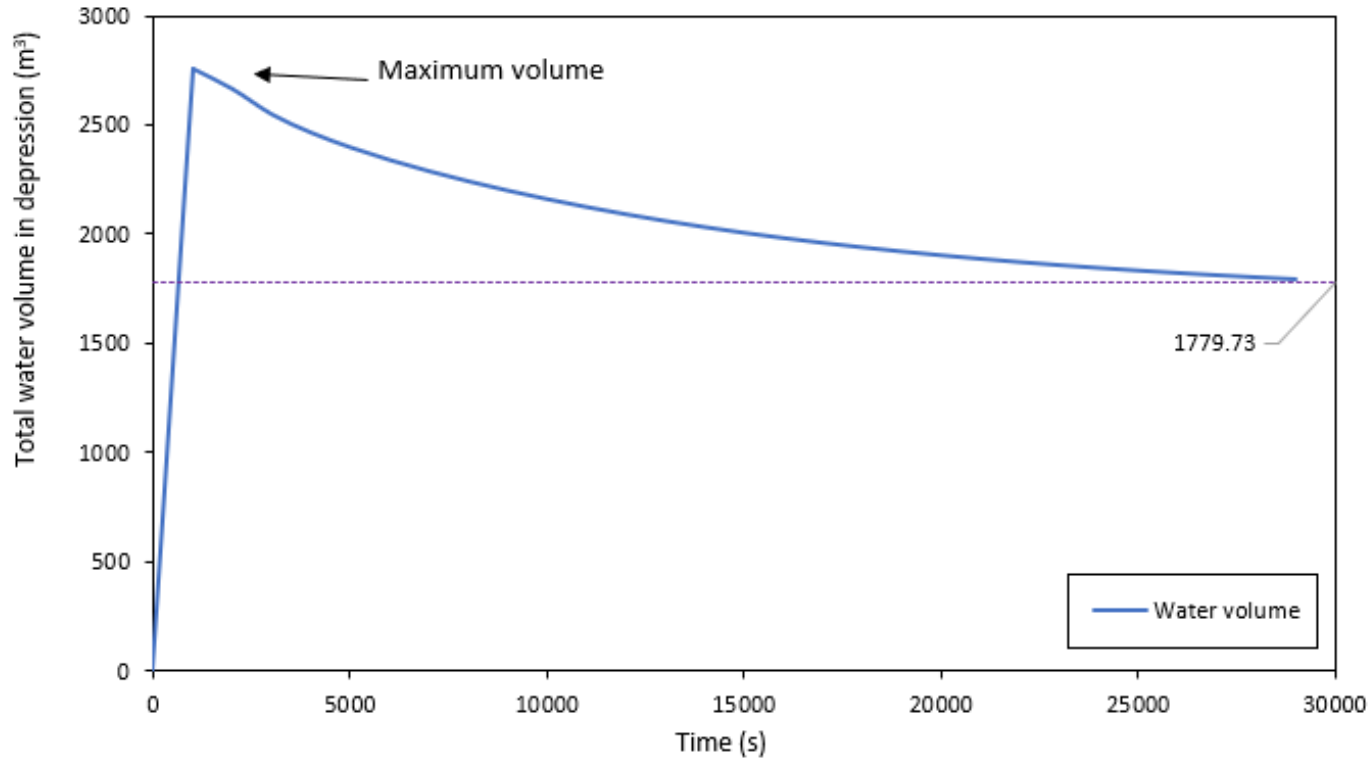

Figure 3.13 Water volume changes during the outflow exercise.

With respect to the water surface elevations, the level in the watershed depression increases as the storm progresses, decreasing with the end of the precipitation and as water flows over the pour point. With time, the elevation decreases until it reaches the pour point elevation. At the pour point itself, the water surface remains constant as the depression fills up, increases once the depression is filled and starts to flow out, and then decreases as the volume above the pour point decreases. With time, the water surface elevation returns to the pour point ground elevation when there is no more flow. Because Table 3.2 presents results at given intervals, Fig. 3.13 provides a better picture of what is taking place over time, showing the continuum of volumes. The red dotted line shows the storage volume available if the water surface elevation were exactly at the pour point. Within the first $1000 \mathrm{~s}$, during the rain event, the volume contained within the watershed increases very rapidly, thereafter decreasing more slowly. The water stored in the watershed depression above the pour point is a depiction of reservoir routing where there is simultaneous storage and outflow. As the water flows out, and the water depth above 
the pour point ground surface decreases, the rate of decrease slows down. This would be expected as the head decreases. This drainage out takes place over approximately eight hours because the land surface has a very mild slope and is very rough. With time, the volume gradually returns to the volume available at the pour point elevation.

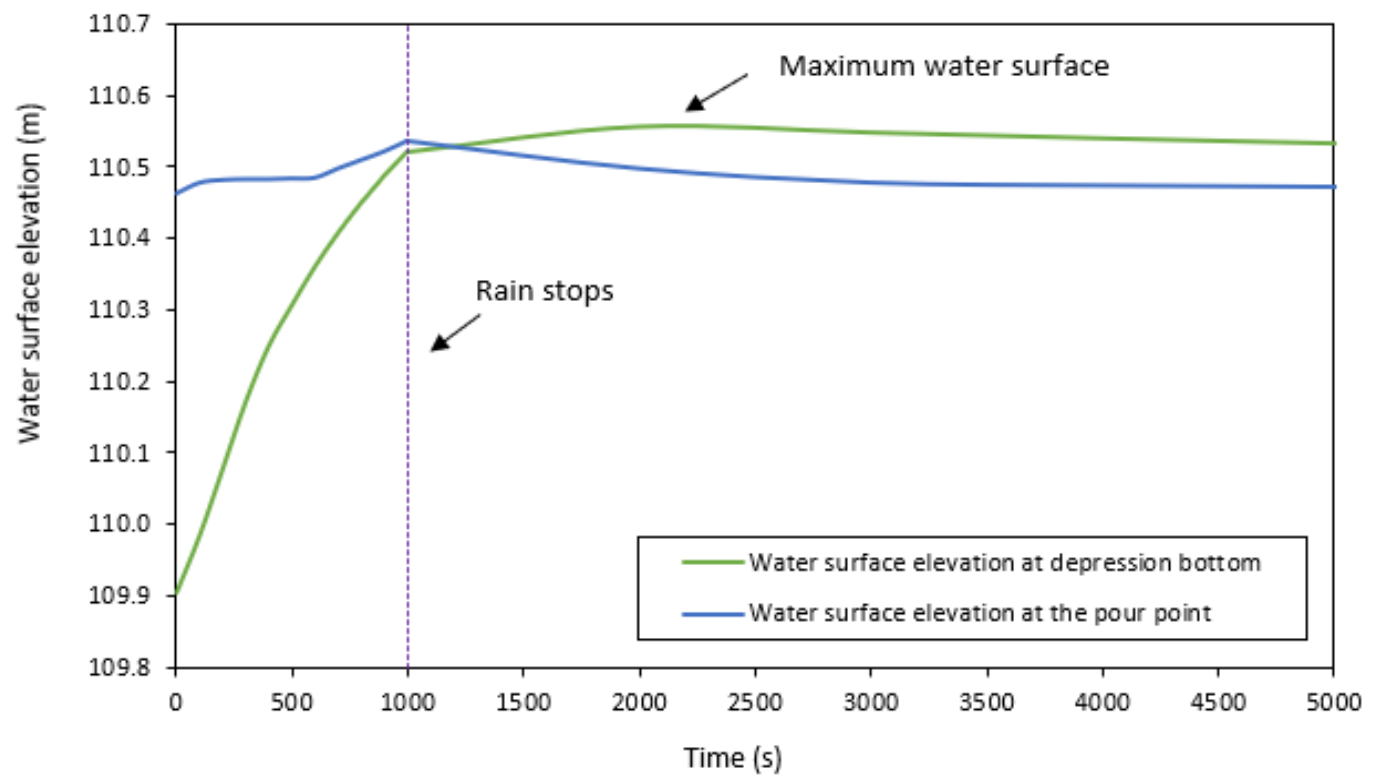

Figure 3.14 Water surface elevation changes for both the depression and the pour point for the first 5000s of the outflow exercise.

Fig. 3.14 displays the surface elevations for the first $5000 \mathrm{~s}$ of the simulation for both the depression (the green line) and the pour point (the blue line). With the precipitation, the water surface elevation for the depression increases rapidly. The shape of the green line is not straight, reflecting the fact that the watershed depression opens up in an irregular fashion. Because water must flow from the farthest portions of the watershed, the maximum water surface elevation is not reached until approximately $1000 \mathrm{~s}$ after the rain has stopped, after which time the elevation decreases as water flows out. At the pour point, a shallow depth of precipitation sits on the pour point at the beginning of the storm but remains essentially constant as the depression fills. The elevation line becomes steeper towards the end of the storm, reflecting a steepening of the walls of the pour 
point. The steepness of the pour point walls allows water to flow there more rapidly than from the flatness of the water surface, artificially increasing the depth at the pour point above that of the depression. The pour point water surface elevation decreases from the maximum showing the results of the outflow. Fig. 3.15 displays the simulation results for 29,000 s (almost 8 hours), where it becomes apparent that over time, there is a slow, asymptotic movement of water from the depression to the pour point, with the water surface elevation at the depression eventually reaching the pour point ground elevation. At this point, there is no outflow and $1798.41 \mathrm{~m}^{3}$ of water are held by the depression. Comparing the water held in the depression with the $1779.73 \mathrm{~m}^{3}$ depression storage volume calculated from the DEM, one observes a difference of $18.68 \mathrm{~m}^{3}$, or $1.05 \%$.

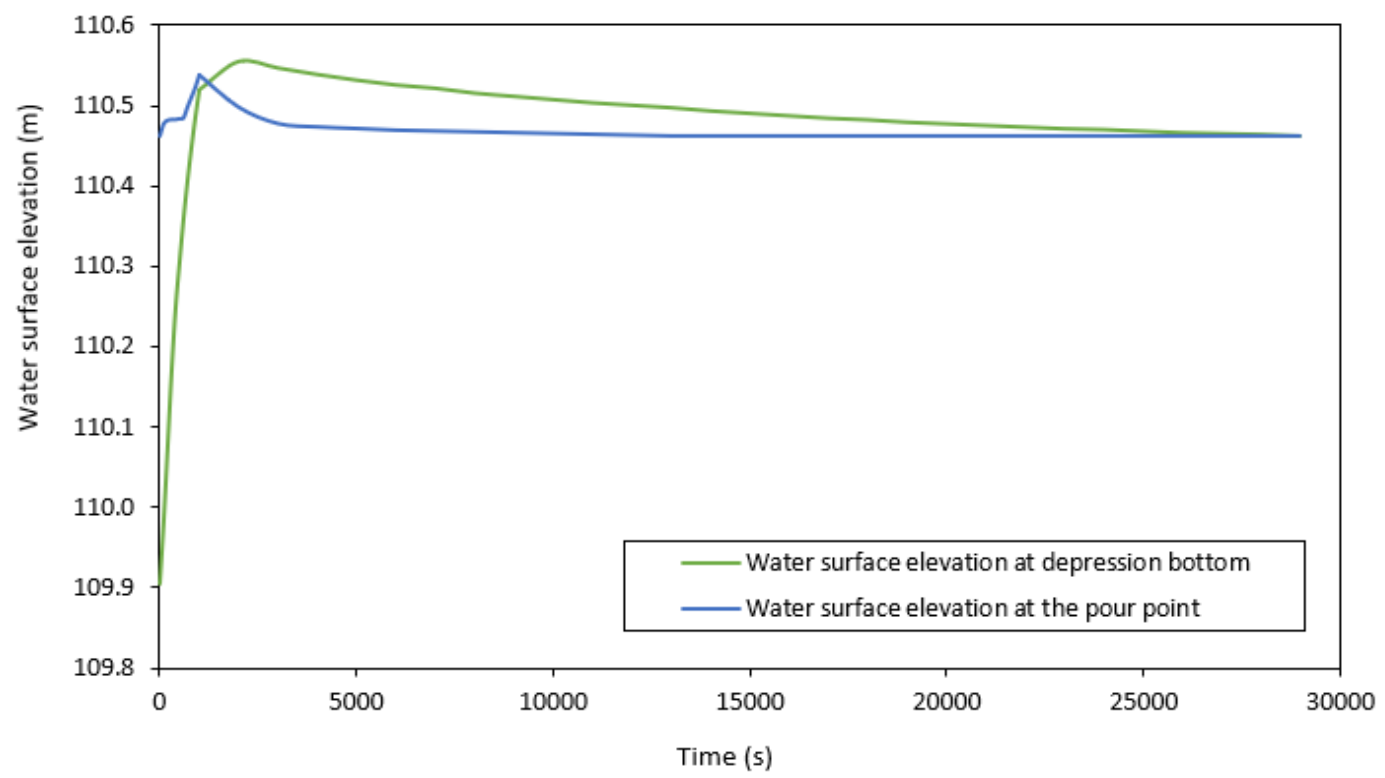

Figure 3.15 Water surface elevation changes for both the depression and the pour point for the entire duration of the outflow exercise.

\subsubsection{Results of Landscape Demonstrations}

With recorded precipitation, the model approximates the water in a depression on August 1, 2010, starting from an initial area of free water surface on August 1, 2009. Fig. 
3.16 and 3.17 show the precipitation data and total water volume of water in the depressions. Plots of the calculated water volume in storage over time show increases during periods of precipitation. The plots also show decreased storage volume in between rain events, when infiltration and evaporation are occurring, particularly during the growing season, when ET can have a considerable impact on water surfaces.

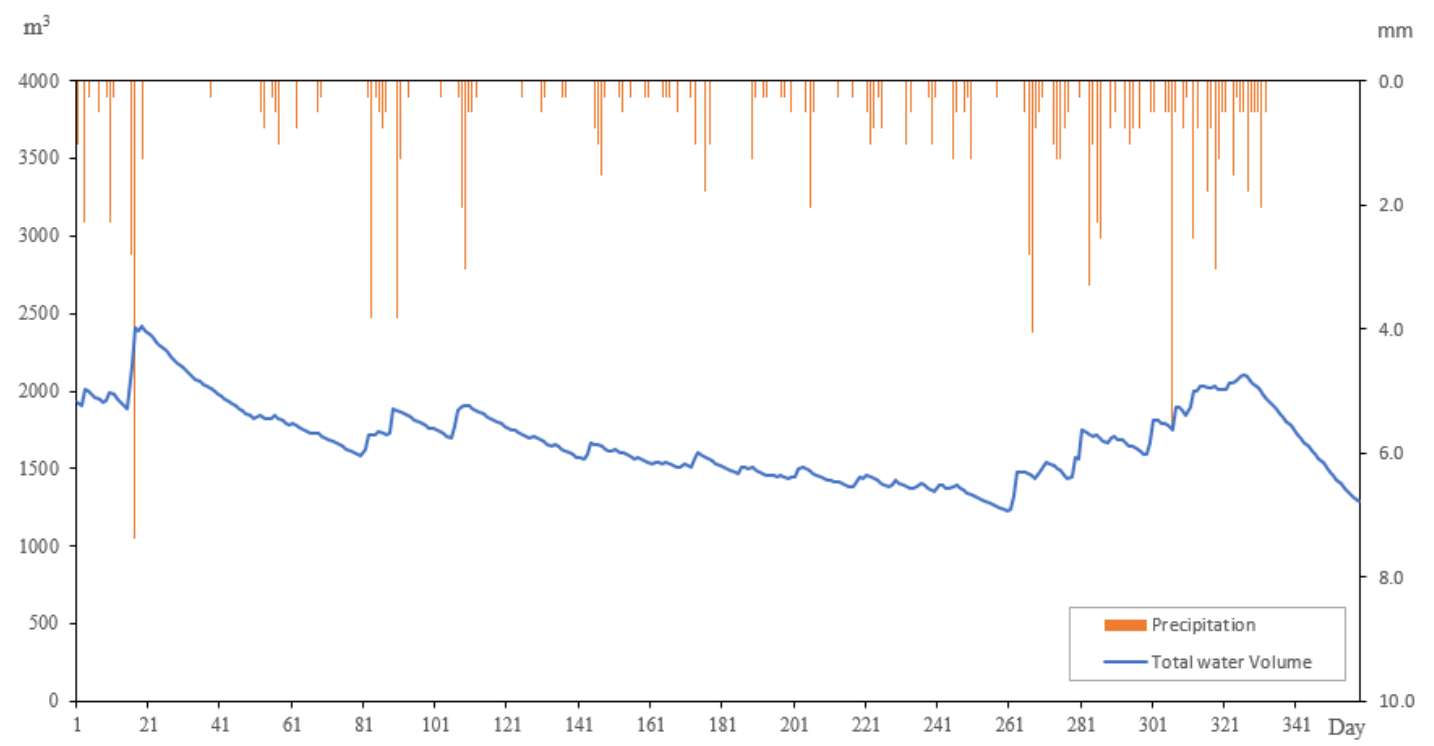

Figure 3.16 Precipitation and total water volume over time in the North depression.

For the South site, the total water volume from the summer 2009 image is $1919.27 \mathrm{~m}^{3}$ and the total water volume from the summer 2010 image is $1308.22 \mathrm{~m}^{3}$. In the model simulation, total water volume in the depression changes from $1919.27 \mathrm{~m}^{3}$ to $1285.75 \mathrm{~m}^{3}$. The difference in the water volumes is $1.72 \%$. For the North site, the total water volume from the summer 2009 image is $10,498.64 \mathrm{~m}^{3}$ and the total water volume from the summer 2010 image is $9541.71 \mathrm{~m}^{3}$. In the model simulation, the total water volume in the depression changes from $10,496.11 \mathrm{~m}^{3}$ to $8432.19 \mathrm{~m}^{3}$. For the North site, the difference 
between the assessed storage volume at the end of the period and the modeled storage volume at the end of the period is $11.6 \%$.

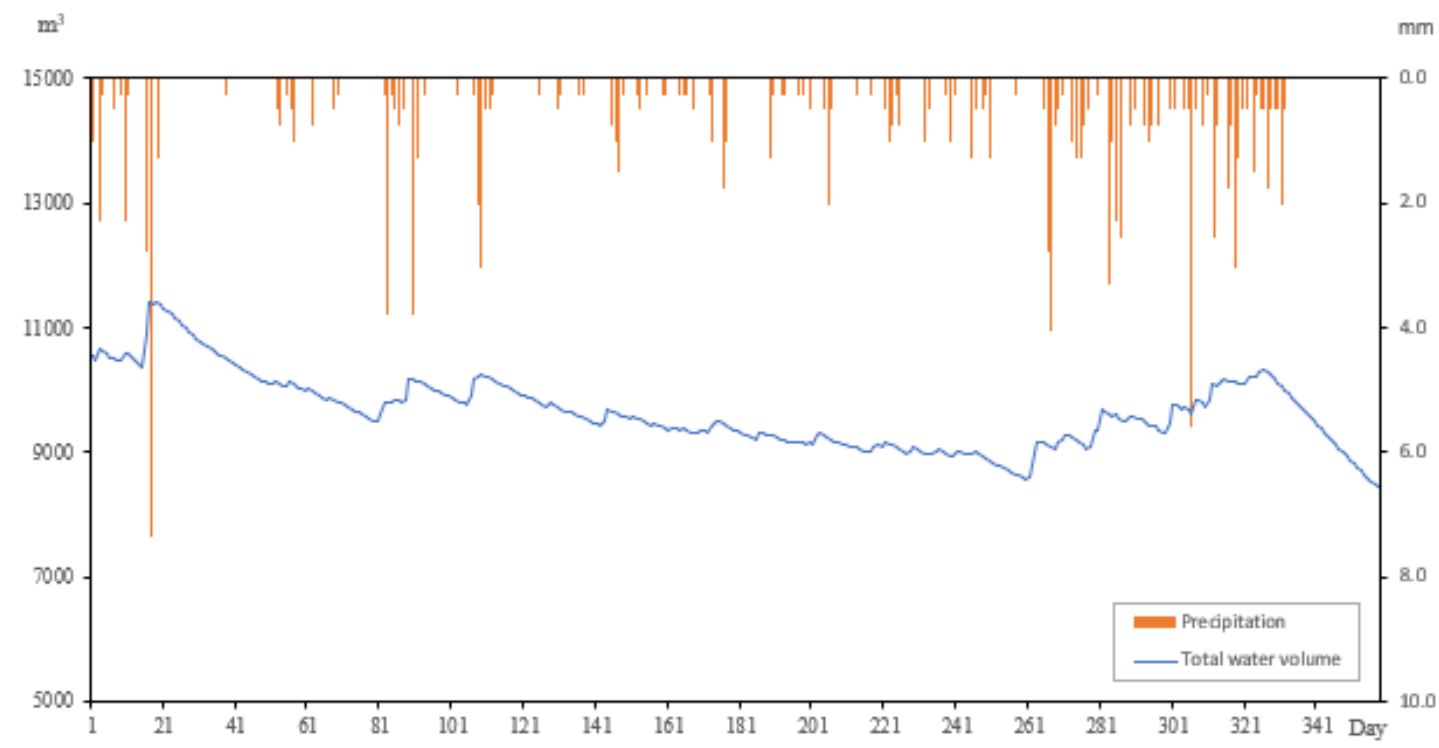

Figure 3.17 Precipitation and total water volume over time in the South depression.

Some variation between the observed and the modeled storage volumes would be expected because of variations in several factors, with the manner in which ET information is available from agricultural investigations (i.e., expected ET values are based on long-terms averages rather than on actual temperatures) being a considerable factor. In addition, the estimated topography of the depressions might be expected to cause additional variability, in addition to the uncertainty associated with the dates of the aerial imagery.

\subsection{Conclusion and Future Activities}

This proposed methodology fills a gap in incorporating infiltration and ET with the hydraulics of flow over a landscape in a modeling framework suitable for investigating multiple locations and scenarios. It provides an efficient means to simulate overland 
runoff and accumulation in depressions. It is built on time step calculations using Manning's equation and continuity on each cell. It considers sinks as actual features and uses dynamic flow direction as a key factor in simulating the water movement over the landscape. The calculations show that this model can predict water movement and depth on individual cells with an accuracy that could support decision making.

Calibration and verification were accomplished without significant manipulation of the input parameters. The results from both the exercises and field demonstrations are consistent with hydraulic principles and field conditions. In the first exercise, on an artificial landscape with insufficient rainfall to cause the overflow of water from a depression, the ability to track the movement of water over the landscape and accurately record the volume in the bottom of the depression was demonstrated. The second exercise was again conducted on an artificial landscape, but this time with sufficient rainfall to cause water to flow out of the depression. In this case, the Python script was shown to be capable of tracking water as it flowed out of the depression, with the water surface elevation asymptotically approaching the land surface elevation of the depression pour point. While the two exercises on the artificial landscape were conducted without the consideration of infiltration or ET, the field demonstrations incorporated them both. The results from the two demonstrations that simulated the water budget over a two-year period indicate the ability of the Python script to combine the horizontal movement of water on the landscape with the vertical processes of precipitation, infiltration and ET. Given the potential error of ET assessments and the dates of the aerial photographs, at the end of each simulation, the extent of the modeled open water surface approximated that in the available aerial photographs. 
The simulation methodology has the capability to consider flow from one depression to another and can record the total water volume in depressions of interest, indicating the water accumulating and dispersing. As result, this new model can be applied to test wetland management practices, construction designs and flood control.

With the ability to model water flow over the landscape, into and out of depressions, land managers now have the ability to analyze the water balance for small, isolated locations. The Python script can be run over long periods of time (a year or more) to identify the extent and duration of surface water for comparison with the needs of the flora and fauna of interest. It utilizes publicly available information but could also be run with artificial precipitation sequences (e.g., to simulate particularly wet or dry years). The ease with which modeling scenarios can be set up and run allows multiple locations to be analyzed to support decision making with respect to candidate compensatory wetland locations.

Now that the model exists and the ability to track the movement of water over a landscape has been demonstrated, several activities will be undertaken to improve the accuracy and extend the functionality of the model. The model will be revised for a more detailed treatment of infiltration and evapotranspiration that incorporates their interconnectedness through the tracking of water content. Seasonal plant growth may result in Manning's roughness coefficients that change over time. The ability to incorporate variable $\mathrm{n}$ values may prove to be useful in locations where there are significant changes in plant height and density over time. While it did not introduce significant errors for these demonstrations, other sites might be impacted by potential interactions between 
surface and groundwater. The modeling described here could be extended to address these conditions. 


\section{MODIFIED GREEN AMPT MODEL FOR UNSTEADY}

\section{RAINFALL}

\subsection{Introduction}

Infiltration is one of the most significant components in hydrology which has been researched for decades (Liu, Zhang and Feng, 2008; Chen, Hill and Urbano, 2009; Ali et al., 2016). Different kinds of models, including empirical models (Tan and O'Connor, 1996; Mishra, Tyagi and Singh, 2003) and physical models (Chu, 1978; Warrick et al., 2005; Chen, Hill and Urbano, 2009), are available to describe this complex process. The Green Ampt Infiltration model (Green and Ampt, 1911) has become the most widely used infiltration model because of its simplicity, its physical grounding in the law of conservation of mass and use of Darcy's law (Mishra, Tyagi and Singh, 2003; Wang, Chen and $\mathrm{Yu}, 2018)$. Multiple studies using the Green Ampt model have been conducted at different spatial scales and in different locations (Kalman, 1960; Chen and Young, 2006; Kacimov, Al-Ismaily and Al-Maktoumi, 2010; Chen et al., 2015).

Because of its simplicity, several assumptions are made before applying the Green Ampt method. For example, it assumes a homogenous soil profile and a uniform distribution of initial water condition (Chu and Mariño, 2005; Kale and Sahoo, 2011). Additionally, it does not consider unsteady rainfall or surface water movement in the horizontal direction (Chu, 1978; Mao et al., 2016). However, this model is still one of the most popular models to describe infiltration. 
In its original development, the Green Ampt methodology considered only steady precipitation. The objective of this research is to build upon enhancements to the original Green Ampt methodology (i.e., considering unsteady rainfall as a sequence of very short periods of steady rainfall) in order to calculate infiltration rates with unsteady precipitation over the landscape. This landscape-based assessment of infiltration is carried out using a GIS-based Python script. The GIS-based Python script for infiltration was coupled with the Dynamic Flow Direction (DFD) model, to incorporate surface water movement. The implication of surface water movement is the consideration of water running on to and running off from each cell in the landscape as a determinant of infiltration. That is, if water runs on to a cell, continued excess water on the surface will cause continued infiltration. However, water running off from a cell can leave no excess precipitation and infiltration would cease. Such an integrated treatment of unsteady rainfall has the potential to improve the development of inundation maps and the calculation of depression discharges. Previous Studies

\subsubsection{Green Ampt Model}

Prediction of volume and discharge from a rainfall event is significant for designing hydraulic structures and normally the infiltration is greater than the runoff (Mullem, 1991). The Green-Ampt infiltration model, which was first proposed in 1911 by Green and Ampt, is used to compute the portion of water entering the soil based on a simple application of Darcy's law (Stewart, 2018). Since then, due to its simplicity and capability, this model has drawn lots of attention and it is widely used in different applications. 
The Green-Ampt (GA) method is a physical, time-based model which also considers the impacts from rainfall intensity and duration (Philip, 1957). It includes several assumptions. First, the GA method assumes that the soil has a homogenous profile and uses uniformly antecedent water content in the soil profile. Second, water content remains constant between the soil surface and the wetting front when it moves deeper into the soil, and meanwhile the soil water pressure head at the wetting front also remains constant. Third, it is applied under steady rainfall, which has a constant rainfall intensity.

Based on these assumptions, the Green Ampt model categorizes the infiltration process into two different scenarios (Mein and Larson, 1973):

1. Before ponding is achieved: When the rainfall intensity is less than the potential infiltration rate, all precipitation infiltrates into the soil and there is no water accumulation on the landscape surface. During this period, the actual infiltration rate is constant and equal to the rainfall intensity.

2. After ponding is achieved: When the rainfall rate is greater than the infiltration rate, water starts to accumulate on the land surface and generate runoff.

The Green Ampt equation establishes an implicit relationship between the cumulative infiltration and time. To identify the infiltration rate at a certain time, the hydrologist must use a iterative process to calculate the time, $t$, for a selected value of the cumulative infiltration, F. Once the cumulative infiltration versus time relationship is constructed in this manner, the infiltration rate versus time curve may be inferred (Serrano, 2003). A modified Green Ampt equation which determines the time to ponding time, and more generally, time in the infiltration process, for steady rainfall events was developed by 
Mein and Larson (1973) and Swartzendruber (1974). A numerical iteration process was also introduced to solve the Green Ampt equation by Salvucci and Entekhabi(1994). Serrano (2003) proposed a decomposition solution to solve the Green Ampt equation with a maximum error of approximately $0.15 \%$. Further, Serrano (2003) continued to improve the decomposition solution and found this solution is applicable for a wide range of condition. An important error does occur when the rainfall intensity is very high.

Van Mullem (1991) used the Green-Ampt infiltration model in comparison with the Soil Conservation Service (SCS) curve number procedure to predict runoff and peak discharge in 12 different sites. All soil parameters were collected from the USDA soil survey. Before the infiltration occurs, the interception storage (ranging from 0 to 0.38 $\mathrm{mm}$ ) must be satisfied. Depression storage of $1.27 \mathrm{~mm}$ (caused by surface tension or minor depressions), was subtracted from the runoff increment. A unit hydrograph model based on runoff volume obtained from the Green-Ampt model was applied to predict peak discharge (Van Mullem, 1991).

There are also limitations with the Green Ampt model. First, it does not consider the horizontal movement of the runoff. When considering the landscape characteristics, surface water in high-elevation areas drains out faster and low-elevation area accumulate more water than other locations. As a result, high-elevation areas have shorter durations for infiltration and low-elevation locations have longer infiltration times. Second, the Green Ampt model can't accommodate unsteady rainfall. During long-duration rainfall events, rain intensity may decrease or increase with time (Philip, 1993). Chu (1978) first modified the GA equation for unsteady rainfall for homogeneous soil. To account for unsteady rainfall, Chu (1978) divided the rainfall event into many short periods of 
constant rainfall intensity. Based on this theory, there can exist several ponding times during an unsteady rainfall event. For each time when the surface ponding begins, the ponding time must be calculated, describing the infiltration rate through an implicit function. When applying the Green-Ampt infiltration model for varying intensity rainfall events, it is reasonable to assume that recovery of the infiltration capacity is relatively slow, and that brief dry or drizzle periods during the event do not affect the calculations (Chu, 1978). Reeves and Miller (1975) suggested that if the dry period exceeded about 12 hours, the following rainfall event should be considered as a separate event. The initial moisture for all storms is assumed constant. Philip (1993) proposed a method to calculate ponded infiltration under variable rainfall. At the ponding time, rainfall intensity equals the infiltration rate and the soil becomes fully saturated. However, the equation used to calculate infiltration still relies on the cumulative infiltration depth to pair time and infiltration rate. Additionally, the horizontal movement of surface water was not considered.

\subsubsection{Runoff Model}

Taking advantage of high-performance computers and high-resolution geospatial data, multiple hydrologic and hydraulic models have been designed for simulating overland flow (Maheshwari and McMahon, 1992; Esteves et al., 2000b; Giustolisi and Berardi, 2011). Various methods and equations are employed in these models, including Manning's equation, the kinematic wave equation, and the dynamic wave equation.

Distributed hydrologic models can calculate the volume of water on each grid cell of a digital elevation model (DEM), which can easily be imagined as a finite amount of water stored on the land surface. Due to gravity, water will flow from cell to cell. For a 
cell-to-cell calculation, the time step is subject to a stability condition. Water movement cannot move further than the grid size during one-time step (Esteves et al., 2000a). This constraint requires defining a suitable time step based on the flow velocity.

Infiltration characteristics, flow velocity, roughness and land surface condition are variables when simulating overland flow, which make this process so complex. Roughness is one of the critical components in the model which is also the most difficult to estimate. It varies based on different conditions of soil moisture, vegetation and flow depth. To develop a shallow runoff model, researchers usually need to deal with a very small water depth. In this situation, elevation accuracy, mass balance and flow resistance (roughness) are extremely crucial factors (Maheshwari and McMahon, 1992).

A Dynamic Flow Direction (DFD) model has been developed for simulating overland runoff on landscapes containing depressions without considering the recharge from ground water. The model utilizes a DEM which retains the depressions that may otherwise be removed from consideration. In this model, an additional layer which represents the water depth is created to determine the dynamic flow direction within the DEM layer.

\subsection{Methodology}

\subsubsection{Modified Green Ampt Model}

When precipitation is falling on the landscape, water will first infiltrate into the soil, and then generate overland flow to lower-elevation locations. For each landscape cell on a DEM, the water budget can be described as follows: 


$$
P=F+G+R
$$

where $P$ is the cumulative rainfall (m); $F$ is the cumulative infiltration (m); $G$ is the depth of water ponding on the landscape surface (m); and $R$ is combination of inflow and outflow of each cell (m). Evaporation can be neglected because of the short time duration and the impact of air moisture.

In the traditional Green Ampt model, the infiltration process during a rainfall is divided into two scenarios based on $t_{p}$ (time to ponding). The infiltration rate $f$ is estimated by:

$$
\begin{array}{ll}
f(t)=K_{s}+K_{s} \frac{\left|\varphi_{f}\right|\left(\vartheta_{s}-\vartheta_{i}\right)}{F} & \text { for } t>t_{p} \\
f(t)=P & \text { for } t \leq t_{p}
\end{array}
$$

where $\varphi_{f}$ is soil water suction head; Ks is saturated hydraulic conductivity; $\vartheta_{s}$ is saturated soil water content; $\vartheta_{i}$ is initial soil water content; $P$ is rainfall rate and $F$ is the cumulative amount of water that has infiltrated. Since there is no time variable in the Eq. 4.2, Eq. 4.2 can be transformed to

$$
t=t_{p}+\frac{1}{K_{s}}\left[F-F_{p}+\left|\varphi_{f}\right|\left(\vartheta_{s}-\vartheta_{i}\right) \ln \left(\frac{\left|\varphi_{f}\right|\left(\vartheta_{s}-\vartheta_{i}\right)+F_{p}}{\left|\varphi_{f}\right|\left(\vartheta_{s}-\vartheta_{i}\right)+F}\right)\right]
$$

using $f=d f / d t$ (Mein and Larson, 1973), where $F_{p}$ is the cumulative infiltration that has occurred up to the time of ponding, $t_{p} . F_{p}$, and $t_{p}$ can be calculated by:

$$
F_{p}=\frac{\left|\varphi_{f}\right| K_{s}\left(\vartheta_{s}-\vartheta_{i}\right)}{P-K_{S}}
$$




$$
t_{p}=\frac{F_{p}}{P}
$$

To analyze the relationship between time and the infiltration rate, $F_{p}$ and $t_{p}$ should first be calculated with steady rainfall. Additionally, Eq. 4.4 is an implicit equation for $t$ and $F$. It is common to employ a column of $F$, which is incremented by small amounts, to calculate $t$ (Eq. 4.4) and $f(t)$ (Eq. 4.2). To solve this problem, Eq.4.4, Eq.4.5 and Eq.4.6 can be transformed into Eq.4.7 and Eq.4.8 (unlike what Mein and Larson(1973) did), which show the relationship between $t$ and $f(t)$ directly.

$$
t=t_{p}+\frac{v a l}{f(t)-K_{s}}-\frac{F_{p}}{K_{s}}+\frac{v a l}{K_{s}} \ln \left(\frac{P\left(f(t)-K_{s}\right)}{\left(P-K_{s}\right) f(t)}\right)
$$

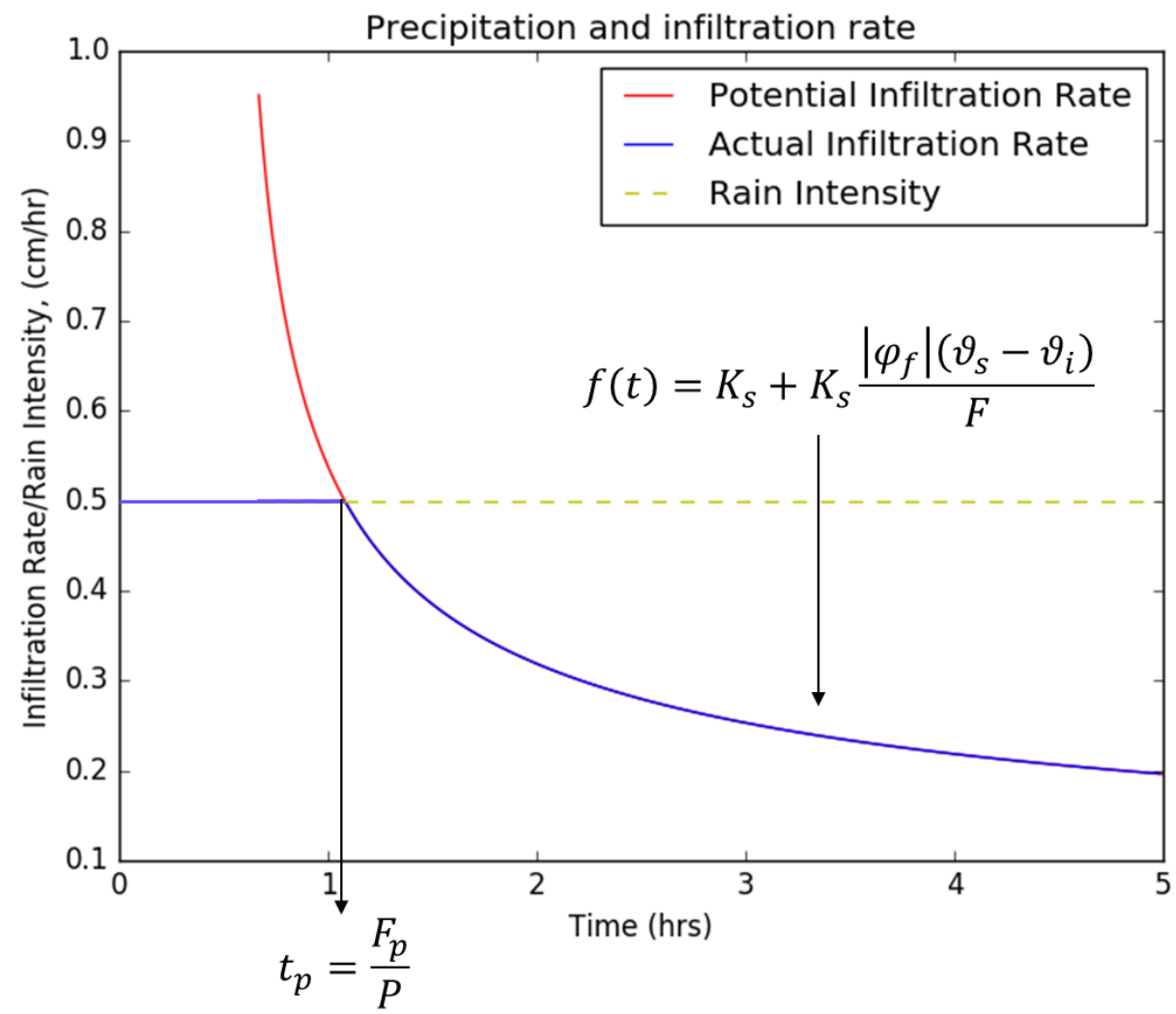

Figure 4.1. Infiltration rate based on Green Ampt model.

$$
\text { val }=\left|\varphi_{f}\right|\left(\vartheta_{s}-\vartheta_{i}\right)
$$


Fig. 4.1 shows the traditional infiltration curve with a steady rainfall of $0.5 \mathrm{~cm} / \mathrm{hr}$. Before the ponding time $\left(t_{p}\right)$, the potential infiltration rate is much higher than the rain intensity, which means that all precipitation will infiltrate into the soil. As a result, the actual infiltration rate is equal to rain intensity. After the ponding time $\left(t_{p}\right)$, the infiltration rate is calculated using Eq. 4.2 and reduces to below the rain intensity. Water starts to accumulate on the land surface and generate overland flow.

For unsteady rainfall, rain intensity changes all the time. Eq. 4.5 and Eq. 4.6 are inadequate to calculate time to ponding $\left(t_{p}\right)$ and cumulative infiltration to ponding $\left(F_{p}\right)$. However, before the ponding time $\left(t_{p}\right)$, it is certain that all accumulated precipitation $P_{t}$ moves into the soil, which equals cumulative infiltration to ponding $\left(F_{p}\right)$ :

$$
P_{t}=F_{p}
$$

and the infiltration rate at ponding time equals rain intensity at ponding time:

$$
f(t)=R(t) .
$$

Then, Eq. 4.2 can be converted to:

$$
R(t)=K_{s}+K_{s} \frac{\left|\varphi_{f}\right|\left(\vartheta_{s}-\vartheta_{i}\right)}{P_{t}}
$$

because

$$
P_{t}=\int_{0}^{t} R d t
$$

Thus, the ponding time $\left(t_{p}\right)$ and cumulative infiltration to time of ponding $\left(F_{p}\right)$ can be calculated using Eqs. 4.9, 4.10 and 4.11. Because Eq. 4.4 is an implicit equation for $t$ and 
$F_{p}$, solving the implicit equation process is embedded in a Python script to obtain a precise value in an efficient fashion.Now, the real-time potential infiltration rate is calculated during an unsteady rainfall event (Fig. 4.2). The actual infiltration rate can be corrected by precipitation data and the potential infiltration rate, because the infiltration rate cannot be larger than the precipitation rate.

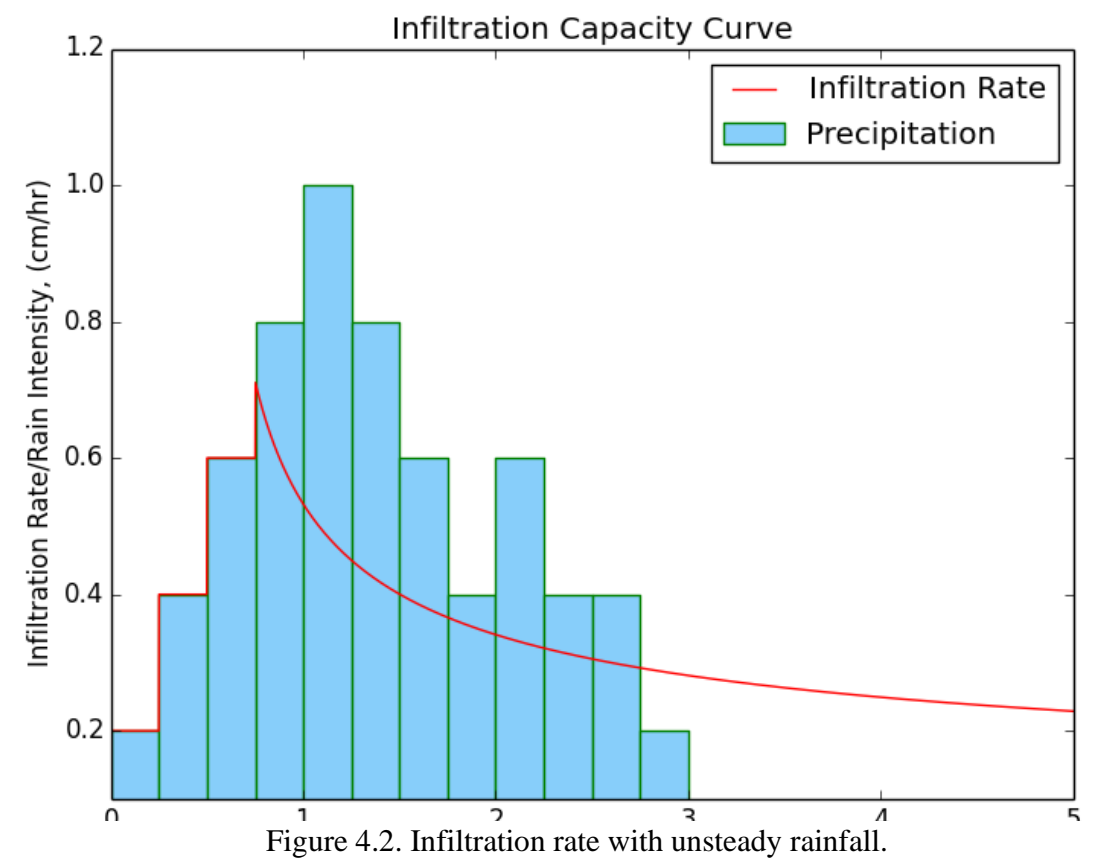

\subsubsection{Coupling the MGA model with DFD Model}

In the Dynamic Flow Direction (DFD) model, the water budget on each cell is calculated during each short time step. Often, the infiltration rate is calculated based steady rainfall for the entire duration of the event for computational efficiency. However, using constant rainfall intensity is inadequate to quantify the infiltration rate in each time step. Different infiltration rates directly impact the calculated time to ponding and the cumulative infiltration, which could result in different surface water volumes. As a result, it is preferable to calculate the infiltration rate simultaneously under an unsteady rainfall event instead of only for a steady rainfall event. Thus, the Modified Green Ampt (MGA) 
model is applied to determine the infiltration rate and the rainfall excess in an unsteady rainfall event.

This MGA equation can be utilized by inputting the precipation data in a Python script written for this effort. This real time infiltration rate is combined in the water budget calculation in each time step for every cell.

It should be recognized that traditionally, the Green-Ampt method is applied on a field without considering surface water movement. In an overland flow model, surface water will move and accumulate in lower elevation areas. This means that cells which have net outflow will end infiltration faster and cells which have net inflow will have longer periods of infiltration. Because of this, in the overland flow model, the only determining varible is the water volume on each cell. If there is no water on a given cell, there will be no infiltration and vice versa.

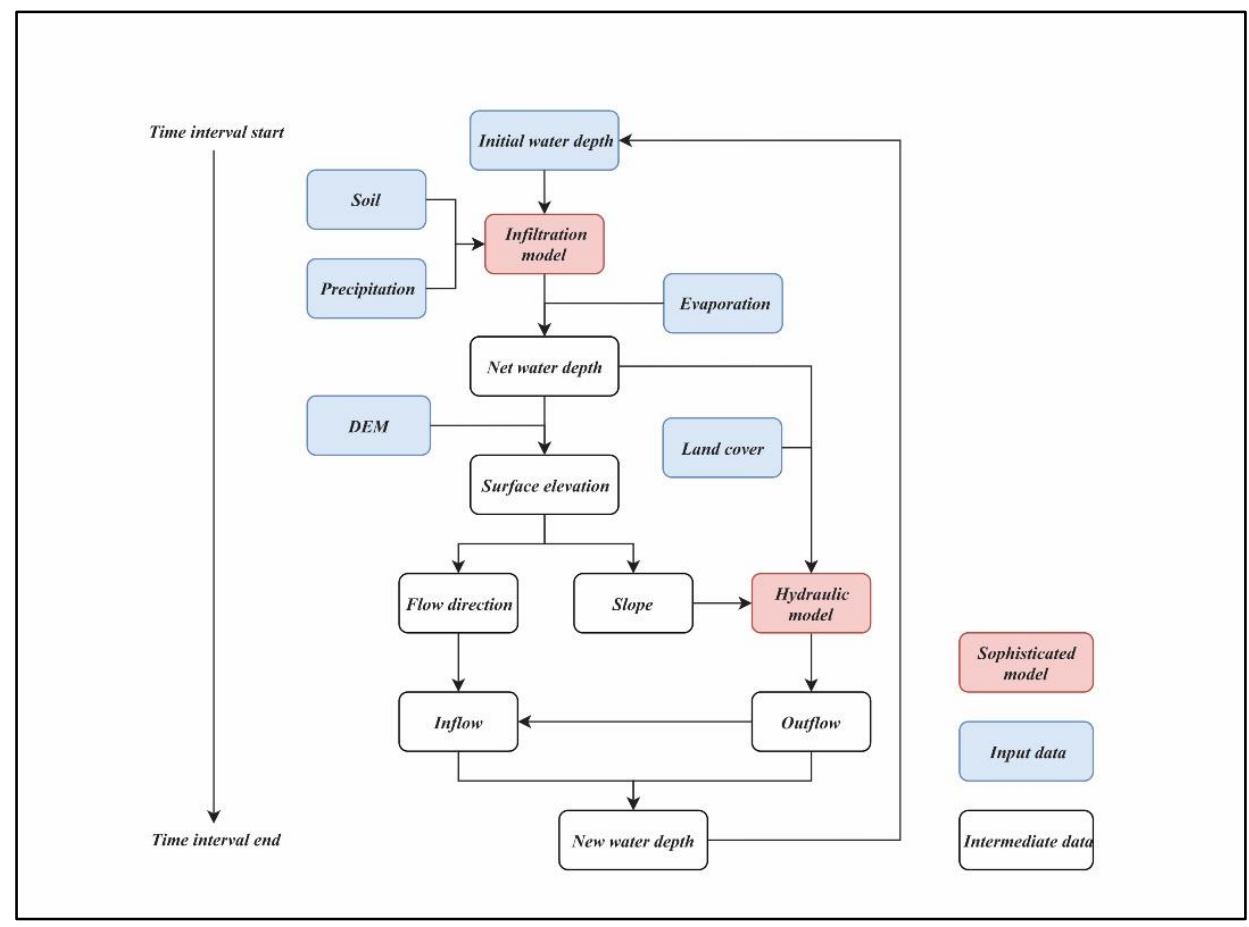

Figure 4.3. Flow chart of the coupling of the MGA model with the DFD model. 


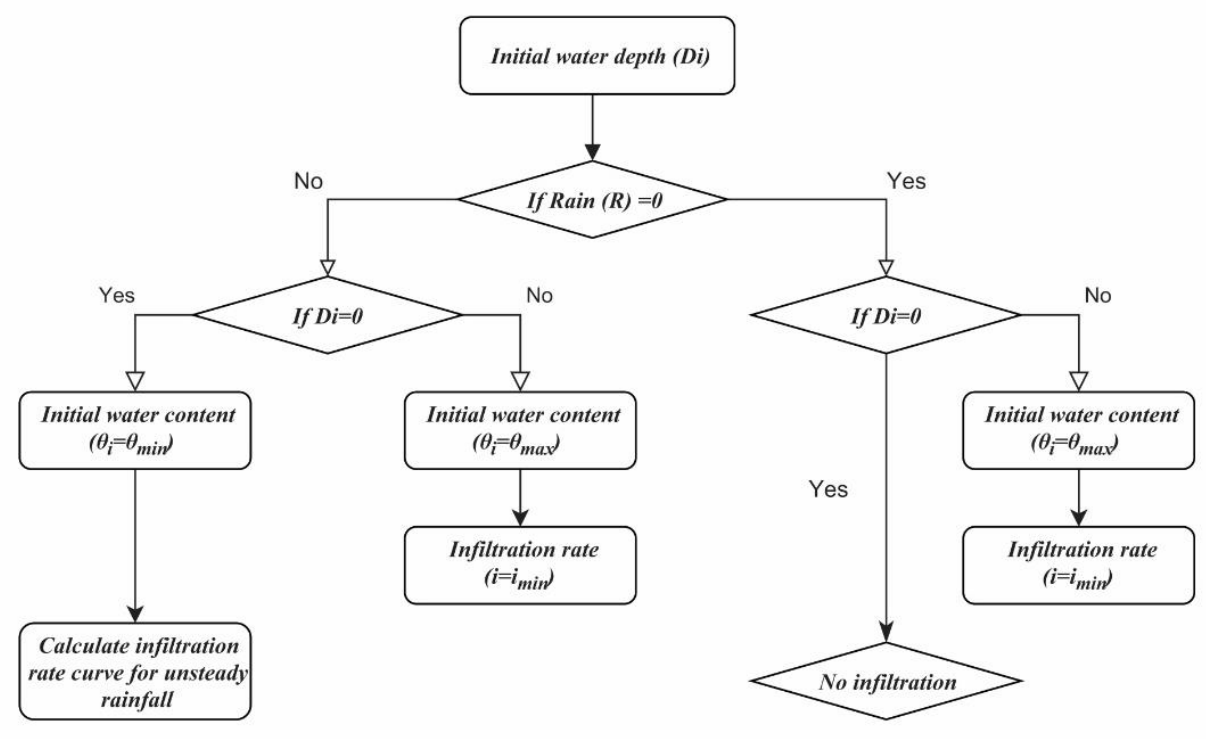

Figure 4.4. Flow chart for determining the infiltration rate.

Figure 4.3 shows the workflow for the entire process. The MGA model is embedded at the beginning of each time step. It can calculate the infiltration rate based on soil texture and precipitation. In the MGA model, there are also conditional statements to determine the infiltration rate, which increases the computational efficency (Fig. 4.4).

\subsection{Result and Discussion}

\subsubsection{Comparison Between TGA and MGA Model}

Because the traditional Green Ampt model can only compute an infiltration rate over time for steady rainfall, for a designed unsteady rainfall, one option may be to use average rain intensity as input. In this test, the average rain intensity is $0.5 \mathrm{~cm} / \mathrm{hr}$. Soil saturated conductivity is set to $0.044 \mathrm{~cm} / \mathrm{hr}$. The soil suction head is set to $22.4 \mathrm{~cm}$. Saturated moisture content and initial moisture content are 0.5 and 0.25 . These values are selected for arbitrary research purpose. Based on these given parameters, $t_{p}$ and $F_{p}$ from 
the TGA model can be calculated as $1.08 \mathrm{hr}$ and $0.54 \mathrm{~m}$. The grey line in Fig. 4.5 shows how the infiltration rate ( $y$ value) changes with respected to time ( $x$ value).

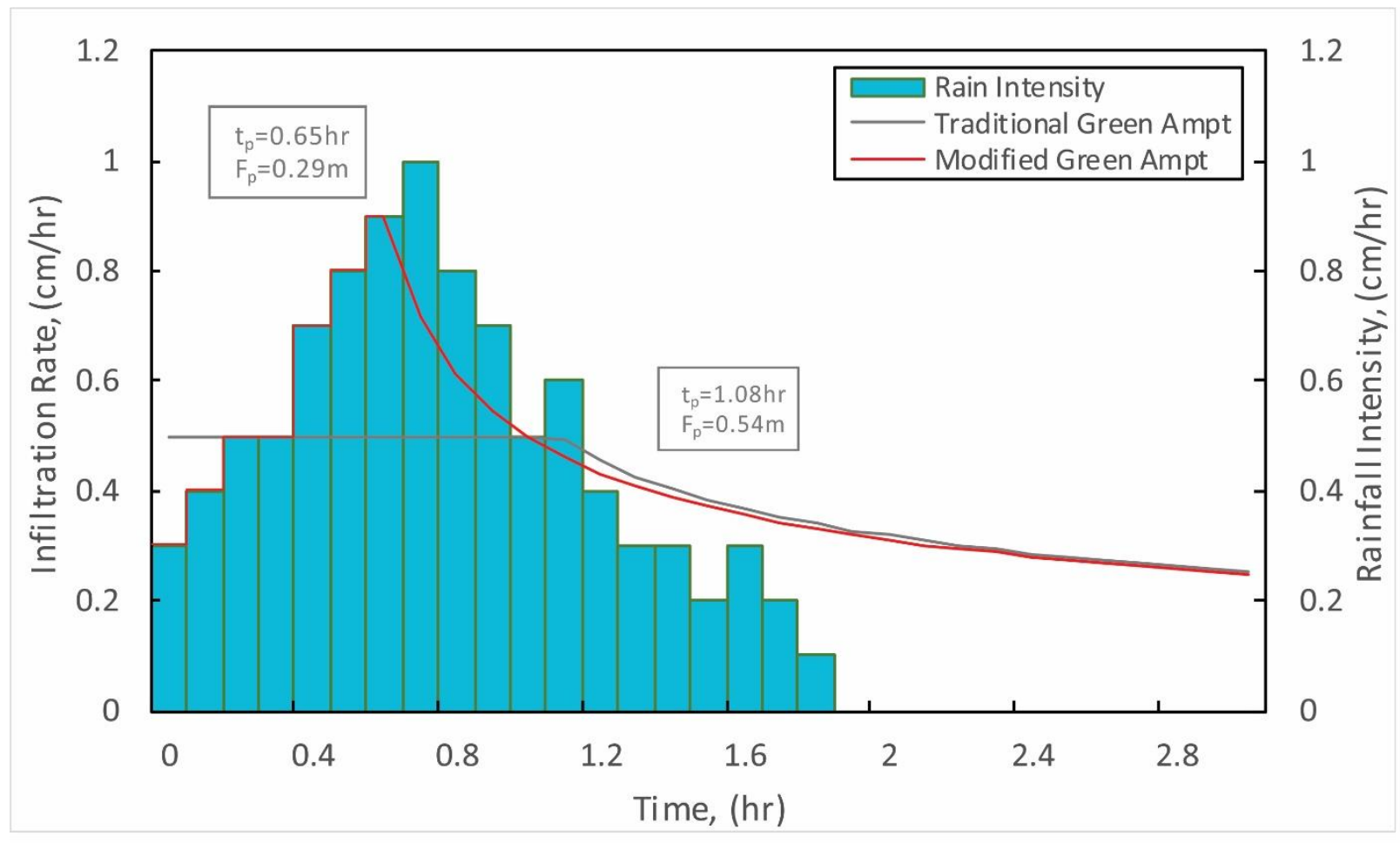

Figure 4.5. Infiltration rate comparison between TGA and MGA models.

The result of the MGA model is a $t_{p}$ of $0.65 \mathrm{hr}$, which is much shorter than the $t_{p}$ from the TGA. Additionally, the $F_{p}$ is $0.29 \mathrm{~m}$ which is smaller than $F_{p}$ from the TGA. The difference also can be observed during the period before ponding is reached. In the TGA, the infiltration rate is constant because it operates from an average rainfall intensity, which fails to represent the variability of unsteady rainfall. Meanwhile, in the MGA, the infiltration rate changes with the rainfall intensity even before the condition of ponding is reached. The difference in the water budget can be seen in Table 4.1. Based on the MGA model, the accumulated infiltration is also larger with the TGA model. 
Table 4.1. Comparison of results from the TGA and the MGA models.

\begin{tabular}{cccc}
\hline Time(hr) & TGA & MGA & Diff \\
\hline 0 & 0.5 & 0.3 & 0.2 \\
0.1 & 0.5 & 0.4 & 0.1 \\
\hline 0.2 & 0.5 & 0.5 & 0 \\
0.3 & 0.5 & 0.5 & 0 \\
\hline 0.4 & 0.5 & 0.7 & -0.2 \\
\hline 0.5 & 0.5 & 0.8 & -0.3 \\
0.6 & 0.5 & 0.9 & -0.4 \\
\hline 0.7 & 0.5 & 0.71 & -0.21 \\
\hline 0.8 & 0.5 & 0.61 & -0.11 \\
\hline 0.9 & 0.5 & 0.55 & -0.05 \\
\cline { 2 - 2 } 1 & 0.5 & 0.50 & 0.00 \\
\hline 1.5 & 0.38 & 0.37 & 0.01 \\
\hline 2 & 0.32 & 0.31 & 0.01 \\
\hline 2.5 & 0.28 & 0.27 & 0.00 \\
\hline 3 & 0.25 & 0.25 & 0.00 \\
\hline $\begin{array}{c}\text { Accmulated } \\
\text { infiltation(m) }\end{array}$ & 1.21 & 1.29 & -0.08 \\
\hline
\end{tabular}

\subsubsection{Calculation of Spatial and Temporal Water Budget on the Landscape}

During a rainfall, each cell on a landscape (as represented by a DEM) has both input and output in both the horizonal and the vertical directions. In a traditional Green Ampt methodology application, input and output in the vertical direction are the only factors considered. By coupling the MGA and the DFD models, it is possible to track the spatial and temporal water budget on each cell, which also has impacts on the infiltration rate. Based on the infiltration rate generated from the prior comparison, two series of inundation maps are created to represent the water distribution on the landscape during the designed unsteady rainfall. 
Fig. 4.6 indicates two inundation maps using the TGA and the MGA at $0.5 \mathrm{hr}$. At this time step, the total water volume on the landscape with MGA is 5.3\% less than the result with TGA. To better reflect the water distribution, the blue color only depicts water depths larger than $0.05 \mathrm{~m}$. Based on this information, the inundation area which is deeper than $0.05 \mathrm{~m}$ with MGA is $4.8 \%$ smaller than the result with TGA.
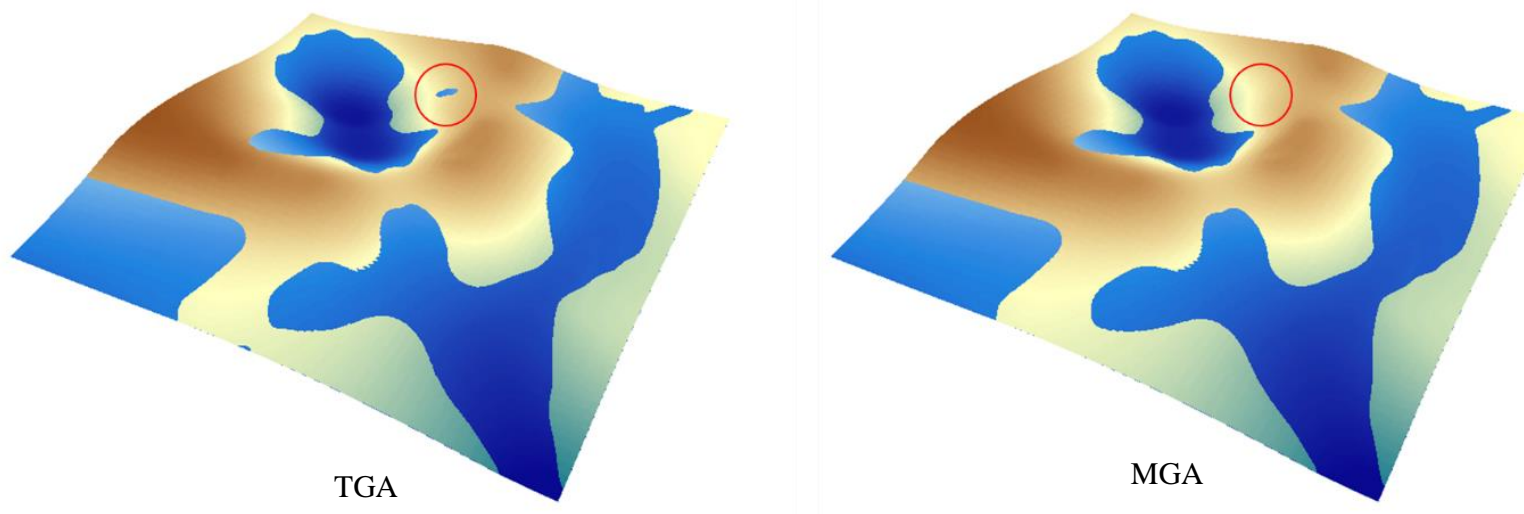

Figure 4.6. Inundation maps created with the TGA and the MGA models.

\subsection{Conclusion}

This study modifies the widely used Green Ampt infiltration model for unsteady rainfall. It incorporates a new method to calculate the ponding time and cumulative infiltration, and then establishes an implicit equation to build the connection between time and infiltration rate. The entire process, including the solution of the implicit equation, are implemented in a Python script. The infiltration rate from MGA can accommodate unsteady rainfall intensity. This proposed method is examined by comparing with the traditional Green Ampt model. The results show that the MGA model has a shorter time to ponding, a larger maximum infiltration rate, smaller cumulative infiltration at the ponding time (the time of surface saturation) and a larger cumulative infiltration over a longer period of time. 
Based on the results from the previous comparison, the MGA model is coupled with DFD model to evaluate the effects for horizontal movement of overland flow. With the consideration of inflow and outflow, the results show that the study area has a larger total infiltration volume with MGT, which mean less water content on the landscape. As a result, the inundation area is relatively smaller than with the calculation using TGA. These results have implications for multiple aspects of surface water runoff management, from the performance of stormwater best management practices (BMPs) to the assessment of locations for potential mitigation wetlands. 


\section{CONCLUSIONS}

\subsection{Backwater Effect on Surface Water Profile}

An efficient methodology for using the Modified Euler's method to calculate water surface profiles over a natural landscape on the mild slopes connecting wetlands has been developed. A Python script has been created to perform the calculations, including the extraction of landscape data directly from a DEM, eliminating the need for a field survey at every potential depression of interest. The efficiency of the methodology allows for widespread scoping calculations to assess locations for more detailed investigations for wetland protection or mitigation. Its simplicity and automation can help users with little hydraulics background to calculate profiles for decision-making.

Multiple tests have been performed to verify the accuracy of this methodology. The Python script created for this project automatically extracts the necessary data and computes all necessary hydraulic parameters. The first test recreated a drawdown curve demonstration in a textbook. This was accomplished by generating an artificial landscape matching the trapezoidal channel of the example. The Python script extracted the necessary landscape parameters from the DEM, calculated the appropriate hydraulic parameters and developed the drawdown curve, exactly matching the published results in a textbook. The second test was performed on a natural landscape with a discharge that would be associated with an intense storm. This set of conditions produced a sequence of backwater (M1) curves expected as landscape characteristics change, causing the water surface profile to adjust accordingly in moving from one reach to another. The third test was conducted on the same natural landscape (while changing one surface roughness 
value), but with a less intense storm. The lower flows associated with these more common, less intense storms, are of particular interest for continued wetland functioning. With the lower discharge, the script demonstrated the ability to calculate a water surface profile that incorporates both backwater (M1) and drawdown (M2) curves.

This effort addresses the challenge of quantifying the flow characteristics (i.e., a water surface profile) over a landscape in contrast to the current focus on flow in defined channels. It is able to accommodate the inherent variability in the landscape elevations and land covers. It is now possible to make assessments that could provide a first-step screening tool for wetland scientists to assist in the selection of locations that may warrant further investigation with respect to the preservation, restoration or mitigation of wetlands. Effort is ongoing, specifically in the depiction of the landscape implications of a given water surface profile - the extent of the land surface that would be covered by water from the given profile), leading to infiltration to support wetland function.

\subsection{Overland Flow Simulation through Wetlands}

The methodology developed here fills a gap in incorporating infiltration and ET with the hydraulics of flow over a landscape in a modeling framework suitable for investigating multiple locations and scenarios. It provides an efficient means to simulate overland runoff and accumulation in depressions. It is built on time step calculations using Manning's equation and continuity on each cell. It considers sinks as actual features and uses dynamic flow direction as a key factor in simulating the water movement over the landscape. The calculations show that this model can predict water movement and depth on individual cells with an accuracy that could support decision making. 
Calibration and verification were accomplished without significant manipulation of the input parameters. The results from both the exercises and field demonstrations are consistent with hydraulic principles and field conditions. In the first exercise, on an artificial landscape with insufficient rainfall to cause the overflow of water from a depression, the ability to track the movement of water over the landscape and accurately record the volume in the bottom of the depression was demonstrated. The second exercise was again conducted on an artificial landscape, but this time with sufficient rainfall to cause water to flow out of the depression. In this case, the Python script was shown to be capable of tracking water as it flowed out of the depression, with the water surface elevation asymptotically approaching the land surface elevation of the depression pour point. While the two exercises on the artificial landscape were conducted without the consideration of infiltration or ET, the field demonstrations incorporated them both. The results from the two demonstrations that simulated the water budget over a two-year period indicate the ability of the Python script to combine the horizontal movement of water on the landscape with the vertical processes of precipitation, infiltration and ET. Given the potential error of ET assessments and the dates of the aerial photographs, at the end of each simulation, the extent of the modeled open water surface approximated that in the available aerial photographs.

The simulation methodology has the capability to consider flow from one depression to another and can record the total water volume in depressions of interest, indicating the water accumulating and dispersing. As result, this new model can be applied to test wetland management practices, construction designs and flood control. 
With the ability to model water flow over the landscape, into and out of depressions, land managers now have the ability to analyze the water balance for small, isolated locations. The Python script can be run over long periods of time (a year or more) to identify the extent and duration of surface water for comparison with the needs of the flora and fauna of interest. It utilizes publicly available information but could also be run with artificial precipitation sequences (e.g., to simulate particularly wet or dry years). The ease with which modeling scenarios can be set up and run allows multiple locations to be analyzed to support decision making with respect to candidate compensatory wetland locations.

Now that the model exists and the ability to track the movement of water over a landscape has been demonstrated, several activities will be undertaken to improve the accuracy and extend the functionality of the model. The model will be revised for a more detailed treatment of infiltration and evapotranspiration that incorporates their interconnectedness through the tracking of water content. Seasonal plant growth may result in Manning's roughness coefficients that change over time. The ability to incorporate variable $n$ values may prove to be useful in locations where there are significant changes in plant height and density over time. While it did not introduce significant errors for these demonstrations, other sites might be impacted by potential interactions between surface and groundwater. The modeling described here could be extended to address these conditions. 


\subsection{Infiltration Calculation based on Modified Green Ampt Model}

The Green Ampt infiltration model is modified for unsteady rainfall. It incorporates a new method to calculate the ponding time and cumulative infiltration, and then establishes an implicit equation to build the connection between time and infiltration rate. The entire process, including the solution of the implicit equation, is implemented in a Python script.

The infiltration rate from the MGA can accommodate unsteady rainfall intensity. An exercise comparing the performance of the Green Ampt methodology using a steady average rainfall with the performance with an unsteady event of the same total rainfall utilizing the Python script has been undertaken. The results of this single-cell assessment indicate the ability of the script to calculate instantaneous and cumulative infiltration of a magnitude generally expected. The observed differences in the results are expected based on the differences in the time to ponding calculated by the two methodologies.

The GIS-based Python script for infiltration was coupled with the Dynamic Flow Direction (DFD) model, to incorporate surface water movement. The implication of surface water movement is the consideration of water running on to and running off from each cell in the landscape as a determinant of infiltration. That is, if water runs on to a cell, continued excess water on the surface will cause continued infiltration. However, water running off from a cell can leave no excess precipitation and infiltration would cease. An additional comparison of the constant and variable precipitation over the landscape has been undertaken. Differences in surface water depths over time can be seen, suggesting that this integrated treatment of unsteady rainfall has the potential to improve the development of inundation maps and calculating depression discharges. 
These results have implications for multiple aspects of surface water runoff management, from the performance of stormwater best management practices to the assessment of locations for potential mitigation wetlands.

\subsection{Summary}

This research developed three methodologies to quantify the hydrologic and hydraulic processes in wetlands, including creating surface water profile between wetlands, simulating overland flow through wetlands and modifying the infiltration model for unsteady rainfall. All of these modeling efforts are developed to investigate the water movement in wetlands. The hydrological processes determine the function and performance of wetlands. The spatial and temporal distribution of water provide a basis for understanding wetlands for future studies, such as flood control, pollutant transport and biological studies. 


\section{REFERENCES}

Ali, S. et al. (2016) 'Green-Ampt approximations: A comprehensive analysis', Journal of Hydrology. Elsevier B.V., 535, pp. 340-355. doi:

10.1016/j.jhydrol.2016.01.065.

Amezaga, J. M., Santamaría, L. and Green, A. J. (2002) 'Biotic wetland connectivity - Supporting a new approach for wetland policy', Acta Oecologica. doi: 10.1016/S1146609X(02)01152-9.

Anderson, C. J. and Mitsch, W. J. (2005) 'Effect of pulsing on macrophyte productivity and nutrient uptake: A wetland mesocosm experiment', American Midland Naturalist. doi: 10.1674/0003-0031(2005)154[0305:EOPOMP]2.0.CO;2.

Arguelles, A. C. C. et al. (2013) 'Evaluation of overland flow model for a hillslope using laboratory flume data', Water Science and Technology. doi: 10.2166/wst.2013.341.

Arnold, N. (2010) 'A new approach for dealing with depressions in digital elevation models when calculating flow accumulation values', Progress in Physical Geography. doi: $10.1177 / 0309133310384542$.

Audusse, E. et al. (2004) 'A fast and stable well-balanced scheme with hydrostatic reconstruction for shallow water flows', SIAM Journal of Scientific Computing. doi: $10.1137 / \mathrm{S} 1064827503431090$.

Barber, C. P. and Shortridge, A. (2005) 'Lidar elevation data for surface hydrologic modeling: Resolution and representation issues', Cartography and Geographic Information Science. doi: 10.1559/152304005775194692.

Barnes, R., Lehman, C. and Mulla, D. (2014) 'An efficient assignment of drainage direction over flat surfaces in raster digital elevation models', Computers and Geosciences. doi: 10.1016/j.cageo.2013.01.009.

Braskerud, B. C. (2002) 'Factors affecting phosphorus retention in small constructed wetlands treating agricultural non-point source pollution', Ecological Engineering. doi: 10.1016/S0925-8574(02)00014-9.

Brix, H. (1994) 'Use of constructed wetlands in water pollution control: Historical development, present status, and future perspectives', in Water Science and Technology. doi: 10.2166/wst.1994.0413.

Carollo, F. G., Ferro, V. and Termini, D. (2002) 'Flow velocity measurements in vegetated channels', Journal of Hydraulic Engineering. doi: 10.1061/(ASCE)07339429(2002)128:7(664).

Carpenter, S. R. et al. (1998) 'Nonpoint pollution of surface waters with phosphorus and nitrogen', Ecological Applications. doi: 10.1890/10510761(1998)008[0559:NPOSWW]2.0.CO;2.

Cea, L. et al. (2014) 'Experimental validation of a 2D overland flow model using high resolution water depth and velocity data', Journal of Hydrology. doi: 
10.1016/j.jhydrol.2014.03.052.

Chen, J., Hill, A. A. and Urbano, L. D. (2009) 'A GIS-based model for urban flood inundation', Journal of Hydrology. Elsevier B.V., 373(1-2), pp. 184-192. doi: 10.1016/j.jhydrol.2009.04.021.

Chen, L. et al. (2015) 'Optimal parameters for the Green-Ampt infiltration model under rainfall conditions', Journal of Hydrology and Hydromechanics, 63(2), pp. 93 101. doi: 10.1515/johh-2015-0012.

Chen, L. and Young, M. H. (2006) 'Green-Ampt infiltration model for sloping surfaces’, Water Resources Research, 42(7), pp. 1-9. doi: 10.1029/2005WR004468.

Cheng, S. et al. (2002) 'Efficiency of constructed wetlands in decontamination of water polluted by heavy metals', Ecological Engineering. doi: 10.1016/S09258574(01)00091-X.

Chow, V. T. (1959) Open-Channel Hydraulics, Science.

Chu, S. T. (1978) 'Infiltration during an unsteady rain', Water Resources Research, 14(3), pp. 461-466. doi: 10.1029/WR014i003p00461.

Chu, X. and Mariño, M. A. (2005) 'Determination of ponding condition and infiltration into layered soils under unsteady rainfall', Journal of Hydrology, 313(3-4), pp. 195-207. doi: 10.1016/j.jhydrol.2005.03.002.

Costa-Cabral, M. C. and Burges, S. J. (1994) 'Digital Elevation Model Networks (DEMON): A model of flow over hillslopes for computation of contributing and dispersal areas', Water Resources Research. doi: 10.1029/93WR03512.

Costabile, P., Costanzo, C. and MacChione, F. (2012) 'Comparative analysis of overland flow models using finite volume schemes', Journal of Hydroinformatics. doi: 10.2166/hydro.2011.077.

Daniels, M. H., Maxwell, R. M. and Chow, F. K. (2011) 'Algorithm for flow direction enforcement using subgrid-scale stream location data', Journal of Hydrologic Engineering. doi: 10.1061/(ASCE)HE.1943-5584.0000340.

Dawson, F. H. and Robinson, W. N. (1984) 'Submerged macrophytes and the hydraulic roughness of a lowland chalkstream', SIL Proceedings, 1922-2010. doi: 10.1080/03680770.1983.11897598.

Defina, A. (2000) 'Two-dimensional shallow flow equations for partially dry areas', Water Resources Research. doi: 10.1029/2000WR900167.

Esteves, M. et al. (2000a) 'Overland flow and infiltration modelling for small plots during unsteady rain: Numerical results versus observed values', Journal of Hydrology. doi: 10.1016/S0022-1694(00)00155-4.

Esteves, M. et al. (2000b) 'Overland flow and infiltration modelling for small plots during unsteady rain: Numerical results versus observed values', Journal of Hydrology, 228(3-4), pp. 265-282. doi: 10.1016/S0022-1694(00)00155-4. 
Fennessy, M. S. and Cronk, J. K. (1997) 'The effectiveness and restoration potential of riparian ecotones for the management of nonpoint source pollution, particularly nitrate', Critical Reviews in Environmental Science and Technology. doi: 10.1080/10643389709388502.

Garbrecht, J. and Martz, L. W. (1997) 'The assignment of drainage direction over flat surfaces in raster digital elevation models', Journal of Hydrology. doi: 10.1016/S00221694(96)03138-1.

Gąsiorowski, D. (2014) 'Modelling of flood wave propagation with wet-dry front by one-dimensional diffusive wave equation', Archives of Hydroengineering and Environmental Mechanics. doi: 10.1515/heem-2015-0007.

Giustolisi, O. and Berardi, L. (2011) 'Water distribution network calibration using enhanced GGA and topological analysis', Journal of Hydroinformatics. doi: 10.2166/hydro.2010.088.

Golden, H. E. et al. (2014) 'Hydrologic connectivity between geographically isolated wetlands and surface water systems: A review of select modeling methods', Environmental Modelling and Software. doi: 10.1016/j.envsoft.2013.12.004.

Gritzner, J. H. (2006) 'Identifying Wetland Depressions in Bare-Ground LIDAR for Hydrologic Modeling', North.

Heber Green, W. and Ampt, G. A. (1911) 'Studies on Soil Phyics.', The Journal of Agricultural Science. 2009/03/27. Cambridge University Press, 4(1), pp. 1-24. doi: DOI: 10.1017/S0021859600001441.

Heeren, D. M. et al. (2014) 'Divergence and flow direction as indicators of subsurface heterogeneity and stage-dependent storage in alluvial floodplains', Hydrological Processes. doi: 10.1002/hyp.9674.

Holmgren, P. (1994) 'Multiple flow direction algorithms for runoff modelling in grid based elevation models: An empirical evaluation', Hydrological Processes. doi: 10.1002/hyp.3360080405.

Howes, D. A., Abrahams, A. D. and Pitman, E. B. (2006) 'One- and two-dimensional modelling of overland flow in semiarid shrubland, Jornada basin, New Mexico', Hydrological Processes. doi: 10.1002/hyp.5922.

Jenkins, D. G. and McCauley, L. A. (2006) 'GIS, sinks, fill, and disappearing wetlands: Unintended consequences in algorithm development and use', in Proceedings of the ACM Symposium on Applied Computing.

Jenson, S. K. and Domingue, J. O. (1988) 'Extracting topographic structure from digital elevation data for geographic information system analysis', Photogrammetric Engineering and Remote Sensing.

Kacimov, A. R., Al-Ismaily, S. and Al-Maktoumi, A. (2010) 'Green-ampt onedimensional infiltration from a ponded surface into a heterogeneous soil', Journal of Irrigation and Drainage Engineering, 136(1), pp. 68-72. doi: 10.1061/(ASCE)IR.19434774.0000121. 
Kadlec, R. H. et al. (2000) 'Constructed Wetlands for Pollution Control', Scientific and Technical Report series. doi: 10.1016/j.geomorph.2012.04.023.

Kalbitz, K. and Wennrich, R. (1998) 'Mobilization of heavy metals and arsenic in polluted wetland soils and its dependence on dissolved organic matter', Science of the Total Environment. doi: 10.1016/S0048-9697(97)00302-1.

Kale, R. V. and Sahoo, B. (2011) Green-Ampt Infiltration Models for Varied Field Conditions: A Revisit, Water Resources Management. doi: 10.1007/s11269-011-9868-0.

Kalman, R. E. (1960) 'A new approach to linear filtering and prediction problems', Journal of Fluids Engineering, Transactions of the ASME. doi: 10.1115/1.3662552.

Karim, F. et al. (2012) 'Modelling wetland connectivity during overbank flooding in a tropical floodplain in north Queensland, Australia', Hydrological Processes. doi: 10.1002/hyp.8364.

Kenny, F., Matthews, B. and Todd, K. (2008) 'Routing overland flow through sinks and flats in interpolated raster terrain surfaces', Computers and Geosciences. doi: 10.1016/j.cageo.2008.02.019.

Kollet, S. J. and Maxwell, R. M. (2006) 'Integrated surface-groundwater flow modeling: A free-surface overland flow boundary condition in a parallel groundwater flow model', Advances in Water Resources. doi: 10.1016/j.advwatres.2005.08.006.

Kumar, C. et al. (2012) 'Multiphysics Modelling of convective drying of food materials', Proceedings of the Global Engineering, Science and Technology Conference.

Lane, S. N. (1998) 'Hydraulic modelling in hydrology and geomoprhology: a review of high resolution approaches', Hydrological Processes. doi: 10.1002/(SICI)10991085(19980630)12:8<1131::AID-HYP611>3.0.CO;2-K.

Lang, M. et al. (2012) 'Enhanced detection of wetland-stream connectivity using lidar', Wetlands. doi: 10.1007/s13157-012-0279-7.

Lapidus, A. (1967) 'A detached shock calculation by second-order finite differences', Journal of Computational Physics. doi: 10.1016/0021-9991(67)90032-0.

Lax, P. D. and Wendroff, B. (1964) 'Difference schemes for hyperbolic equations with high order of accuracy', Communications on Pure and Applied Mathematics. doi: 10.1002/cpa.3160170311.

Lin, Y.-F. et al. (2002) 'Removal of Solids and Oxygen Demand from Aquaculture Wastewater with a Constructed Wetland System in the Start-Up Phase', Water Environment Research. doi: 10.2175/106143002x139848.

Lindsay, J. B. and Creed, I. F. (2005) 'Removal of artifact depressions from digital elevation models: Towards a minimum impact approach', Hydrological Processes. doi: 10.1002/hyp.5835.

Liu, J., Zhang, J. and Feng, J. (2008) 'Green-Ampt Model for Layered Soils with Nonuniform Initial Water Content Under Unsteady Infiltration’, Soil Science Society of 
America Journal, 72(4), pp. 1041-1047. doi: 10.2136/sssaj2007.0119.

Liu, Q. Q. et al. (2004) 'Two-dimensional kinematic wave model of overland-flow', Journal of Hydrology. doi: 10.1016/j.jhydrol.2003.12.023.

Löpez, F. and Garcia, M. H. (2001) 'Mean flow and turbulence structure of openchannel flow through non-emergent vegetation', Journal of Hydraulic Engineering. doi: 10.1061/(ASCE)0733-9429(2001)127:5(392).

Maheshwari, B. L. and McMahon, T. A. (1992) 'Modeling shallow overland flow in surface irrigation', Journal of Irrigation and Drainage Engineering. doi:

10.1061/(ASCE)0733-9437(1992)118:2(201).

Manning, R. (1891) 'On the Flow of Water in Open Channels and Pipes', Transactions of the Institution of Civil Engineers of Ireland.

Mao, L. et al. (2016) 'A new method to estimate soil water infiltration based on a modified Green-Ampt model', Soil and Tillage Research, 161, pp. 31-37. doi: 10.1016/j.still.2016.03.003.

Martz, L. W. and Garbrecht, J. (1999) 'An outlet breaching algorithm for the treatment of closed depressions in a raster DEM', Computers and Geosciences. doi: 10.1016/S0098-3004(99)00018-7.

Mateo Lázaro, J. et al. (2015) 'A new adaptation of linear reservoir models in parallel sets to assess actual hydrological events', Journal of Hydrology. doi: 10.1016/j.jhydrol.2015.03.009.

Mein, R. L. L. G. and Larson, C. L. (1973) 'Reply [to "Comments on 'Modeling infiltration during a steady rain' by Russell G. Mein and Curtis L. Larson”]', 9(5), p. 1973.

Mishra, S. K., Tyagi, J. V. and Singh, V. P. (2003) 'Comparison of infiltration models', Hydrological Processes, 17(13), pp. 2629-2652. doi: 10.1002/hyp.1257.

Mitsch, W. J. and Gossilink, J. G. (2000) 'The value of wetlands: Importance of scale and landscape setting', Ecological Economics. doi: 10.1016/S0921-8009(00)00165-8.

Mullem, V. (1991) 'R U N O F F AND PEAK DISCHARGES USING', 117(3).

O'Callaghan, J. F. and Mark, D. M. (1984) 'The extraction of drainage networks from digital elevation data.', Computer Vision, Graphics, \& Image Processing. doi: 10.1016/S0734-189X(84)80011-0.

Oimoen, M. (2000) 'An effective filter for removal of production artifacts in US Geological Survey 7.5-minute digital elevation models', ... of the Fourteenth International Conference on Applied ....

Peckham, S. D. (2009) Geomorphometry and spatial hydrologic modelling, Developments in Soil Science. doi: 10.1016/S0166-2481(08)00025-1.

Pezeshki, S. R. (2001) 'Wetland plant responses to soil flooding', Environmental and Experimental Botany. doi: 10.1016/S0098-8472(01)00107-1. 
Philip, J. R. (1957) 'The theory of infiltration: 4. Sorptivity and algebraic infiltration equations', Soil Science. doi: 10.1097/00010694-195709000-00010.

Philip, J. R. (1993) 'Variable-head ponded infiltration under constant or variable rainfall', Water Resources Research, 29(7), pp. 2155-2165. doi: 10.1029/93WR00748.

Quinn, P. et al. (1991) 'The prediction of hillslope flow paths for distributed hydrological modelling using digital terrain models', Hydrological Processes. doi: 10.1002/hyp.3360050106.

Rampi, L. P., Knight, J. F. and Lenhart, C. F. (2014) 'Comparison of flow direction algorithms in the application of the cti for mapping wetlands in minnesota', Wetlands. doi: 10.1007/s13157-014-0517-2.

Robb, G. A., Novotny, V. and Olem, H. (1996) 'Water Quality: Prevention, Identification and Management of Diffuse Pollution', The Geographical Journal. doi: $10.2307 / 3060267$.

Roe, J. H., Brinton, A. C. and Georges, A. (2009) 'Temporal and spatial variation in landscape connectivity for a freshwater turtle in a temporally dynamic wetland system', Ecological Applications. doi: 10.1890/08-0101.1.

Salvucci, G. D. and Entekhabi, D. (1994) 'Explicit expressions for Green-Ampt (delta function diffusivity) infiltration rate and cumulative storage', Water Resources Research. doi: 10.1029/94WR01494.

Saunders, W. (1999) 'Preparation of DEMs for use in environmental modeling analysis', Esri User Conference.

Seibert, J. and McGlynn, B. L. (2007) 'A new triangular multiple flow direction algorithm for computing upslope areas from gridded digital elevation models', Water Resources Research. doi: 10.1029/2006WR005128.

Semlitsch, R. D. and Bodie, J. R. (1998) 'Are small, isolated wetlands expendable?', Conservation Biology. doi: 10.1046/j.1523-1739.1998.98166.x.

Serrano, S. E. (2003) 'Improved decomposition solution to green and ampt equation', Journal of Hydrologic Engineering, 8(3), pp. 158-160. doi: 10.1061/(ASCE)10840699(2003)8:3(158).

Shi, J. Z. et al. (2013) 'Hydrological characteristics of vegetated river flows: a laboratory flume study', Hydrological Sciences Journal, 58(5), pp. 1047-1058. doi: 10.1080/02626667.2013.797580.

Singh, V. P. (2010) 'Entropy theory for derivation of infiltration equations', Water Resources Research, 46(3), pp. 1-20. doi: 10.1029/2009WR008193.

Snodgrass, J. W. et al. (2000) 'Relationships among isolated wetland size, hydroperiod, and amphibian species richness: Implications for wetland regulations', Conservation Biology. doi: 10.1046/j.1523-1739.2000.99161.x.

Stewart, R. D. (2018) 'A Dynamic Multidomain Green-Ampt Infiltration Model', 
Water Resources Research, 54(9), pp. 6844-6859. doi: 10.1029/2018WR023297.

Straub, L. G. (1932) 'Hydraulic and sedimentary characteristics of rivers', Eos, Transactions American Geophysical Union. Wiley Online Library, 13(1), pp. 375-382.

Sturm, T. W. (2010) Open Channel Hydraulics. McGraw-Hill (McGraw-Hill series in water resources and environmental engineering). Available at: https://books.google.com/books?id=cOUiPwAACAAJ.

Sturm, T. W. and Tuzson, J. (2001) 'Open channel hydraulics'. American Society of Mechanical Engineers Digital Collection.

Tan, B. Q. and O'Connor, K. M. (1996) 'Application of an empirical infiltration equation in the SMAR conceptual model', Journal of Hydrology, 185(1-4), pp. 275-295. doi: 10.1016/0022-1694(95)02993-1.

Tarboton, D. G. (1997) 'A new method for the determination of flow directions and upslope areas in grid digital elevation models', Water Resources Research. doi: 10.1029/96WR03137.

US Army Corps of Engineers (2010) 'HEC-RAS River Analysis System, User's Manual', HEC-RAS River Analysis System, User's Manual, Version 4.1. doi: CPD-68.

Wang, J., Chen, L. and Yu, Z. (2018) 'Modeling rainfall infiltration on hillslopes using Flux-concentration relation and time compression approximation', Journal of Hydrology. Elsevier B.V., 557, pp. 243-253. doi: 10.1016/j.jhydrol.2017.12.031.

Warrick, A. W. et al. (2005) 'Infiltration under variable ponding depths of water', Journal of Irrigation and Drainage Engineering, 131(4), pp. 358-363. doi: 10.1061/(ASCE)0733-9437(2005)131:4(358).

Willson, J. D. et al. (2006) 'Post-drought responses of semi-aquatic snakes inhabiting an isolated wetland: Insights on different strategies for persistence in a dynamic habitat', Wetlands. doi: 10.1672/0277-5212(2006)26[1071:PROSSI]2.0.CO;2.

Zandbergen, P. (2010) 'Accuracy considerations in the analysis of depressions in medium-resolution lidar DEMs', GIScience and Remote Sensing. doi: 10.2747/15481603.47.2.187. 


\begin{abstract}
VITA
Zhentao Wang gets his Ph.D. degree in the Department of Civil and Environmental Engineering at the University of Missouri in May 2020. Before beginning his doctoral studies, Mr. Wang received his B.S. degree in Urban and Rural Planning at Nanjing University in China. After completed his master's degree in Hydrology at Nanjing University, he worked as an engineer at a thermal power plant owned by the China Resources Power Holdings Company. His research interests lie in the areas of hydrologic and hydraulic modeling. He has been focusing on simulating and analyzing overland runoff through wetlands using ArcGIS and python programming.
\end{abstract}

